UNIVERSIDADE DE SÃO PAULO

ESCOLA POLITÉNICA

KAMILA RODRIGUES CASSARES

ANÁLISE NÃO LINEAR DE SÓLIDOS VISCOELÁSTICOS BIDIMENSIONAIS: IMPLEMENTAÇÃO EM ELEMENTOS FINITOS E CONTRIBUIÇÃO PARA APLICAÇÃO A TÚNEIS 
KAMILA RODRIGUES CASSARES

ANÁLISE NÃO LINEAR DE SÓLIDOS VISCOELÁSTICOS BIDIMENSIONAIS: IMPLEMENTAÇÃO EM ELEMENTOS FINITOS E CONTRIBUIÇÃO PARA APLICAÇÃO A TÚNEIS

Dissertação apresentada à Escola Politécnica da Universidade de São Paulo para obtenção do título de Mestre em Engenharia 
KAMILA RODRIGUES CASSARES

\section{ANÁLISE NÃO LINEAR DE SÓLIDOS VISCOELÁSTICOS BIDIMENSIONAIS: IMPLEMENTAÇÃO EM ELEMENTOS FINITOS E CONTRIBUIÇÃO PARA APLICAÇÃO A TÚNEIS}

Dissertação apresentada à Escola Politécnica da Universidade de São Paulo para obtenção do título de Mestre em Engenharia

Área de concentração: Engenharia de Estruturas

Orientador: Prof. Dr. Eduardo M. B. Campello 


\section{AGRADECIMENTOS}

À Deus que sempre ilumina minha vida e guia meus passos.

Ao meu orientador, Eduardo de Morais Barreto Campello, por todos os conselhos, orientações e discussões durante este período de trabalho.

Aos professores Marcos Aurélio Marques Noronha e Paulo de Mattos Pimenta pelos conselhos e valiosos conceitos.

Aos professores Alex Alves Bandeira e Rita Moura Fortes pelo incentivo em perseguir a vida acadêmica.

Aos meus pais Duverney Rodrigues Cassares e Eliana Croques Silva Cassares por todo o empenho, esforço e incentivo realizados durante a minha vida acadêmica.

À minha irmã Karolina Rodrigues Cassares e minha avó Maria Josefa Croques Beade Silva pelo incentivo.

Ao Daniel Seko por toda a ajuda e incentivo.

Aos engenheiros, Odair Boari Thomaz e Roberto Tamotsu Ogassawara, e equipe da Geodactha Eng. De Solos e Fundações pelo incentivo. 


\section{RESUMO}

O objetivo deste trabalho é aplicar uma formulação viscoelástica bidimensional sob não linearidade geométrica para estado plano de deformação baseada em grandezas energicamente conjugadas a partir do gradiente da transformação e do primeiro tensor das tensões de PiolaKirchhoff. Esta formulação viscoelástica é composta pela equação constitutiva hiperelástica de Kircchoff- Saint Venant e a função de fluência do modelo viscoelástico de Kelvin-Voigt. A formulação é aplicada em análises numéricas com método dos elementos finitos. Para tal aplicação, foi proposto o uso de elementos triangulares T6 que não apresentaram o fenômeno de travamento e são adequados para a utilização em malhas não estruturadas. Esta implementação foi aplicada para prever deslocamentos no concreto projetado de túneis.

Palavras-chave: Método dos elementos finitos. Análise não linear de estruturas. Viscoelasticidade das estruturas. Túneis. 


\begin{abstract}
The objective of this work is to apply a geometrically nonlinear two-dimensional viscoelastic formulation for plane strain where deformation gradient is energetically conjugated with first Piola-Kircchoff stress tensor. This formulation is from constitutive equation St. Venant Kirchhoff and creep compliance Kelvin-Voigt rheological model. This is applied in numerical analysis with finite element method. Use of triangular elements was proposed. Locking is not observed in numerical examples and this kind of element is appropriate for use in unstructured mesh. Displacement prediction of shotcrete support in a tunnel was made with this formulation and excellent results were found.
\end{abstract}

Keywords: Finite element method. Nonlinear analysis of structure. Viscoelasticity of structure. Tunnel. 


\section{LISTA DE FIGURAS}

Figura 1 - Equipamento concluiu túnel que dá acesso à Estação Paulista do Metrô.

Figura 2 - Acidente durante a construção da linha amarela do metrô da cidade de São Paulo.

Figura 3 - Cinemática do sólido deformável.

Figura 4 - Sólido em EPD

Figura 5 - Modelo representativo do material elástico.

Figura 6 - Modelo de barra com comportamento elástico. 32

Figura 7 - Modelo representativo do material viscoso.

Figura 8 - Modelo de barra com comportamento viscoso.

Figura 9 - Modelo de Kelvin-Voigt. 34

Figura 10 - Função degrau unitário de Heaviside. 35

Figura 11 - Ensaio de fluência do modelo Kelvin-Voigt 36

Figura 12 - Tensões no ensaio de fluência do modelo Kelvin-Voigt. 36

Figura 13 - Modelo viscoelástico de três parâmetros 37

Figura 14 - Ensaio de fluência do modelo viscoelástico de três parâmetros. 39

Figura 15 - Discretização do sólidos: (a) tridimensional; (b) em EPD. 46

Figura 16 - Elemento triangular de seis nós. 47

Figura 17 - Triangulo de Pascal - 2D 48

Figura 18 - Visão geral do método de Newton. 51

Figura 19 - Exemplo 1: características geométricas e propriedades do material......... 53

Figura 20 - Exemplo 1: (a) condições de contorno; (b) malha de elementos finitos com $6 \times 3$ divisões nas faces; (c) malha de elementos finitos com $12 \times 6$ divisões nas faces; 
(d) malha de elementos finitos com $24 \times 12$ divisões nas faces; (e) malha de elementos finitos com $48 \times 24$ divisões nas faces.

Figura 21 - Exemplo 1: Campo de deslocamentos na direção do eixo X (componente horizontal) obtido para a malha $48 \times 24$ divisões nas faces (linearidade geométrica)

Figura 22 - Exemplo 1: Campo de deslocamentos na direção do eixo Y (componente vertical) obtido para a malha $48 \times 24$ divisões nas faces (linearidade geométrica). 56

Figura 23 - Exemplo 1: Campo de deslocamentos obtido para a malha com $48 \times 24$ divisões nas faces (não linearidade geométrica) - (a) Deslocamentos na direção do eixo X / (b) Deslocamentos na direção eixo Y. 57

Figura 24 - Modelo 2: características geométricas e propriedades do material. 58

Figura 25 - Exemplo 2: (a) condições de contorno; (b) malha de elementos finitos com $2 \times 2$ divisões nas faces; (c) malha de elementos finitos com $4 \times 4$ divisões nas faces; (d) malha de elementos finitos com $8 \times 8$ divisões nas faces; (e) malha de elementos finitos com $16 \times 16$ divisões nas faces; (f) malha de elementos finitos com $32 \times 32$ divisões nas faces. 59

Figura 26 - Exemplo 2: Campo de deslocamentos obtido para a malha com $32 \times 32$ divisões nas faces (linearidade geométrica) e $\nu=0,30$ - Deslocamentos na direção Y.. 60

Figura 27 - Exemplo 2: Campo de deslocamentos obtido para a malha com $32 \times 32$ divisões nas faces (linearidade geométrica) e $\nu=0,35$ - Deslocamentos na direção Y.. 60

Figura 28 - Exemplo 2: Campo de deslocamentos obtido para a malha com $32 \times 32$ divisões nas faces (linearidade geométrica) e $\nu=0,40$ - Deslocamentos na direção Y..61

Figura 29 - Exemplo 2: Campo de deslocamentos obtido para a malha com $32 \times 32$ divisões nas faces (linearidade geométrica) e $\nu=0,45$ - Deslocamentos na direção Y..61 
Figura 30 - Exemplo 2: Campo de deslocamentos obtido para a malha com $32 \times 32$ divisões nas faces (linearidade geométrica) e $\nu=0,49$ - Deslocamentos na direção Y..61

Figura 31 - Exemplo 2: Campo de deslocamentos obtido para a malha com $32 \times 32$ divisões nas faces (linearidade geométrica) e $\nu=0,499$ - Deslocamentos na direção Y.62

Figura 32 - Exemplo 2: Campo de deslocamentos obtido para a malha com $32 \times 32$ divisões nas faces (não linearidade geométrica) e $\nu=0,30$ - Deslocamentos na direção Y.

Figura 33 - Exemplo 2: Campo de deslocamentos obtido para a malha com $32 \times 32$ divisões nas faces (não linearidade geométrica) e $\nu=0,35$ - Deslocamentos na direção Y.

Figura 34 - Exemplo 2: Campo de deslocamentos obtido para a malha com $32 \times 32$ divisões nas faces (não linearidade geométrica) e $\nu=0,40$ - Deslocamentos na direção Y.

Figura 35 - Exemplo 2: Campo de deslocamentos obtido para a malha com $32 \times 32$ divisões nas faces (não linearidade geométrica) e $\nu=0,45$ - Deslocamentos na direção Y.

Figura 36 - Exemplo 2: Campo de deslocamentos obtido para a malha com $32 \times 32$ divisões nas faces (não linearidade geométrica) e $\nu=0,49$ - Deslocamentos na direção Y.

Figura 37 - Exemplo 2: Campo de deslocamentos obtido para a malha com $32 \times 32$ divisões nas faces (não linearidade geométrica) e $\nu=0,499$ - Deslocamentos na direção Y. 64

Figura 38 - Exemplo 3: características geométricas e propriedades do material...... 65 
Figura 39 - Exemplo 3: (a) condições de contorno; (b) malha de elementos finitos com 16×6 divisões nas faces. 66

Figura 40 - Exemplo 3: Campo de deslocamentos obtido para a malha com $16 \times 6$ divisões nas faces no instante $t=90$ dias (linearidade geométrica) - (a) Deslocamentos na direção do eixo X / (b) Deslocamentos na direção do eixo Y. 68

Figura 41 - Exemplo 3: Campo de deslocamentos na direção do eixo X obtido para a malha com $16 \times 6$ divisões nas faces no instante $t=90$ dias (não linearidade geométrica).

Figura 42 - Exemplo 3: Campo de deslocamentos na direção do eixo Y obtido para a malha com $16 \times 6$ divisões nas faces no instante $t=90$ dias (não linearidade geométrica).

Figura 43 - Exemplo 4: características geométricas e propriedades do material. 70

Figura 44 - Exemplo 4: (a) condições de contorno; (b) malha de elementos finitos com 16×3 divisões.

Figura 45 - Exemplo 4: Campo de deslocamentos na direção do eixo X obtido para a malha com $16 \times 3$ divisões nas faces no instante $t=120$ dias (linearidade geométrica). 72

Figura 46 - Exemplo 4: Campo de deslocamentos na direção do eixo Y obtido para a malha com $16 \times 3$ divisões nas faces no instante $t=120$ dias (linearidade geométrica) .73

Figura 47 - Exemplo 4: Campo de deslocamentos obtido para a malha com $16 \times 3$ divisões nas faces no instante $t=120$ dias (não linearidade geométrica) - (a) Deslocamentos na direção do eixo X / (b) Deslocamentos na direção do eixo Y.74 Figura 48 - Exemplo 5: características geométricas e propriedades do material...... 75 Figura 49 - Exemplo 5: (a) condições de contorno; (b) malha de elementos finitos com $24 \times$ 12 divisões. 
Figura 50 - Exemplo 5: Campo de deslocamentos (componente vertical) para o ponto A (linearidade geométrica).

Figura 51 - Exemplo 5: Campo de deslocamentos (componente vertical) para o ponto A (não linearidade geométrica). 77

Figura 52 - Análise longitudinal de um túnel.

Figura 53 - Aspectos gerais do método convergência-confinamento.

Figura 54 - Sequência executiva do método NATM. 83

Figura 55 - Exemplo de parcialização da seção transversal de um túnel.

Figura 56 - Modelo de um túnel em elementos finitos: (a) vista 3-D frontal; (b) vista em

perspectiva.

Figura 57 - Problema 1: seção transversal de um túnel e propriedades. 87

Figura 58 - Problema 1: malha $40 \times 60$ divisões. 88

Figura 59 - Problema 1: configuração deformada para o instante $t=100$ dias (linearidade geométrica).

Figura 60 - Problema 1: campo de deslocamentos verticais para o instante $t=100$ dias (linearidade geométrica) 90

Figura 61 - Problema 1: campo de deslocamentos verticais para o instante $t=300$ dias (não linearidade geométrica).

Figura 62 - Problema 2: seção transversal e propriedades. 92

Figura 63 - Problema 2: malha $40 \times 60$ divisões. 92

Figura 64 - Problema 2: configuração deformada para o instante $t=100$ dias (linearidade geométrica). 94

Figura 65 - Problema 2: campo de deslocamentos verticais para o instante $t=100$ dias (linearidade geométrica). 
Figura 66 - Problema 2: campo de deslocamentos verticais para o instante $t=300$ dias (não

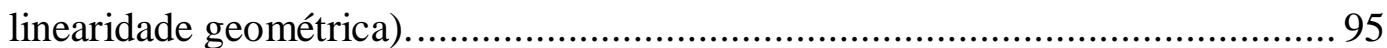




\section{LISTA DE GRÁFICOS}

Gráfico 1 - Exemplo 3: deslocamentos dos pontos A e D (linearidade geométrica). 67

Gráfico 2 - Exemplo 3: deslocamentos dos pontos B e C (linearidade geométrica)..... 67

Gráfico 3 - Exemplo 3: deslocamentos em função do tempo (não linearidade geométrica)... 69

Gráfico 4 - Exemplo 4: deslocamentos em função do tempo (linearidade geométrica). 72

Gráfico 5 - Exemplo 4: deslocamentos em função do tempo (não linearidade geométrica)... 73

Gráfico 6 - Exemplo 5: deslocamentos verticais do ponto A em função do tempo (linearidade geométrica) 76

Gráfico 7 - Exemplo 5: deslocamentos verticais do ponto A em função do tempo (não linearidade geométrica). 77

Gráfico 8 - Problema 1: deslocamento vertical do ponto A em função do tempo (linearidade geométrica) 89

Gráfico 9 - Problema 1: Deslocamento na direção vertical em função do tempo para o ponto

A (não linearidade geométrica).

Gráfico 10 - Problema 2: deslocamentos verticais para o ponto A em função do tempo (linearidade geométrica). 93

Gráfico 11 - Problema 2: Deslocamento na direção vertical em função do tempo para o ponto A (não linearidade geométrica). 95 


\section{LISTA DE TABELAS}

Tabela 1 - Funções de interpolação do elemento triangular de seis nós. 48

Tabela 2 - Resultados obtidos para o Exemplo 1 - Solução Numérica sob linearidade geométrica.

Tabela 3 - Resultados obtidos para o Exemplo 1 - Solução numérica sob não linearidade geométrica.

Tabela 4 - Resultados obtidos para o Exemplo 2 - Solução numérica sob linearidade geométrica. 60

Tabela 5 - Resultados obtidos para o Exemplo 2 - Solução numérica sob não linearidade geométrica. 


\section{SUMÁRIO}

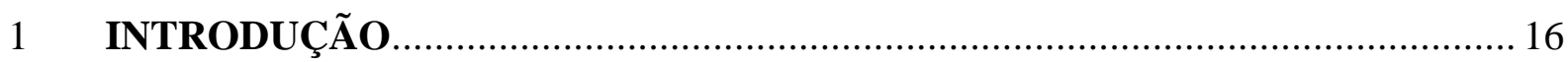

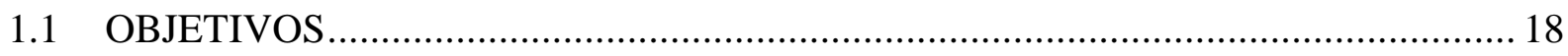

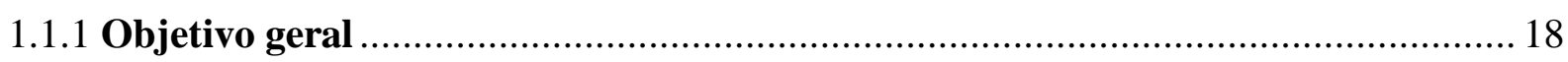

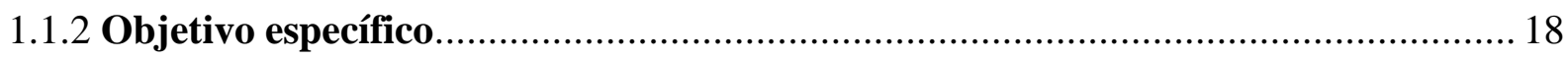

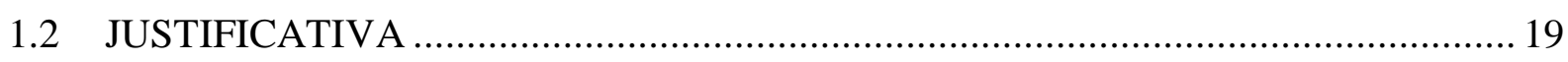

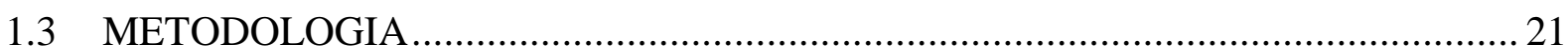

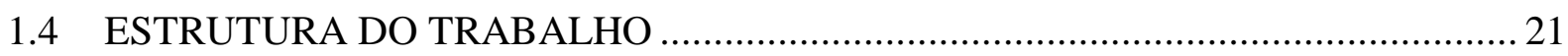

2 MECÂNICA NÃO LINEAR DOS SÓLIDOS DEFORMÁVEIS E SUA PARTICULARIZAÇÃO PARA PROBLEMAS BIDIMENSIONAIS .................... 23

2.1 FORMULAÇÃO NÃO LINEAR DA MECÂNICA DOS SÓLIDOS DEFORMÁVEIS

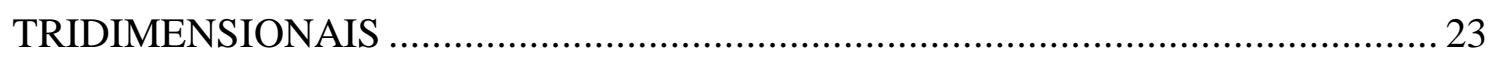

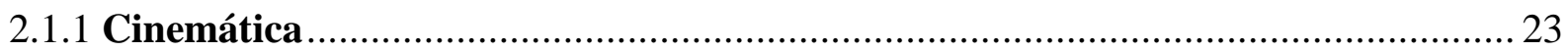

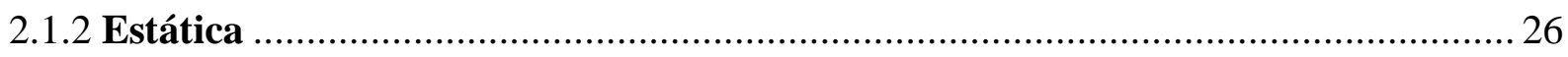

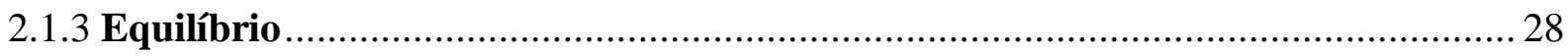

2.2 PARTICULARIZAÇÃO PARA PROBLEMAS BIDIMENSIONAIS...........................29

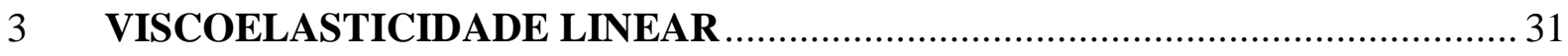

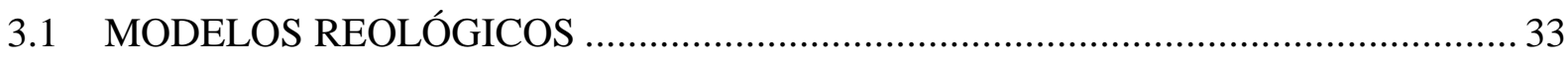

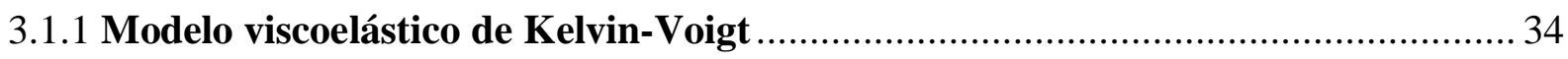

3.1.2 Modelo viscoelástico de três parâmetros ………………………………………….... 37

3.2 EQUAÇÃO CONSTITUTIVA VISCOELÁSTICA PARA SÓLIDOS EM EPD...........39

4 IMPLEMENTAÇÃO EM ELEMENTOS FINITOS............................................. 45

4.1 IMPLEMENTAÇÃO DO MODELO VISCOELÁSTICO COM EPD ……………….... 46 
4.2 VALIDAÇÃO DA IMPLEMENTAÇÃO EM ELEMENTOS FINITOS ...................... 52

5 APLICAÇÃO À ANÁLISE DE TÚNEIS ................................................... 78

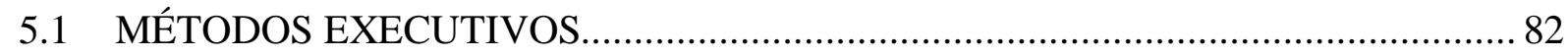

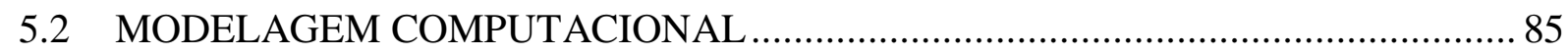

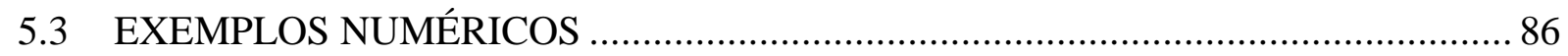

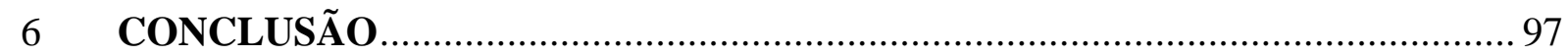

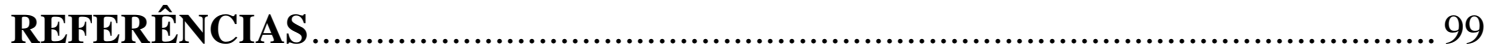




\section{INTRODUÇÃO}

A Mecânica dos Sólidos Deformáveis pode ser estudada sobre os aspectos da cinemática, tensão, equilíbrio e equação constitutiva. A não linearidade do problema pode ser geométrica ou física. Problemas sob não linearidade geométrica apresentam grandes deslocamentos, sendo que as deformações podem apresentar qualquer magnitude. Muitos materiais desempenham um comportamento não linear, a chamada não linearidade física, onde este é caracterizado, por exemplo, por uma relação não linear entre tensões e deformações.

A Engenharia deseja executar obras em que o material empregado é explorado ao máximo em relação ao seu desempenho mediante a atuação dos esforços previstos. Para tal feito, deve-se conhecer o comportamento individual dos materiais, sua interação e, muitas vezes, considerar a não linearidade do problema.

O uso de modelos matemáticos para realizar estudos em relação ao comportamento de diversos materiais tem sido frequente e crescente dentro das engenharias de estrutura e geotécnica. A solução dos problemas da engenharia é conduzida para equações diferenciais ordinárias e parciais, sendo o Método dos Elementos Finitos (MEF) uma poderosa ferramenta para solucioná-las. O MEF consiste em dividir o domínio do problema em um número finito de subdomínios, denominados elementos, conectados por nós, sendo resolvidas as equações apenas nestes nós. A solução para os demais pontos do domínio é obtida por interpolação dos valores nodais, sendo assim caracterizada uma solução aproximada.

Este trabalho apresenta a aplicação de uma formulação viscoelástica sob não linearidade geométrica, baseada em grandezas energicamente conjugadas a partir do gradiente da transformação e do primeiro tensor das tensões de Piola-Kirchhoff. Esta formulação é baseada no emprego da equação constitutiva hiperelástica de Kirchhoff-Saint Venant com um módulo de elasticidade longitudinal dependente do tempo. Esta dependência, por simplicidade, é regida pela função de fluência do modelo viscoelástico de Kelvin-Voigt, evitando-se a integração numérica das tensões. Com a implementação em elementos finitos no PEFSYS, programa computacional desenvolvido na Escola Politécnica, esta formulação será utilizada para fazer análises bidimensionais de sólidos viscoelásticos, com vistas à previsão de deslocamentos do revestimento (concreto projetado) de túneis. 
O uso do espaço subterrâneo para sistemas de transporte metroviário, galerias e túneis é importante e necessário, por se desejar preservar o espaço e o meio-ambiente. Cidades altamente edificadas, como São Paulo, necessitam de métodos que proporcionem a execução dos túneis sem interdições de vias públicas, por exemplo. Ou seja, a tecnologia torna-se mais atrativa com o intuito de minimizar impactos e oferecer maior custo-benefício.

A técnica adotada para execução de um túnel depende do tipo de material constituinte da camada a ser escavada, pois esta atividade está diretamente relacionada ao comportamento deste material. O estudo prévio e o planejamento são destacados como fatores primordiais para uma execução bem sucedida.

Inicialmente, túneis foram abertos através da execução de galerias escoradas com madeira e revestidas com pedras e tijolos.

A técnica de escavação mecanizada teve origem na Inglaterra, em 1825, onde com o intuito de escavar um túnel sobre o Rio Tâmisa, em solo pouco estável, o primeiro equipamento, denominado "shield", foi criado. Este permitia a escavação e a execução do revestimento em segurança sob sua couraça metálica (MEDEIROS, 2006). Com o avanço da tecnologia, hoje, há vários tipos de máquinas tuneladoras, chamadas de TBM ("tunnel boring machine").

A escavação de túneis com máquinas tuneladoras foi empregada pela primeira vez na cidade de São Paulo durante a construção da Linha 1- Azul do metrô nos anos 70, sendo esta também pela primeira vez no Brasil (COMPANHIA DO METROPOLITANO DE SÃO PAULO, 2008). Um exemplo brasileiro atual de aplicação de escavação mecanizada é a nova linha do sistema metroviário da cidade de São Paulo, onde se utilizou esta técnica para execução de um túnel de 12,8 km de extensão e 9,5 m de diâmetro, comportando duas vias (no sentido Vila Sônia e outra no sentido Estação da Luz). A Figura 1mostra a cabeça de corte desse equipamento.

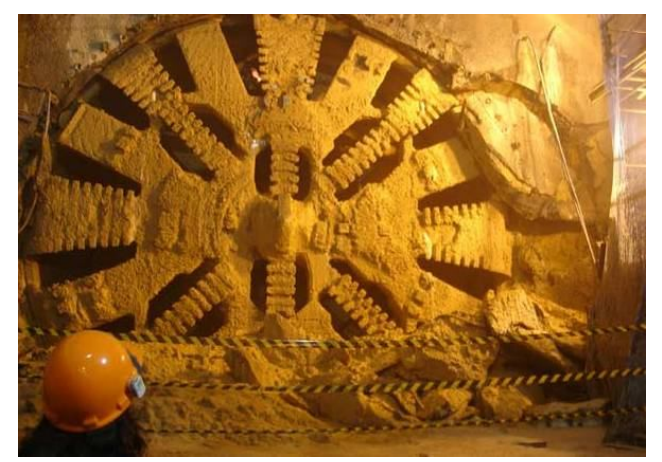

Figura 1 - Equipamento concluiu túnel que dá acesso à Estação Paulista do Metrô.

FONTE: BRITO, L. (2008). 
Outra técnica muito utilizada é NATM ("New Austrian Tunnelling Method"). Este método consiste em uma escavação sequencial do maciço, sendo aplicado concreto projetado para dar suporte ao túnel. Descrição da sequência executiva está brevemente apresentada no item 5.1 .

Os túneis podem apresentar suporte e revestimento. O suporte é uma estrutura provisória para manter a abertura do túnel estável pelo menos durante o período de execução do revestimento (execução do concreto projetado que gera resistência inicial rápida). Já o revestimento é uma estrutura que manterá a abertura estável durante a vida útil da obra.

O comportamento desempenhado por um suporte, ou um revestimento, ou por um maciço pode ser representado pelo comportamento de um material viscoelástico. Isso se deve a uma relação de dependência com o tempo.

\subsection{OBJETIVOS}

\subsubsection{Objetivo geral}

Aplicar uma formulação viscoelástica bidimensional em problemas de grandes deslocamentos e/ou deformações, a partir da equação constitutiva hiperelástica de KirchhoffSaint Venant e da função de fluência do modelo viscoelástico de Kelvin-Voigt.

\subsubsection{Objetivo específico}

Implementação computacional da equação constitutiva de Kirchhoff- Saint Venant e função de fluência do modelo viscoelástico de Kelvin-Voigt. Simulação computacional de problemas clássicos para validação das implementações, sendo realizadas comparações entre os resultados obtidos e os apresentados na literatura. Simulação numérica de seções transversais de túneis. 


\subsection{JUSTIFICATIVA}

O domínio da tecnologia de construção de túneis é um aspecto estrategicamente importante para o desenvolvimento da infra-estrutura básica de cidades e estados brasileiros. Obras de túneis apresentam grandes benefícios em relação ao encurtamento de distâncias e ao uso racional do espaço subterrâneo, e geram o menor impacto ambiental possível. Pode-se observar que as obras subterrâneas estão sendo executadas constantemente, devido ao alto custo das desapropriações e às grandes perturbações ao tráfego no caso de serem executadas a céu aberto.

Existe a necessidade de estudar e aprimorar as tecnologias disponíveis para a análise e execução de túneis subterrâneos. Este trabalho traz um estudo que pretende colaborar para este desenvolvimento.

Aplica-se a Lei de Hooke à Mecânica dos Sólidos Deformáveis, porém nem sempre materiais, como metais, concreto, madeira e solo, apresentam um comportamento elástico linear. Esta aplicação é realizada, pois oferece simplicidade na determinação do campo de tensões e deslocamentos. O comportamento de determinados materiais pode, contudo, ser representado também através da teoria da plasticidade e teoria da viscoelasticidade. Este trabalho busca representar o comportamento do concreto projetado em túneis dependente do tempo através da teoria viscoelástica.

A complexidade matemática dos modelos constitutivos adotados para obter soluções analíticas à maioria dos problemas na engenharia gera uma grande dificuldade. As soluções analíticas para estes problemas são possíveis apenas em casos simples e mesmo assim são necessárias hipóteses simplificadoras, sendo que estas soluções também podem ser limitadas pela geometria do problema.

Com o desenvolvimento dos recursos computacionais, contudo, a aplicação dos métodos numéricos cresceu e contribuiu para o desenvolvimento de novas formulações e a modelagem mais detalhada dos problemas de engenharia. Ressalta-se que este avanço permitiu a representação mais realística do comportamento dos materiais e o desenvolvimento da chamada mecânica computacional.

O campo de aplicação dos métodos numéricos tem crescido, sendo estes aplicados também nas áreas da engenharia mecânica, aeronáutica, biomecânica, medicina, dentre outras. Um dos métodos numéricos mais versáteis é o Método dos Elementos Finitos. 
O Método dos Elementos de Contorno é utilizado na Engenharia para analisar o comportamento dos materiais durante a execução dos túneis, como o realizado, por exemplo, por Mesquita (2002) e Oliveira (2009). Por se tratar de uma contribuição para sólidos viscoelásticos bidimensionais sob não linearidade geométrica, o MEF foi escolhido.

O estudo de túneis envolve um grande número de variáveis, onde a metodologia executiva é uma das mais difíceis de ser considerada. A consideração das etapas construtivas como variáveis torna difícil a aplicação de métodos analíticos ou outros mais simplificados, porém pode ser incorporada em uma análise numérica, onde muitas vezes apenas a capacidade computacional é restritiva à análise (BEER; SWOBODA 1985).

Ressalta-se a importância da simulação numérica em conjunto com a experiência acumulada pela comunidade de engenharia de túneis. Os métodos numéricos podem ser considerados ferramentas auxiliares com uso crescente no desenvolvimento de projetos, por causa da disseminação e popularização dos recursos computacionais, pela redução de custos e tempo gastos em relação à simulação através de análises experimentais, pela possibilidade de analisar modelos mais fiéis ao problema físico em questão. Tem-se como consequência projetos com grande sofisticação cada vez mais frequentes, considerando avanços tecnológicos e melhorias na economia.

$\mathrm{Na}$ literatura geotécnica há poucos casos documentados de ruptura ou colapso de túneis. Um dos primeiros relatos bem documentados é o da ruptura do túnel singelo Oeste, do Prolongamento Norte do Metrô-SP em 1981 (KOCHEN; RIBEIRO NETO, 2000). O número ainda alto de acidentes com consequências graves na execução das obras subterrâneas caracteriza o elevado fator de risco destas construções. Este aspecto pode ser exemplificado com o acidente no metrô do Município de São Paulo, ocorrido no início do ano de 2007 (Figura 2).
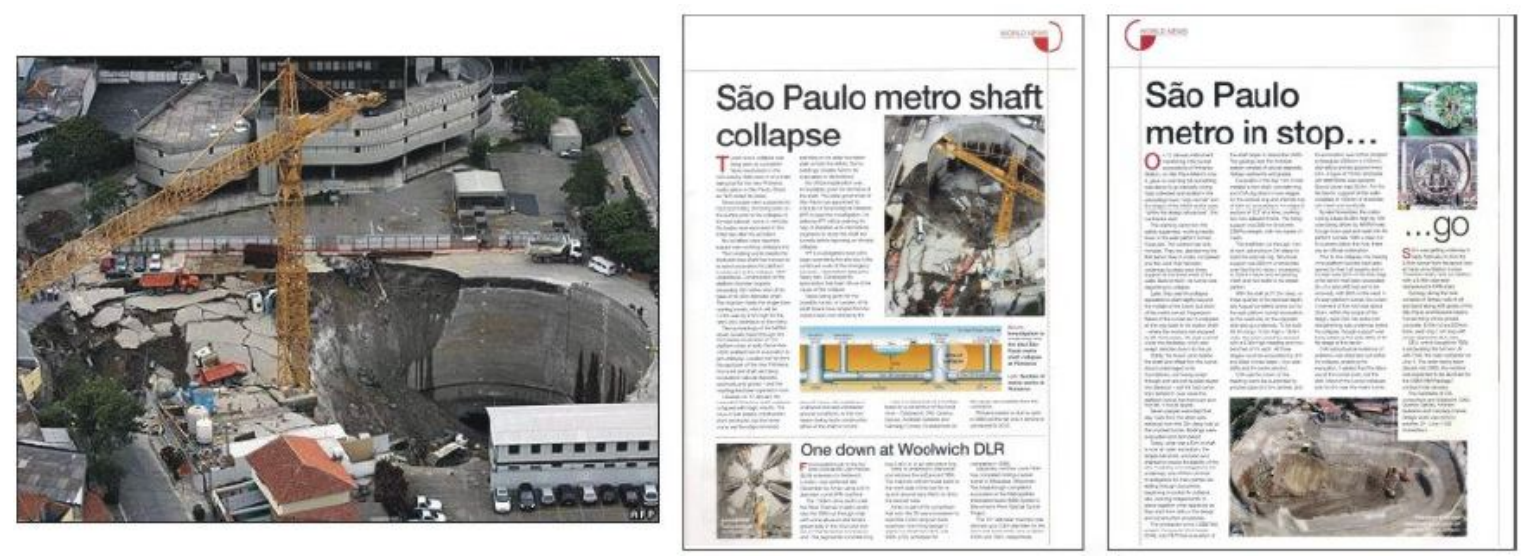

Figura 2 - Acidente durante a construção da linha amarela do metrô da cidade de São Paulo. FONTE: OLIVEIRA (2009, p.16) 
Em resumo, a utilização de métodos numéricos permite a consideração adequada de geometria complexas, das etapas construtivas e das características dos materiais como variáveis na análise. Justifica-se assim a importância do presente estudo para auxiliar na concepção de projetos seguros e econômicos no âmbito das obras subterrâneas no Brasil.

\subsection{METODOLOGIA}

Este trabalho foi desenvolvido por meio do levantamento e análise de referências sobre Mecânica dos Sólidos Deformáveis, teoria da viscoelasticidade, método dos elementos finitos e análise de túneis.

No programa PEFSYS (desenvolvido pelos Prof. Dr. Eduardo M. B. Campello e Prof. Dr-Ing Paulo de Mattos Pimenta) foi realizada a implementação da equação constitutiva hiperelástica de Kirchhoff-Saint Venant e da função de fluência do modelo viscoelástico de Kelvin-Voigt com o intuito de simular o comportamento de materiais dependente do tempo. Esta programação foi validada através de exemplos clássicos, onde se propõe apresentar os resultados obtidos através de gráficos e tabelas. Estes resultados serão comparados com os obtidos na literatura. Para então aplicar esta implementação em um problema de túneis.

\subsection{ESTRUTURA DO TRABALHO}

O trabalho está composto por seis capítulos.

Apresenta-se no Capítulo 1 a introdução composta por objetivos geral e específico, justificativa e metodologia.

No Capítulo 2 será apresentada uma breve revisão bibliográfica e a formulação da mecânica não linear dos sólidos deformáveis para problemas de duas dimensões.

O Capítulo 3 é composto pela apresentação da teoria da viscoelasticidade linear, de modelos viscoelásticos e da formulação viscoelástica matricial a ser adotada no trabalho. 
O Capítulo 4 apresenta a formulação do problema viscoelástico bidimensional com não linearidade geométrica em elementos finitos, e sua implementação no programa PEFSYS, desenvolvido na Escola Politécnica da Universidade de São Paulo. Exemplos de validação desta implementação também serão apresentados.

No Capítulo 5 são apresentados brevemente o método NATM, considerações sobre modelagem computacional de túneis, análises bidimensionais da interação solo/rochaestrutura e a simulação computacional de duas seções transversais de um túnel a partir da implementação em elementos finitos realizada no programa PEFSYS.

O Capítulo 6 é composto por considerações finais sobre o trabalho desenvolvido e propostas para futuras pesquisas. 


\section{MECÂNICA NÃO LINEAR DOS SÓLIDOS DEFORMÁVEIS E SUA PARTICULARIZAÇÃO PARA PROBLEMAS BIDIMENSIONAIS}

A seguir será apresentada a formulação não linear da mecânica dos sólidos deformáveis tridimensionais para então ser simplificada para sólidos bidimensionais.

Quanto à notação utilizada ao longo de todo o trabalho, letras minúsculas latinas ou gregas em itálico $(a, b, \ldots, \alpha, \beta, \ldots)$ representam grandezas escalares, já as apresentadas em negrito $(\mathbf{a}, \mathbf{b}, \ldots, \boldsymbol{\alpha}, \boldsymbol{\beta}, \ldots)$ denotam vetores. Letras maiúsculas latinas ou gregas em negrito-itálico $(\mathbf{A}, \mathbf{B}, \ldots)$ representam tensores de segunda ordem, todos no espaço Euclidiano tridimensional. Vetores e matrizes construídos com componentes tensoriais (como, por exemplo, para fins computacionais) serão expressos por letras latinas em negrito não-itálico $(\mathbf{A}, \mathbf{B}, \ldots, \mathbf{a}, \mathbf{b}, \ldots)$. Adota-se a convenção de somatório sobre índices repetidos,

sendo subentendido que estes tomam valores entre $\{1,2\}$ para letras gregas ou entre $\{1,2,3\}$ para letras latinas.

\subsection{FORMULAÇÃO NÃO LINEAR DA MECÂNICA DOS SÓLIDOS DEFORMÁVEIS TRIDIMENSIONAIS}

A formulação não linear da mecânica dos sólidos deformáveis tridimensionais está baseada em Bonet e Wood (1997), nas notas de aula de Pimenta (2008), Wriggers (2008) e notas de aula de Campello e Pimenta (2009). Esta formulação será apresentada sob três aspectos: cinemática, estática e equilíbrio.

\subsubsection{Cinemática}

Restrições quanto aos deslocamentos, alongamentos e distorções não serão feitas. A seguir, será apresentada a formulação do problema quase-estático da Mecânica dos Sólidos Deformáveis, sendo este tipo de problema o objeto do trabalho. 
Considere-se o sólido deformável (Figura 3) que ocupa uma região $\mathrm{V}^{\mathrm{r}}$ do espaço físico e apresenta uma superfície externa $S^{r}$ na configuração de referência. Ao analisar a configuração atual (configuração deformada), o sólido ocupa a região $\vee$ do mesmo espaço e apresenta uma superfície externa S. Considera-se a configuração inicial do sólido como a configuração de referência durante a formulação. Seja $\left\{\mathbf{e}_{1}, \mathbf{e}_{2}, \mathbf{e}_{3}\right\}$ uma base ortonormal.

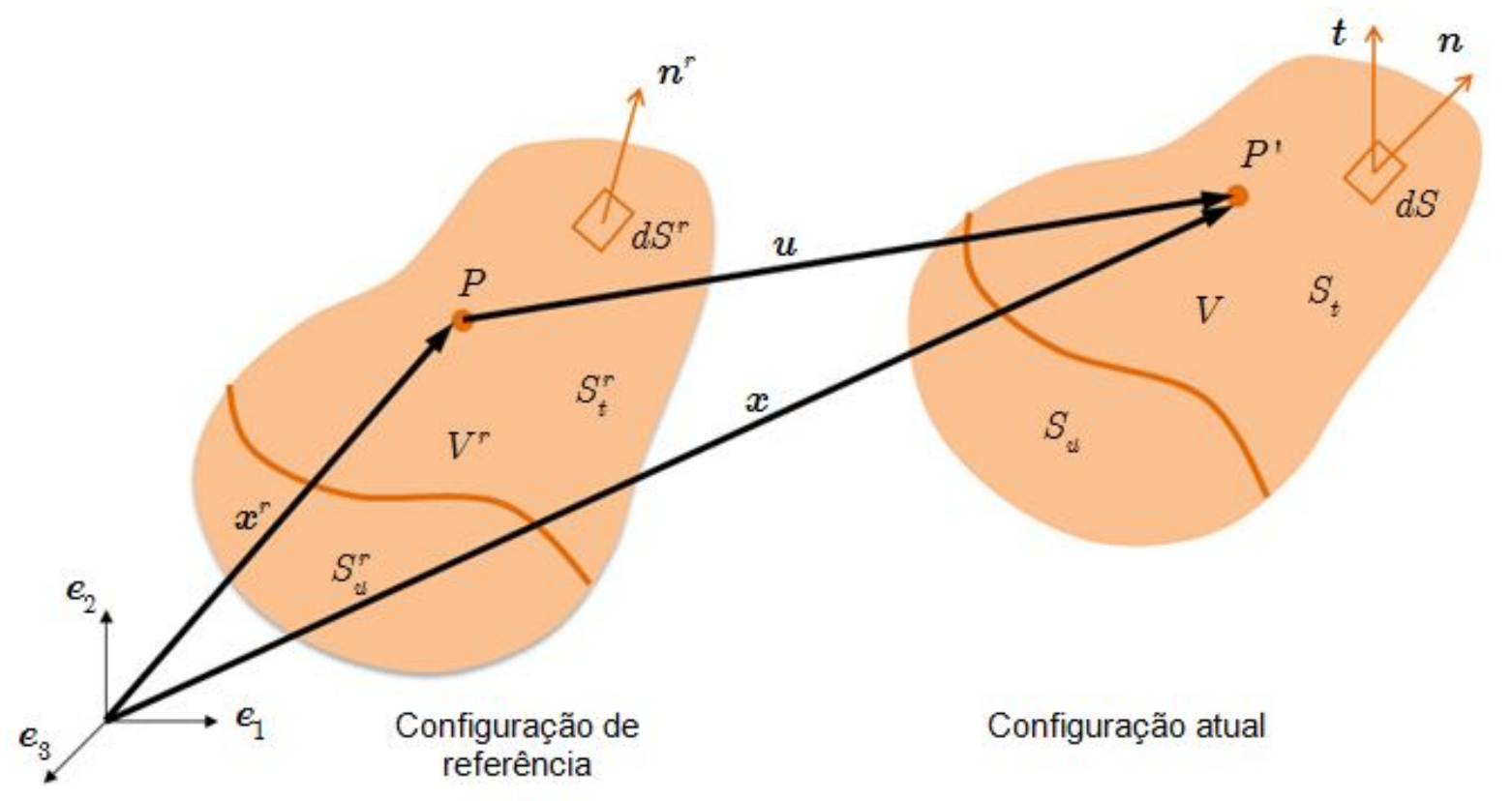

Figura 3 - Cinemática do sólido deformável.

Considerem-se o vetor força de volume $\mathbf{b}^{\boldsymbol{r}}$ por unidade de volume da configuração de referência e as condições de contorno vetor deslocamento $\mathbf{u}$ e vetor força superficial $\overline{\mathbf{t}}^{r}$ por unidade de superfície da configuração de referência aplicados sobre o sólido, variáveis no tempo. A cada instante $\mathrm{t}$, um problema estático sob não linearidade geométrica deverá ser resolvido. A solução ao longo do tempo deste problema é denominada problema quase-estático.

$O$ vetor posição do ponto $P$ na configuração de referência pode ser definido por

$$
\mathbf{x}^{r}=x_{1}^{r} \mathbf{e}_{1}+x_{2}^{r} \mathbf{e}_{2}+x_{3}^{r} \mathbf{e}_{3}=x_{i}^{r} \mathbf{e}_{1}
$$

A transformação sofrida pelo sólido em decorrência das forças aplicadas e das condições de contorno é descrita por um campo vetorial 


$$
\mathbf{x}=\hat{\mathbf{x}}\left(\mathbf{x}^{r}, \mathrm{t}\right)
$$

onde $\mathbf{X}^{r}$ e $\mathbf{X}$ são os vetores posição de um mesmo ponto material nas configurações de referência e atual, respectivamente, e t é um instante de tempo. Através da Figura 3, observase que

$$
\mathbf{x}=\mathbf{x}^{r}+\mathbf{u}
$$

onde $\mathbf{u}=\hat{\mathbf{u}}\left(\mathbf{x}^{\mathrm{r}}, \mathrm{t}\right)$ é o vetor deslocamento do ponto $\mathrm{P}$.

O gradiente da transformação $\mathbf{F}$ é definido como

$$
\mathbf{F}=\nabla \mathbf{x}=\frac{\partial \mathbf{x}}{\partial \mathbf{x}^{r}}=\frac{\partial \mathbf{x}}{\partial \mathbf{x}_{i}^{r}} \otimes \mathbf{e}_{i}=\mathbf{f}_{\mathrm{i}} \otimes \mathbf{q},
$$

onde

$$
\mathbf{f}_{i}=\frac{\partial \mathbf{x}}{\partial \mathbf{x}_{i}^{r}}
$$

são os vetores-coluna de $\mathbf{F}$.

O gradiente $\mathbf{L}$ do campo dos deslocamentos pode ser definido como

$$
\mathbf{L}=\nabla \mathbf{u}=\frac{\partial \mathbf{u}}{\partial \mathbf{x}^{r}}=\frac{\partial \mathbf{u}}{\partial \mathbf{x}_{i}^{r}} \otimes \mathbf{q}=\gamma_{i} \otimes \mathbf{e}_{i},
$$

onde

$$
\gamma_{i}=\frac{\partial \mathbf{u}}{\partial x_{i}^{r}}
$$

são os vetores-coluna de $\mathbf{L}$. Estes também podem ser escritos como

$$
\gamma_{i}=\left[\begin{array}{ccc}
\frac{\partial}{\partial \mathbf{x}_{i}^{r}} & 0 & 0 \\
0 & \frac{\partial}{\partial \mathbf{x}_{i}^{r}} & 0 \\
0 & 0 & \frac{\partial}{\partial \mathbf{x}_{i}^{r}}
\end{array}\right] \mathbf{u}=\Delta_{i} \mathbf{u}
$$

onde $\boldsymbol{\Delta}_{\mathrm{i}}$ é um operador diferencial.

A partir da substituição da equação (3) em (4), tem-se que

$$
\mathbf{F}=\nabla \mathbf{x}=\nabla\left(\mathbf{x}^{\mathbf{r}}+\mathbf{u}\right)=\nabla \mathbf{x}^{r}+\nabla \mathbf{u}
$$

Identifica-se $\mathbf{L}$ e I (tensor identidade de segunda ordem) na equação anterior. 
Pode-se reescrever esta equação como

$$
\mathbf{F}=\mathbf{L}+\mathbf{I}
$$

de modo que

$$
\mathbf{f}_{\mathrm{i}}=\gamma_{\mathrm{i}}+\mathbf{e}_{\mathrm{i}} .
$$

O tensor das deformações de Green é definido por

$$
\mathbf{E}=\frac{1}{2}\left(\mathbf{F}^{\top} \mathbf{F}-\mathbf{I}\right)
$$

pode-se introduzir a equação (10) na equação anterior e reescrevê-la como

$$
\mathbf{E}=\frac{1}{2}\left(\mathbf{L}+\mathbf{L}^{\top}+\mathbf{L}^{\top} \mathbf{L}\right)
$$

sendo $\mathbf{E}$ um tensor simétrico.

Pode-se definir o gradiente das velocidades como

$$
\dot{\mathbf{F}}=\frac{\partial \mathbf{F}}{\partial \mathrm{t}}=\frac{\partial \dot{\mathbf{u}}}{\partial \mathbf{x}^{r}}=\dot{\mathbf{f}}_{\mathrm{i}} \otimes \mathbf{e}
$$

onde

$$
\dot{\mathbf{f}}_{\mathrm{i}}=\frac{\partial \dot{\mathbf{x}}}{\partial \mathbf{x}_{\mathrm{i}}^{r}}=\frac{\partial \dot{\mathbf{u}}}{\partial \mathbf{x}_{\mathrm{i}}^{r}}=\dot{\gamma}_{\mathrm{i}}
$$

\subsubsection{Estática}

O tensor das tensões de Cauchy, $\mathbf{T}$, é um operador vetorial que associa o vetor força superficial $\mathbf{t}$ (vetor tensão por unidade de área na configuração atual) atuante em um ponto segundo um determinado plano com o vetor unitário normal que define este plano, denotado por $\mathbf{n}$. Esta associação é dada por

$$
\mathbf{t}=\mathbf{T} \mathbf{n} \text {. }
$$

$\mathrm{O}$ vetor força superficial $\mathbf{t}^{r}$ por unidade de área na configuração de referência pode ser definido por intermédio de

$$
\mathbf{t}^{r} \mathrm{~d} \mathbf{S}^{r}=\mathbf{t d S}
$$

onde $d S^{r}$ e dS são elementos infinitesimais de superfície respectivamente nas configurações de referência e atual. 
Pode-se definir uma relação análoga a equação (16) para o vetor $\mathbf{t}^{r}$

$$
\mathbf{t}^{r}=\mathbf{P} \mathbf{n}^{r}
$$

onde

$$
\mathbf{P}=\mathrm{J} \mathbf{T} \mathbf{F}^{-\mathrm{T}}
$$

é o Primeiro Tensor das Tensões de Piola-Kirchhoff e $\mathbf{n}^{r}$ é o versor unitário na configuração de referência que define o plano segundo o qual $\mathbf{t}^{r}$ atua.

O tensor $\mathbf{P}$ forma um campo tensorial dado por $\mathbf{P}\left(\mathbf{x}^{r}, t\right)$. Em termos de seus vetores-coluna, $\mathbf{P}$ pode ser expresso por

$$
\mathbf{P}=\tau_{\mathrm{i}} \otimes \mathbf{e}_{\mathrm{i}},
$$

onde $\tau_{\mathrm{i}}$ são tensões por unidade de área que atuam em planos cujas normais são $\mathbf{e}$.

O Segundo Tensor das Tensões de Piola-Kirchhoff é simétrico e definido por

$$
\mathbf{S}=\mathbf{F}^{-1} \mathbf{P}=\mathrm{J} \mathbf{F}^{-1} \mathbf{T} \mathbf{F}^{-\mathrm{T}}
$$

onde a partir desta equação tem-se

$$
\mathbf{P}=\mathbf{F} \mathbf{S} \text {. }
$$

A potência dos esforços externos é definida por

$$
\mathrm{P}_{\mathrm{ext}}=\mathrm{P}_{\mathrm{v}}+\mathrm{P}_{\mathrm{s}}
$$

onde $P_{v}$ é a potência das forças de volume e $P_{S}$ é a potência das forças superficiais. Pode-se definir $\mathrm{P}_{\mathrm{v}}$ como

$$
P_{v}=\int_{V^{r}} \mathbf{b}^{r} \cdot \dot{u} \mathbf{N}^{r}
$$

onde $\mathbf{b}^{\boldsymbol{}}$ é a força de volume aplicada em um ponto na configuração atual (por unidade de volume na configuração de referência) e ù é a velocidade de seu ponto de aplicação. A potência das forças superficiais $P_{s}$ pode ser escrita como

$$
\mathrm{P}_{\mathrm{S}}=\int_{\mathrm{S}^{r}} \overline{\mathbf{t}}^{\mathrm{r}} \cdot \dot{\mathbf{u}} \mathrm{d} \mathrm{S}^{\mathrm{r}}
$$

onde $\overline{\mathbf{t}}_{\mathrm{r}}$ é o vetor força superficial por unidade de área na configuração de referência aplicado na configuração atual e ù é a velocidade de seu ponto de aplicação.

A potência dos esforços externos na configuração de referência pode então ser escrita como

$$
P_{\text {ext }}=\int_{V^{r}} \mathbf{b}^{r} \cdot \dot{\mathbf{u}} d V^{r}+\int_{S^{r}} \overline{\mathbf{t}}^{r} \cdot \dot{\mathbf{u}} d S^{r}
$$


A potência dos esforços internos de um sólido deformável é definida por

$$
\mathrm{P}_{\text {int }}=\int_{V^{r}} \mathbf{P}: \dot{\mathbf{F}} \mathrm{dV}^{r}=\int_{V^{r}}\left(\boldsymbol{\tau}_{\mathrm{i}} \otimes \mathbf{Q}\right):\left(\dot{\mathbf{f}}_{\mathrm{i}} \otimes \mathbf{Q}\right) \mathrm{dV}^{r}=\int_{V^{r}} \tau_{\mathrm{i}} \cdot \dot{\gamma}_{\mathrm{i}} \mathrm{d} \mathrm{V}^{r} \text {. }
$$

\subsubsection{Equilíbrio}

Considere um campo de deslocamentos virtuais $\delta \mathbf{u}$, definidos sobre o volume $\mathrm{V}^{\mathrm{r}}$ da configuração de referência (neste trabalho, procura-se não entrar em detalhes formais quanto á definição deste campo).

Pode-se definir o trabalho virtual dos esforços externos como sendo

$$
\delta \mathbf{W}_{e x t}=\int_{V^{r}} \mathbf{b}^{r} \cdot \delta \mathbf{u} d \mathbf{V}^{r}+\int_{\mathrm{S}^{r}} \overline{\mathbf{t}}^{r} \cdot \delta \mathbf{u d S ^ { r }}
$$

e o trabalho virtual dos esforços internos como se segue

$$
\delta \mathbf{W}_{\text {int }}=\int_{\mathrm{V}^{r}} \mathbf{P}: \delta \mathbf{F} \mathrm{dN}^{\mathrm{r}}
$$

onde

$$
\delta \mathbf{F}=\frac{\partial \delta \mathbf{u}}{\partial \mathbf{x}^{r}}=\frac{\partial \delta \mathbf{u}}{\partial \mathbf{x}_{i}^{r}} \otimes \mathbf{e}_{i}=\delta \gamma_{i} \otimes \mathbf{e},
$$

sendo $\delta \gamma_{\mathrm{i}}$ definido em analogia à definição de $\gamma_{\mathrm{i}}$ na equação (7)

$$
\delta \gamma_{i}=\frac{\partial \delta \mathbf{u}}{\partial \mathbf{x}_{\mathrm{i}}^{r}}=\boldsymbol{\Delta}_{\mathrm{i}} \delta \mathbf{u}
$$

Lembra-se que o operador diferencial $\boldsymbol{\Delta}_{\mathrm{i}}$ foi definido na equação (8).

O equilíbrio estático do sólido pode ser formulado na forma fraca por meio do Teorema dos Trabalhos Virtuais:

$$
\int_{V^{r}} \mathbf{P}: \delta \mathbf{F} \mathbb{d}^{r}=\int_{V^{r}} \mathbf{b}^{r} \cdot \delta \mathbf{u} d \mathbb{V}^{r}+\int_{\mathbf{S}^{r}} \overline{\mathbf{t}}^{r} \cdot \delta \mathbf{u d} \mathrm{S}^{r}, \forall \delta \mathbf{u} .
$$

Utilizando o teorema do divergente, pode-se escrever

$$
\int_{\mathrm{S}^{r}}\left(\mathbf{P} \mathbf{n}^{r}\right) \cdot \delta \mathbf{u d S} S^{r}=\int_{V^{r}}(\operatorname{div} \mathbf{P} \cdot \delta \mathbf{u}+\mathbf{P}: \nabla \delta \mathbf{u}) \mathrm{d}^{r}, \forall \delta \mathbf{u} .
$$

A partir das equações (28), (29) e (33), obtém-se

$$
\int_{V^{r}}\left(\operatorname{div} \mathbf{P}+\mathbf{b}^{r}\right) \cdot \delta \mathbf{u} d \mathbf{N}^{r}+\int_{S^{r}}\left(\overline{\mathbf{t}}^{r}-\mathbf{P} \mathbf{n}^{r}\right) \cdot \delta \mathbf{u d S} S^{r}=0, \forall \delta \mathbf{u},
$$

de onde se chega na primeira equação local de equilíbrio do sólido 


$$
\operatorname{div} \mathbf{P}+\mathbf{b}^{r}=\mathbf{o} \text { em } \bigvee^{r} \text { e }
$$

as condições de contorno estáticas

$$
\overline{\mathbf{t}}^{r}=\mathbf{P} \mathbf{n}^{r} \text { em } \mathbf{S}^{r}
$$

\subsection{PARTICULARIZAÇÃO PARA PROBLEMAS BIDIMENSIONAIS}

Diz-se que um sólido está submetido a um estado plano de deformação (EPD) quando este sólido for prismático e alongado, e estiver sujeito a um carregamento e uma vinculação constantes para qualquer seção transversal perpendicular ao eixo longitudinal (Figura 4). Ressalta-se que o sólido apresenta deslocamentos nulos nas suas extremidades na direção do eixo longitudinal. Em muitas situações, um túnel no interior do maciço pode ser, com razoável precisão, admitido em EPD.

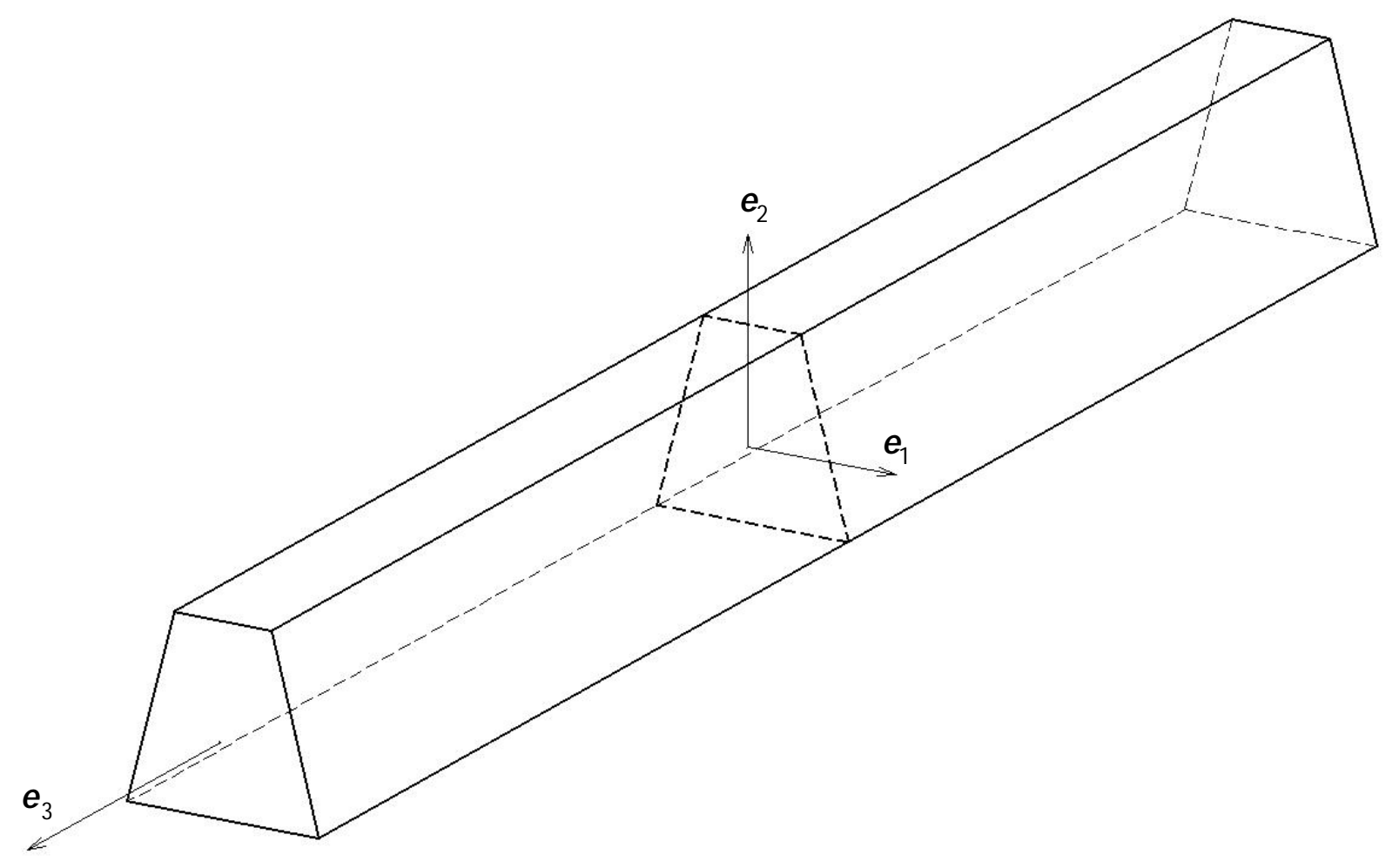

Figura 4 - Sólido em EPD

Ao observar a Figura 4, admite-se que o eixo longitudinal do sólido prismático em EPD é o eixo $\mathbf{e}_{3}$. Assim, o campo de deslocamento é dado por 


$$
\mathbf{u}=\left(u_{1}\left(x_{1}^{r}, x_{2}^{r}\right), u_{2}\left(x_{1}^{r}, x_{2}^{r}\right), 0\right),
$$

sendo $u_{3}$ é nulo e $\mathbf{U}$ não varia em relação a $\mathbf{e}_{3}$.

O gradiente $\mathbf{L}$ do campo dos deslocamentos pode ser reescrito como

$$
\mathbf{L}=\frac{\partial \mathbf{u}}{\partial \mathbf{x}_{i}^{r}} \otimes \mathbf{Q}=\gamma_{\mathrm{i}} \otimes \mathbf{Q}=\left[\begin{array}{ccc}
\gamma_{11} & \gamma_{21} & 0 \\
\gamma_{12} & \gamma_{22} & 0 \\
0 & 0 & 0
\end{array}\right],
$$

onde $\gamma_{3}, \gamma_{13}$ e $\gamma_{23}$ são nulos.

Pode-se escrever o gradiente da transformação $\mathbf{F}$ para problemas bidimensionais como

$$
\mathbf{F}=\mathbf{I}+\mathbf{L}=\mathbf{f}_{\mathrm{i}} \otimes \mathbf{e}=\left[\begin{array}{ccc}
1+\gamma_{11} & \gamma_{21} & 0 \\
\gamma_{12} & 1+\gamma_{22} & 0 \\
0 & 0 & 1
\end{array}\right]
$$

Assim

$$
\begin{gathered}
\begin{array}{c}
\mathbf{f}_{1}=\mathbf{e}_{1}+\gamma_{1} \\
\mathbf{f}_{2}=\mathbf{e}_{2}+\gamma_{2} . \\
\mathbf{f}_{3}=\mathbf{e}_{3}
\end{array} \\
\text { O tensor das deformações de Green é reescrito da seguinte forma } \\
\mathbf{E}=\frac{1}{2}\left(\mathbf{F}^{\top} \mathbf{F}\right)=\left[\begin{array}{ccc}
\gamma_{12}^{2}+\left(1+\gamma_{11}\right)^{2}-1 & \gamma_{21}\left(1+\gamma_{11}\right)+\gamma_{12}\left(1+\gamma_{22}\right) & 0 \\
\gamma_{21}\left(1+\gamma_{11}\right)+\gamma_{12}\left(1+\gamma_{22}\right) & \gamma_{21}^{2}+\left(1+\gamma_{22}\right)^{2}-1 & 0 \\
0 & 0 & 0
\end{array}\right] .
\end{gathered}
$$

Como o tensor das deformações de Green é simétrico, apenas três componentes são não-nulas: $E_{11}, E_{22}$ e $E_{12}$. Pode-se definir

$$
\mathbf{e}=\left[\begin{array}{l}
\mathbf{E}_{11} \\
\mathbf{E}_{22} \\
\mathbf{E}_{12}
\end{array}\right]=\left[\begin{array}{c}
\gamma_{12}^{2}+\left(1+\gamma_{11}\right)^{2}-1 \\
\gamma_{21}^{2}+\left(1+\gamma_{22}\right)^{2}-1 \\
\gamma_{21}\left(1+\gamma_{11}\right)+\gamma_{12}\left(1+\gamma_{22}\right)
\end{array}\right] .
$$




\section{VISCOELASTICIDADE LINEAR}

A previsão do comportamento de materiais na Engenharia é complexa, pois há diversos fatores que influenciam como a temperatura, condições ambientais e de carregamento.

Em diversas situações, o comportamento ao longo do tempo deve ser considerado. A escavação de túneis é uma dessas situações em que o processo apresenta dias de duração e o comportamento dos materiais envolvidos varia com o tempo (MESQUITA, 2002).

O comportamento em uma dimensão de um material viscoelástico se assemelha com o comportamento de um material constituído por elementos elásticos e viscosos. A seguir serão apresentadas as características dos elementos elásticos e viscosos destacadas por Flügge (1967).

Ao se aplicar uma força $P$ nas extremidades de uma mola (Figura 5) ocorre um aumento no comprimento da mesma ( U ). E ao retirar este carregamento, a mola volta a ter seu comprimento original. Este comportamento de não apresentar deformações residuais é denominado elástico. Podem-se relacionar tais informações a uma barra com comportamento elástico linear (Figura 6), onde o material apresenta como lei regente, a Lei de Hooke, dada por

$$
\sigma=\mathrm{E} \varepsilon
$$

onde $\sigma$ é a tensão axial do sistema, E é o módulo de Young ou módulo de elasticidade longitudinal do material e $\varepsilon$ é a deformação.

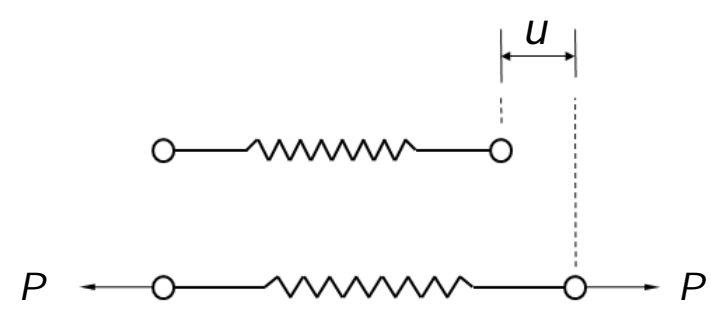

Figura 5 - Modelo representativo do material elástico. 


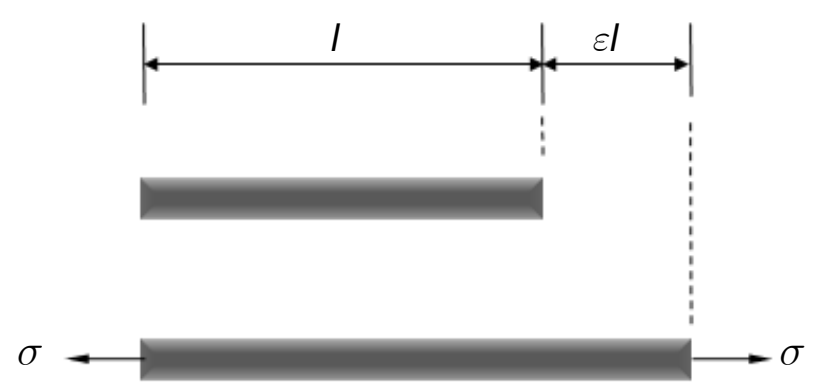

Figura 6 - Modelo de barra com comportamento elástico.

Ao analisar um amortecedor (Figura 7), o pistão se move no interior do cilindro e na direção do fundo perfurado, onde no interior deste não há ar, mas apenas um lubrificante extremamente viscoso. A aplicação de uma força $P$ para que haja o deslocamento do pistão é necessária e quanto maior a intensidade desta força, mais rápido será o deslocamento do pistão. Em sua forma mais simples, esta relação é linear e pode ser expressa como

$$
P=k \frac{d u}{d t}
$$

onde k é o coeficiente de amortecimento, u é o deslocamento provocado e t é o tempo.

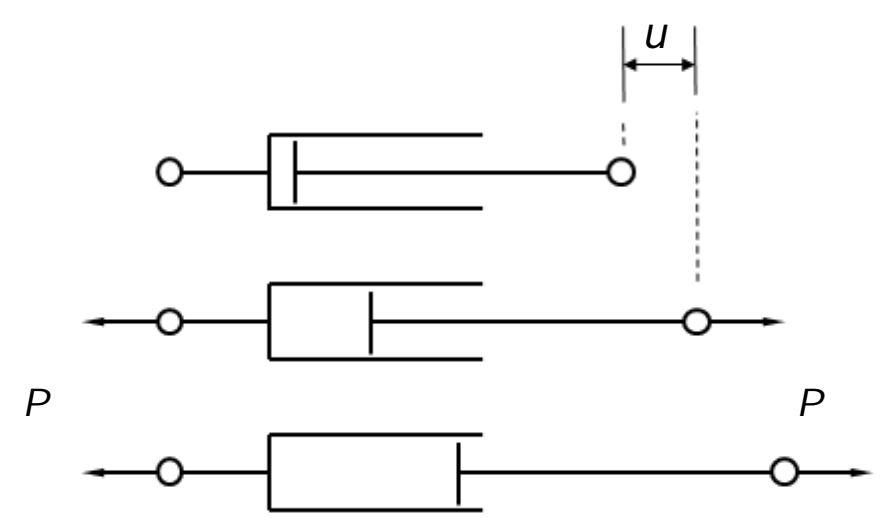

Figura 7 - Modelo representativo do material viscoso.

Novamente se pode relacionar este comportamento ao de uma barra de material viscoso tensionada e esticada (Figura 8). 


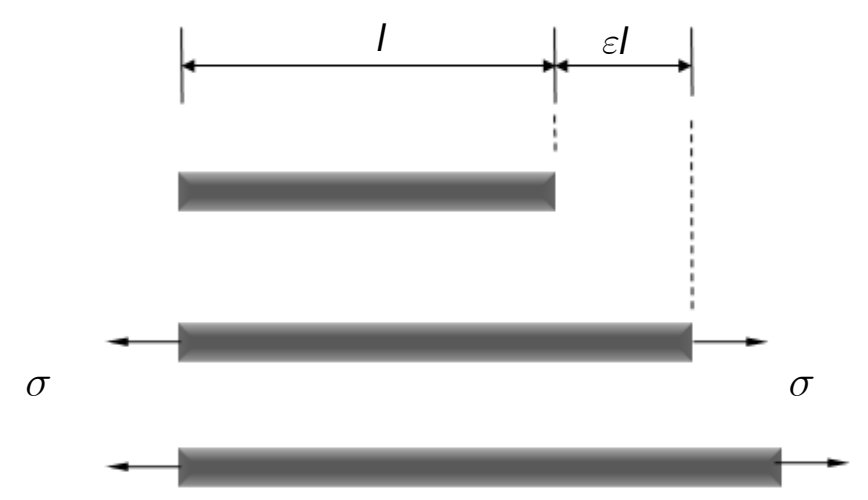

Figura 8 - Modelo de barra com comportamento viscoso.

Um material viscoso linear apresenta tensão proporcional à taxa de deformação e esta relação pode ser escrita da seguinte forma

$$
\sigma=\eta \mathrm{d} \varepsilon / \mathrm{dt}=\eta \dot{\varepsilon},
$$

onde $\eta$ representa a viscosidade do material e $\dot{\varepsilon}$ é a taxa de deformação. Este modelo é conhecido como o "modelo viscoso de Newton".

A tensão de cisalhamento pode ser expressa, também, como o produto entre o coeficiente de viscosidade $\mu$ e a taxa de deformação por cisalhamento $\dot{\gamma}$ da seguinte forma

$$
\tau=\mu \dot{\gamma},
$$

sendo esta a equação constitutiva do líquido viscoso.

\subsection{MODELOS REOLÓGICOS}

O comportamento do material viscoelástico é representado pela combinação de modelos elásticos com modelos viscosos. Estes simples modelos elástico e viscoso são descritos pelas equações (43) e (45), respectivamente, apresentadas anteriormente.

A seguir serão apresentados dois modelos viscoelásticos unidimensionais: o modelo de Kelvin-Voigt e o modelo de três parâmetros, a partir das observações realizadas por Flügge (1967) e Pimenta (2008). 


\subsubsection{Modelo viscoelástico de Kelvin-Voigt}

Este modelo é representado pela combinação em paralelo entre o modelo viscoso de viscosidade $\eta$ e o modelo puramente elástico de módulo de elasticidade $\mathrm{E}$, denominado modelo de Kelvin-Voigt (Figura 9).

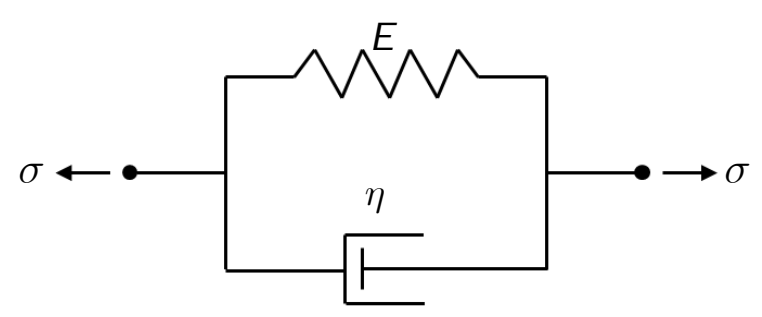

Figura 9 - Modelo de Kelvin-Voigt.

Devido à associação em paralelo, tem-se a mesma deformação nas duas partes do modelo, sendo a soma das tensões em cada parte igual à tensão total aplicada

$$
\sigma=\sigma^{\mathrm{e}}+\sigma^{\mathrm{v}}
$$

onde $\sigma$ é a tensão total aplicada, $\sigma^{\mathrm{e}}$ é a tensão relacionada ao modelo puramente elástico e $\sigma^{\vee}$ é a tensão relacionada ao modelo viscoso.

A tensão relacionada ao modelo elástico é dada por

$$
\sigma^{\mathrm{e}}=\mathrm{E} \varepsilon
$$

esta relação já foi apresentada anteriormente. A tensão relacionada ao modelo viscoso é definida como

$$
\sigma^{\vee}=\eta \dot{\varepsilon}
$$

O modelo viscoso impede uma deformação imediata do conjunto. A deformação da associação entre os modelos é dependente do tempo e isto pode ser observado no ensaio de fluência.

O ensaio de fluência consiste na aplicação de uma tensão $\sigma_{0}$ no instante de tempo inicial $t_{0}\left(t_{0}=0\right)$. Esta tensão é mantida constante ao longo do tempo. Portanto, o carregamento pode ser expresso por

$$
\sigma=\left\{\begin{array}{l}
0, \text { para } \mathrm{t}<0, \mathrm{e} \\
\sigma_{0}, \text { para } \mathrm{t} \geq 0
\end{array}\right.
$$


ou por

$$
\sigma(\mathbf{t})=\mathbf{H}(\mathbf{t}) \sigma_{0}
$$

onde $\mathrm{H}(\mathrm{t})$ é a função degrau unitário de Heaviside. Esta função descontínua $\mathrm{H}(\mathrm{t})$ é dada por

$$
H(t)=\left\{\begin{array}{l}
0, \text { se } t<0, \text { e } \\
1, \text { se } t \geq 0
\end{array}\right.
$$

A função degrau unitário de Heaviside está ilustrada na

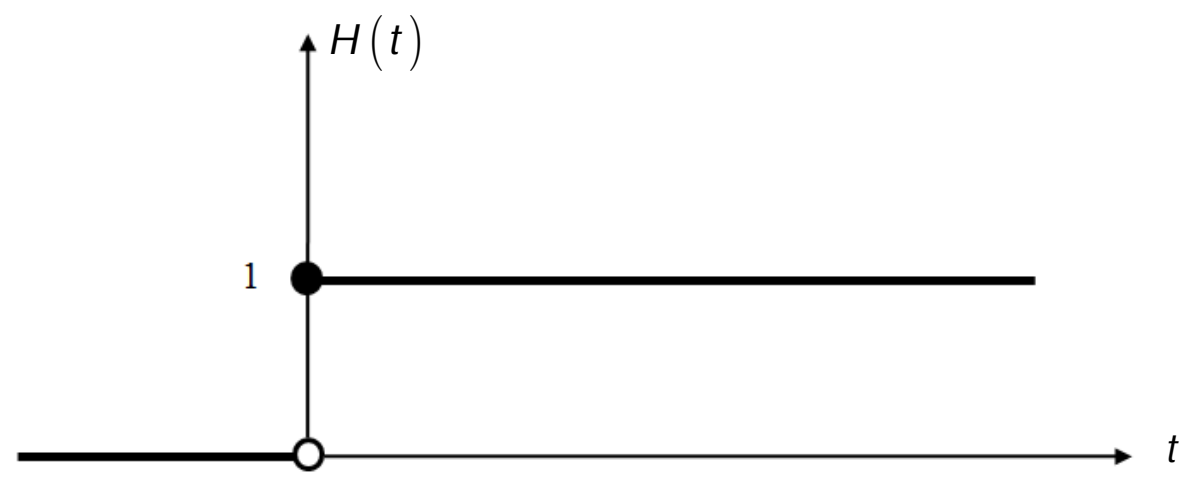

Figura 10 - Função degrau unitário de Heaviside.

A partir das equações (47), (48) e (49), pode-se escrever

$$
\sigma=\mathrm{E} \varepsilon+\eta \dot{\varepsilon}
$$

e obter a equação diferencial ordinária de primeira ordem (EDO) para $t \geq 0$ :

$$
\dot{\varepsilon}+\left(\frac{\mathrm{E}}{\eta}\right) \varepsilon=\left(\frac{1}{\eta}\right) \sigma .
$$

A solução geral desta equação é composta pela soma entre a solução particular e a solução homogênea

$$
\varepsilon(\mathrm{t})=\frac{\sigma_{0}}{\mathrm{E}}+\mathrm{C}_{1} \mathrm{e}^{-\frac{\mathrm{E}}{\eta} \mathrm{t}} .
$$

Lembra-se que com aplicação do carregamento, o modelo não apresenta uma deformação imediata. Assim a condição inicial é dada por

$$
\varepsilon\left(0^{+}\right)=0
$$

e tem-se como solução

$$
\varepsilon(\mathrm{t})=\mathrm{J}(\mathrm{t}) \sigma_{0} .
$$


A função J ( $t$ ) é denominada função de fluência e é dada por

$$
J(t)=\frac{1}{E}\left(1-e^{-\frac{E_{t}}{\eta}}\right) .
$$

A evolução da deformação obtida ao longo do tempo pode ser observada na Figura 11. Flügge (1967) salienta que a deformação não cresce indefinidamente para um intante $\mathrm{t}$ que tende a infinito; esta cresce e se aproxima de um valor limite proporcional à tensão aplicada. Este valor limite é o quociente entre a tensão aplicada $\sigma_{0}$ e o módulo de elasticidade longitudinal do material $\mathrm{E}$.

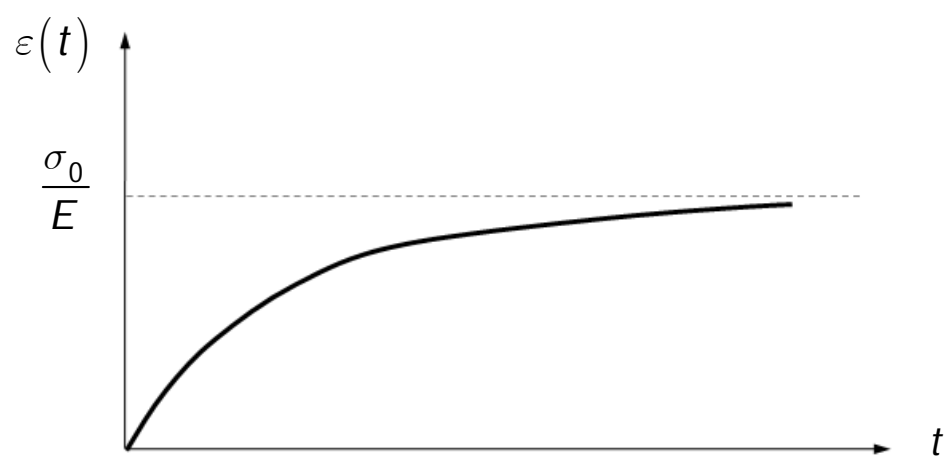

Figura 11 - Ensaio de fluência do modelo Kelvin-Voigt.

Desta forma, as tensões em cada modelo elástico e viscoso passam a ser expressas como

$$
\begin{gathered}
\sigma^{\mathrm{e}}=\sigma_{0}\left(1-\mathrm{e}^{-\frac{\mathrm{E}_{\mathrm{t}}}{\eta}}\right) \mathrm{e} \\
\sigma^{\mathrm{v}}=\sigma_{0} \mathrm{e}^{-\frac{\mathrm{E}_{\mathrm{t}}}{\eta}} .
\end{gathered}
$$

Pode-se observar na Figura 12 que a tensão no modelo elástico é crescente e no modelo viscoso é decrescente em relação ao tempo.

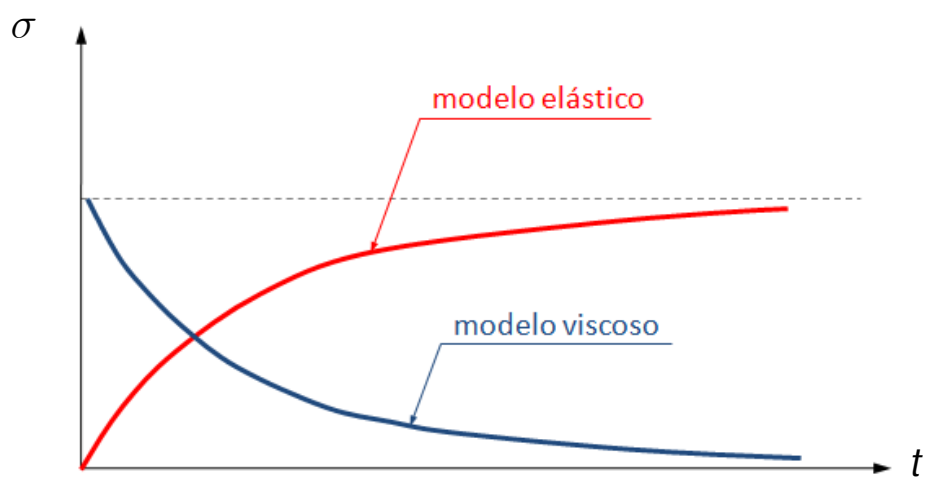

Figura 12 - Tensões no ensaio de fluência do modelo Kelvin-Voigt. 
Uma grandeza comumente definida neste contexto é o chamado módulo de elasticidade $E(t)$ aparente na fluência, motivado por (57) e dado por

$$
E(t)=\frac{1}{J(t)}=\left[\frac{1}{E}\left(1-e^{-\frac{E}{\eta} t}\right)\right]^{-1}
$$

Flügge (1967) destaca que o modelo proposto apresenta um comportamento de certa forma semelhante ao de um sólido elástico. Este comportamento é caracterizado por uma deformação que cresce gradualmente e não assume um valor final de maneira imediata. Pode-se relacionar, portanto, a uma elasticidade atrasada.

\subsubsection{Modelo viscoelástico de três parâmetros}

Este modelo é representado pela combinação em série entre o modelo puramente elástico de módulo de elasticidade $E_{0}$ e o modelo viscoso de Kelvin-Voigt de módulo de elasticidade $\mathrm{E}_{1}$ e viscosidade $\eta_{1}$, denominado como Modelo de Três Parâmetros ou erroneamente como Modelo de Boltzmann (Figura 13). Devido à associação em série, temse a mesma tensão nas duas partes do modelo, sendo a deformação total $\varepsilon$ a soma entre a deformação $\varepsilon^{\mathrm{e}}$ do modelo puramente elástico e a deformação $\varepsilon^{\mathrm{ve}}$ do modelo de KelvinVoigt:

$$
\varepsilon=\varepsilon^{\mathrm{e}}+\varepsilon^{\mathrm{ve}} .
$$

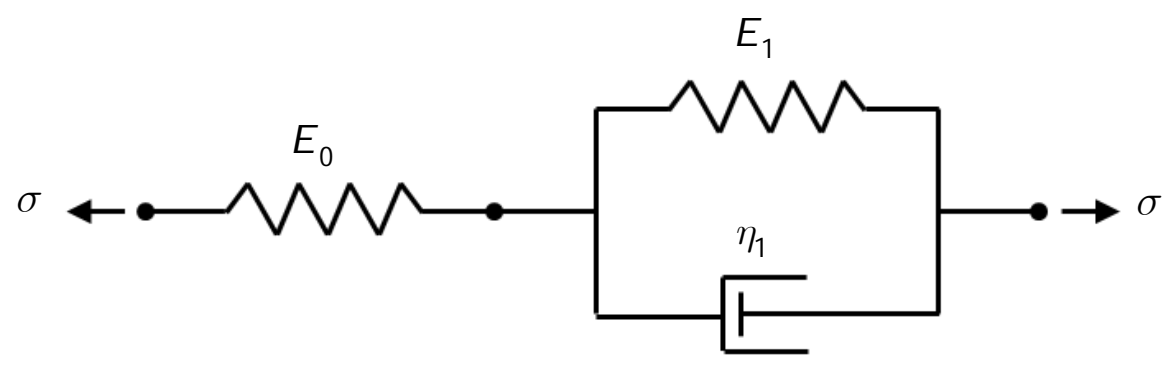

Figura 13 - Modelo viscoelástico de três parâmetros.

A tensão relacionada ao modelo elástico é definida como

$$
\sigma=\mathrm{E}_{0} \varepsilon^{\mathrm{e}}
$$


onde $\mathrm{E}_{0}$ é o módulo de Young do modelo em questão. A tensão relacionada ao modelo de Kelvin-Voigt é dada por

$$
\sigma=\mathrm{E}_{1} \varepsilon^{\mathrm{ve}}+\eta_{1} \dot{\varepsilon}^{\mathrm{ve}}
$$

onde $\mathrm{E}_{1}$ é o módulo de Young, $\eta_{1}$ é a viscosidade e $\dot{\varepsilon}^{\mathrm{ve}}$ é a taxa de deformação relacionada a esta parcela da associação.

Através das equações (62), (63) e (64), pode-se obter a seguinte equação

$$
\dot{\sigma}+\frac{\mathrm{E}_{0}+\mathrm{E}_{1}}{\eta_{1}} \sigma=\mathrm{E}_{0} \dot{\varepsilon}+\frac{\mathrm{E}_{0} \mathrm{E}_{1}}{\eta_{1}} \varepsilon .
$$

Em um ensaio de fluência, em que $\sigma_{0}$ é aplicado constantemente a partir do instante $t_{0}=0$, obtém-se através da equação anterior a seguinte equação diferencial ordinária para $\mathrm{t} \geq 0$

$$
\dot{\varepsilon}+\frac{\mathrm{E}_{1}}{\eta_{1}} \varepsilon=\frac{\mathrm{E}_{0}+\mathrm{E}_{1}}{\mathrm{E}_{0} \eta_{1}} \sigma_{0} .
$$

A condição inicial utilizada

$$
\varepsilon(0)=\frac{\sigma_{0}}{\mathrm{E}_{0}}
$$

proporciona a determinação da solução geral para a equação diferencial ordinária, dada por

$$
\varepsilon(t)=\sigma_{0}\left[\frac{1}{\mathrm{E}_{0}}+\frac{1}{\mathrm{E}_{1}}\left(1-\mathrm{e}^{-\frac{\mathrm{E}_{1}}{\eta_{1}}}\right)\right] .
$$

A solução pode ser escrita como

$$
\varepsilon(\mathrm{t})=\mathrm{J}(\mathrm{t}) \sigma_{0}
$$

onde J (t) é a função de fluência dada por

$$
J(t)=\left[\frac{1}{E_{0}}+\frac{1}{E_{1}}\left(1-e^{-\frac{E_{1}}{\eta_{1}}}\right)\right]
$$

Novamente, pode-se introduzir o módulo de elasticidade aparente na fluência como sendo:

$$
E(t)=\frac{1}{J(t)}=\left[\frac{1}{E_{0}}+\frac{1}{E_{1}}\left(1-e^{-\frac{E_{1}}{\eta_{1}}}\right)\right]^{-1}
$$

Pode-se obter a função de fluência através de ensaios com tensão constante em laboratório. 
A deformação em função do tempo está apresentada na Figura 14. Observa-se que a deformação para o instante $t_{0}=0$ não é nula e dada por

$$
\varepsilon_{0}=\frac{\sigma_{0}}{\mathrm{E}_{0}}
$$

e para um instante que tende a infinito, a deformação $\varepsilon_{\infty}$ tende a um valor dado por

$$
\varepsilon_{\infty}=\frac{\sigma_{0}}{\mathrm{E}_{\infty}}
$$

sendo o módulo de elasticidade $\mathrm{E}_{\infty}$ definido como

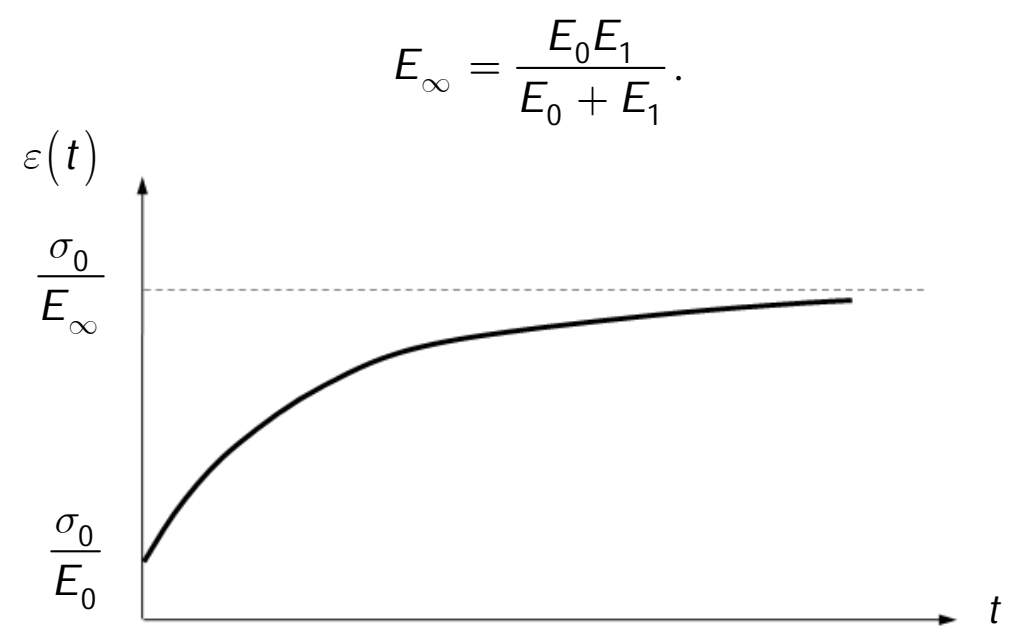

Figura 14 - Ensaio de fluência do modelo viscoelástico de três parâmetros.

\subsection{EQUAÇÃO CONSTITUTIVA VISCOELÁSTICA PARA SÓLIDOS EM EPD}

A parcela elástica do material adotado na presente formulação corresponde a um material hiperelástico do tipo isótropo Kirchhoff-Saint Venant. Como todo material hiperelástico, este possui uma energia de deformação específica $\psi$ e esta é dada por

$$
\psi(\mathbf{E})=\frac{1}{2} \lambda \mathrm{I}_{1}^{2}+2 \mu \mathrm{I}_{2},
$$

sendo $I_{1}$ e $I_{2}$ invariantes do tensor das deformações de Green, definidos como

$$
\begin{gathered}
\mathrm{I}_{1}=\operatorname{tr} \mathbf{E} \\
\mathrm{I}_{2}=\frac{1}{2} \operatorname{tr}^{2},
\end{gathered}
$$


$\lambda$ e $\mu$ as constantes de Lamé.

A partir da equação (75), obtém-se o segundo tensor das tensões de PiolaKirchhoff:

$$
\mathbf{S}=\frac{\partial \psi}{\partial \mathbf{E}}=\lambda \mathbf{I}_{\mathbf{l}} \mathbf{I}+2 \mu \mathbf{E}
$$

Tirando partido da simetria de $\mathbf{S}$ e $\mathbf{E}$, esta relação pode ser escrita matricialmente da seguinte forma

$$
\left[\begin{array}{c}
\mathrm{S}_{11} \\
\mathrm{~S}_{22} \\
\mathrm{~S}_{33} \\
\mathrm{~S}_{12} \\
\mathrm{~S}_{23} \\
\mathrm{~S}_{13}
\end{array}\right]=\left[\begin{array}{cccccc}
\lambda+2 \mu & \lambda & \lambda & 0 & 0 & 0 \\
\lambda & \lambda+2 \mu & \lambda & 0 & 0 & 0 \\
\lambda & \lambda & \lambda+2 \mu & 0 & 0 & 0 \\
0 & 0 & 0 & 2 \mu & 0 & 0 \\
0 & 0 & 0 & 0 & 2 \mu & 0 \\
0 & 0 & 0 & 0 & 0 & 2 \mu
\end{array}\right]\left[\begin{array}{l}
\mathrm{E}_{11} \\
\mathrm{E}_{22} \\
\mathrm{E}_{33} \\
\mathrm{E}_{12} \\
\mathrm{E}_{23} \\
\mathrm{E}_{13}
\end{array}\right] \text { ou }
$$

$$
\left[\begin{array}{l}
\mathrm{S}_{11} \\
\mathrm{~S}_{22} \\
\mathrm{~S}_{33} \\
\mathrm{~S}_{12} \\
\mathrm{~S}_{23} \\
\mathrm{~S}_{13}
\end{array}\right]=\frac{\mathrm{E}(1-\nu)}{(1+\nu)(1-2 \nu)}\left[\begin{array}{cccccc}
1 & \frac{\nu}{1-\nu} & \frac{\nu}{1-\nu} & 0 & 0 & 0 \\
\frac{\nu}{1-\nu} & 1 & \frac{\nu}{1-\nu} & 0 & 0 & 0 \\
\frac{\nu}{1-\nu} & \frac{\nu}{1-\nu} & 1 & 0 & 0 & 0 \\
0 & 0 & 0 & \frac{1-2 \nu}{1-\nu} & 0 & 0 \\
0 & 0 & 0 & 0 & \frac{1-2 \nu}{1-\nu} & 0 \\
0 & 0 & 0 & 0 & 0 & \frac{1-2 \nu}{1-\nu}
\end{array}\right]\left[\begin{array}{l}
\mathrm{E}_{11} \\
\mathrm{E}_{22} \\
\mathrm{E}_{33} \\
\mathrm{E}_{12} \\
\mathrm{E}_{23} \\
\mathrm{E}_{13}
\end{array}\right],
$$

onde $\mathrm{S}_{\mathrm{ij}}$ e $\mathrm{E}_{\mathrm{ij}}$ são as componentes de $\mathbf{S}$ e $\mathbf{E}$, E é o módulo de elasticidade longitudinal e $\nu$ é o coeficiente de Poisson, dados por

$$
\begin{aligned}
& \mathrm{E}=\frac{\mu(3 \lambda+2 \mu)}{\lambda+\mu} \mathrm{e} \\
& \nu=\frac{\lambda}{2(\lambda+\mu)} .
\end{aligned}
$$

Como apresentado no item 2.2, o campo de deslocamentos no EPD é dado por

$$
\mathbf{u}=\left(u_{1}\left(x_{1}^{r}, x_{2}^{r}\right), u_{2}\left(x_{1}^{r}, x_{2}^{r}\right), 0\right)
$$

de modo que as componentes de deformação $E_{33}, E_{23}$ e $E_{13}$ são nulas (ver equação (41) na 
seção 2.2). Neste caso, percebe-se que as únicas componentes de $\mathbf{S}$ que realizam trabalho são $\mathrm{S}_{11}, \mathrm{~S}_{22}$ e $\mathrm{S}_{12}$, assim, estas componentes podem ser agrupadas no vetor $\mathbf{S}$ conforme abaixo

$$
\mathbf{s}=\left[\begin{array}{l}
\mathrm{S}_{11} \\
\mathrm{~S}_{22} \\
\mathrm{~S}_{12}
\end{array}\right],
$$

em analogia à definição do vetor $\mathbf{e}$ em (42). A relação (79) pode ser reduzida a

$$
\begin{gathered}
\mathbf{s}=\mathbf{D e}, \\
\mathrm{S}_{33}=\nu\left(\mathrm{S}_{11}+\mathrm{S}_{22}\right), \\
\mathrm{S}_{13}=\mathrm{S}_{23}=0,
\end{gathered}
$$

onde

$$
\mathbf{D}=\left[\begin{array}{ccc}
\lambda+2 \mu & \lambda & 0 \\
\lambda & \lambda+2 \mu & 0 \\
0 & 0 & 2 \mu
\end{array}\right]=\frac{\mathrm{E}(1-\nu)}{(1+\nu)(1-2 \nu)}\left[\begin{array}{ccc}
1 & \frac{\nu}{1-\nu} & 0 \\
\frac{\nu}{1-\nu} & 1 & 0 \\
0 & 0 & \frac{1-2 \nu}{1-\nu}
\end{array}\right] .
$$

Por sua vez, a parcela viscosa do material requer a consideração das taxas de deformação $\dot{\mathbf{E}}$ ou $\dot{\mathbf{e}}$. Esta consideração introduz a necessidade da realização de integrações no domínio do tempo, no caso geral multiaxial só é possível numericamente. Para certos materiais, contudo, é possível adotar algumas simplificações que eliminam esta necessidade. Segundo McHenry (1943 apud KING; WATSON; ZIENKEWICZ, 1968), Polivka et al (1963 apud ; WATSON; ZIENKEWICZ, 1968) e Pimenta (2008), no caso do concreto, por exemplo, o coeficiente de Poisson pode ser, com razoável precisão, admitido constante ao longo do tempo. Assim, segundo Pimenta (2008), numa situação de tensão constante, como é o caso da fluência e também, aproximadamente, o caso do revestimento de túneis, a consideração do coeficiente de Poisson constante traz como conseqüência a descrição de toda a viscosidade em termos do módulo de elasticidade aparente, $\mathrm{E}(\mathrm{t})$. Ou seja, o comportamento viscoso multiaxial do material pode ser descrito a partir do conhecimento da função de fluência em ensaios uniaxiais. Assim, tirando proveito disso, pode-se escrever a equação constitutiva como sendo

$$
\mathbf{s}=\mathbf{D}(\mathrm{t}) \mathbf{e},
$$

com 


$$
\mathbf{D}(\mathrm{t})=\frac{\mathrm{E}(\mathrm{t})(1-\nu)}{(1+\nu)(1-2 \nu)}\left[\begin{array}{ccc}
1 & \frac{\nu}{1-\nu} & 0 \\
\frac{\nu}{1-\nu} & 1 & 0 \\
0 & 0 & \frac{1-2 \nu}{1-\nu}
\end{array}\right]
$$

onde

$$
E(t)=\frac{1}{J(t)}=\left[\frac{1}{E}\left(1-e^{-\frac{E}{\eta} t}\right)\right]^{-1}
$$

Esta é a lei viscoelástica empregada neste trabalho.

O vetor das tensões $\mathbf{S}$ resulta das equações (42), (85) e (86) e é dado por

$$
\mathbf{s}=\frac{\mathbf{E}(\mathbf{t})(1-\nu)}{2(1+\nu)(1-2 \nu)}\left[\begin{array}{c}
\gamma_{12}^{2}+\left(1+\gamma_{11}\right)^{2}-1+\frac{\nu}{1-\nu}\left[\gamma_{21}^{2}+\left(1+\gamma_{22}\right)^{2}-1\right] \\
\frac{\nu}{1-\nu}\left[\gamma_{12}^{2}+\left(1+\gamma_{11}\right)^{2}-1\right]+\gamma_{21}^{2}+\left(1+\gamma_{22}\right)^{2}-1 \\
\frac{1-2 \nu}{1-\nu}\left[\gamma_{21}\left(1+\gamma_{11}\right)+\gamma_{12}\left(1+\gamma_{22}\right)\right]
\end{array}\right]
$$

O Primeiro Tensor das Tensões de Piola-Kirchhoff pode ser obtido a partir da substituição das componentes de S e F (dadas respectivamente pelas equações (88) e (39), respectivamente) na equação (22). Em termos de seus vetores-coluna, resulta em

$$
\begin{gathered}
\boldsymbol{\tau}_{1}=\left[\begin{array}{ccc}
1+\gamma_{11} & 0 & \gamma_{21} \\
\gamma_{12} & 0 & 1+\gamma_{22} \\
0 & 0 & 0
\end{array}\right]\left[\begin{array}{l}
\mathrm{S}_{11} \\
\mathrm{~S}_{22} \\
\mathrm{~S}_{12}
\end{array}\right] \\
\boldsymbol{\tau}_{2}=\left[\begin{array}{ccc}
0 & \gamma_{21} & 1+\gamma_{11} \\
0 & 1+\gamma_{22} & \gamma_{12} \\
0 & 0 & 0
\end{array}\right]\left[\begin{array}{l}
\mathrm{S}_{11} \\
\mathrm{~S}_{22} \\
\mathrm{~S}_{12}
\end{array}\right] \\
\boldsymbol{\tau}_{3}=\left[\begin{array}{c}
0 \\
0 \\
\mathrm{~S}_{33}
\end{array}\right] .
\end{gathered}
$$

Ao substituir o vetor S (equação (88)) na equação (89), pode-se reescrever os vetores $\tau_{\mathrm{i}}$ da seguinte forma 


$$
\boldsymbol{\tau}_{1}=\phi\left[\begin{array}{c}
\left(1+\gamma_{11}\right)\left\{\gamma_{12}^{2}+\left(1+\gamma_{11}\right)^{2}-1+\frac{\nu}{1-\nu}\left[\gamma_{21}^{2}+\left(1+\gamma_{22}\right)^{2}-1\right]+\right\} \\
+\frac{1-2 \nu}{1-\nu} \gamma_{21}\left[\gamma_{21}\left(1+\gamma_{11}\right)+\gamma_{12}\left(1+\gamma_{22}\right)\right] \\
\gamma_{12}\left\{\gamma_{12}^{2}+\left(1+\gamma_{11}\right)^{2}-1+\frac{\nu}{1-\nu}\left[\gamma_{21}^{2}+\left(1+\gamma_{22}\right)^{2}-1\right]\right\}+ \\
+\frac{1-2 \nu}{1-\nu}\left(1+\gamma_{22}\right)\left[\gamma_{21}\left(1+\gamma_{11}\right)+\gamma_{12}\left(1+\gamma_{22}\right)\right] \\
0
\end{array}\right] \mathrm{e}
$$

$$
\tau_{2}=\phi\left[\begin{array}{c}
\gamma_{21}\left\{\gamma_{21}^{2}+\left(1+\gamma_{22}\right)^{2}-1+\frac{\nu}{1-\nu}\left[\gamma_{12}^{2}+\left(1+\gamma_{11}\right)^{2}-1\right]+\right\} \\
+\frac{1-2 \nu}{1-\nu}\left(1+\gamma_{11}\right)\left[\gamma_{21}\left(1+\gamma_{11}\right)+\gamma_{12}\left(1+\gamma_{22}\right)\right] \\
\left(1+\gamma_{22}\right)\left\{\gamma_{21}^{2}+\left(1+\gamma_{22}\right)^{2}-1+\frac{\nu}{1-\nu}\left[\gamma_{12}^{2}+\left(1+\gamma_{11}\right)^{2}-1\right]\right\}+ \\
+\frac{1-2 \nu}{1-\nu} \gamma_{12}\left[\gamma_{21}\left(1+\gamma_{11}\right)+\gamma_{12}\left(1+\gamma_{22}\right)\right] \\
0
\end{array}\right]
$$

com

$$
\phi=\frac{\mathrm{E}(\mathrm{t})(1-\nu)}{2(1+\nu)(1-2 \nu)} .
$$

As matrizes dos módulos viscoelásticos de rigidez tangente são dadas por

$$
\mathbf{C}_{\alpha \beta}=\frac{\partial \boldsymbol{\tau}_{\alpha}}{\partial \gamma_{\beta}}
$$

A partir das equações (90), (91) e (93), pode-se escrever

$$
\begin{aligned}
& \mathbf{C}_{11}=\left[\begin{array}{ccc}
\mathrm{S}_{11}+\phi\left[2\left(1+\gamma_{11}\right)^{2}+\psi \gamma_{21}^{2}\right] & \phi\left[2 \gamma_{12}\left(1+\gamma_{11}\right)+\psi \gamma_{21}\left(1+\gamma_{22}\right)\right] & 0 \\
\phi\left[2 \gamma_{12}\left(1+\gamma_{11}\right)+\psi \gamma_{21}\left(1+\gamma_{22}\right)\right] & \mathrm{S}_{11}+\phi\left[2 \gamma_{12}^{2}+\psi\left(1+\gamma_{22}\right)^{2}\right] & 0 \\
0 & 0 & 0
\end{array}\right],(94) \\
& \mathbf{C}_{12}=\left[\begin{array}{ccc}
\mathrm{S}_{12}+\phi\left[\varphi \gamma_{21}\left(1+\gamma_{11}\right)\right] & \phi\left[2 \varphi\left(1+\gamma_{11}\right)\left(1+\gamma_{22}\right)+\psi \gamma_{12} \gamma_{21}\right] & 0 \\
\phi\left[2 \varphi \gamma_{12} \gamma_{21}+\psi\left(1+\gamma_{11}\right)\left(1+\gamma_{22}\right)\right] & \mathrm{S}_{12}+\phi\left[\varphi \gamma_{12}\left(1+\gamma_{22}\right)\right] & 0 \\
0 & 0 & 0
\end{array}\right] \text { e (95) }
\end{aligned}
$$




$$
\mathbf{C}_{22}=\left[\begin{array}{ccc}
\mathrm{S}_{22}+\phi\left[2 \gamma_{21}^{2}+\psi\left(1+\gamma_{11}\right)^{2}\right] & \phi\left[2 \gamma_{21}\left(1+\gamma_{22}\right)+\psi \gamma_{12}\left(1+\gamma_{11}\right)\right] & 0 \\
\phi\left[2 \gamma_{21}\left(1+\gamma_{22}\right)+\psi \gamma_{12}\left(1+\gamma_{11}\right)\right] & \mathrm{S}_{22}+\phi\left[2\left(1+\gamma_{22}\right)^{2}+\psi \gamma_{12}^{2}\right] & 0 \\
0 & 0 & 0
\end{array}\right], \quad \text { (96) }
$$

com $S_{11}, S_{22}$ e $S_{12}$ dados por (88). Ressalta-se que

$$
\begin{gathered}
\mathbf{C}_{21}=\mathbf{C}_{12}^{\top}, \\
\psi=\frac{1-2 \nu}{1-\nu} \mathrm{e} \\
\varphi=\frac{\nu}{1-\nu} .
\end{gathered}
$$




\section{IMPLEMENTAÇÃO EM ELEMENTOS FINITOS}

O método dos elementos finitos, MEF ("finite element method" - FEM), foi desenvolvido na década de cinquenta do século XX. O primeiro artigo publicado foi elaborado por M. J. Turner, R. W. Clough, H. C. Martin e L. J. Topp em 1956. Porém o termo elementos finitos foi escrito pela primeira vez por R. W. Clough em um artigo posterior ao comentado anteriormente (BELYTSCHKO; FISH, 2007).

O método dos elementos finitos é uma aproximação numérica, onde equações diferenciais podem ser resolvidas de forma aproximada. Este método é uma ferramenta para resolver problemas de engenharia, como por exemplo, determinação de campos de tensão e deformação, problemas de transferência de calor e de mecânica dos fluidos, através de simulações computacionais.

Segundo Belytschko e Fish (2007), milhões de engenheiros e cientistas em todo o mundo usam métodos dos elementos finitos (MEF) para prever o comportamento de estruturas, sistemas elétricos, sistemas mecânicos, dentre outros. O autor ressalta que em 1991 haviam sido identificados quatrocentos livros sobre este método, estes estariam escritos em inglês e outros idiomas. O mesmo autor também apresenta um segundo levantamento, onde haveriam sido publicados quinhentos e setenta e oito livros entre os anos de 1967 e 2005. Estes dados ressaltam o grande número de publicações realizadas sobre o assunto, onde não são contemplados os números de artigos publicados em congresso e revistas, ou seja, este número é muito maior do que o apresentado. Destaca-se os seguintes livros sobre o assunto: Bonet e Wood (BONET; WOOD, 1997); Taylor e Zienkiewicz (TAYLOR; ZIENKIEWICZ, 2000); Belytschko e Fish (BELYTSCHKO; FISH, 2007); Wriggers (WRIGGERS, 2008).

Em 2002, Mesquita propôs formulações para tratamento de problemas inelásticos via método dos elementos finitos (MEF) e método dos elementos de contorno (MEC). Campello, 2005, apresentou modelos de casca geometricamente exatos e totalmente consistentes para grandes deformações (teoria e implementação em elementos finitos). Já Santos, em 2006, analisou as estruturas de concreto sob a ação do tempo, sendo consideradas a viscoelasticidade, plasticidade, fissuração e protensão. 


\subsection{IMPLEMENTAÇÃO DO MODELO VISCOELÁSTICO COM EPD}

A partir dos conceitos apresentados durante a formulação da mecânica não linear dos sólidos deformáveis, e de conceitos de Bonet e Wood (1997); Taylor e Zienkiewicz (2000); Campello, Pimenta e Wriggers (2003); Belytschko e Fish (2007); Wriggers (2008), foi possível elaborar a forma fraca para a implementação, dada pela equação (32), com as hipóteses da seção 2.2 .

O ponto de partida do Método dos Elementos Finitos consiste na divisão do domínio $\mathrm{V}^{\mathrm{r}}$ ou $\Omega^{\mathrm{r}}$ em subdomínios $\mathrm{V}_{\mathrm{e}}^{\mathrm{r}}$ ou $\Omega_{\mathrm{e}}^{\mathrm{r}}$ (ou elementos finitos), conectados entre si por nós. Esta definição é apresentada na Figura 15 para sólidos tridimensionais e também para sólidos em EPD.

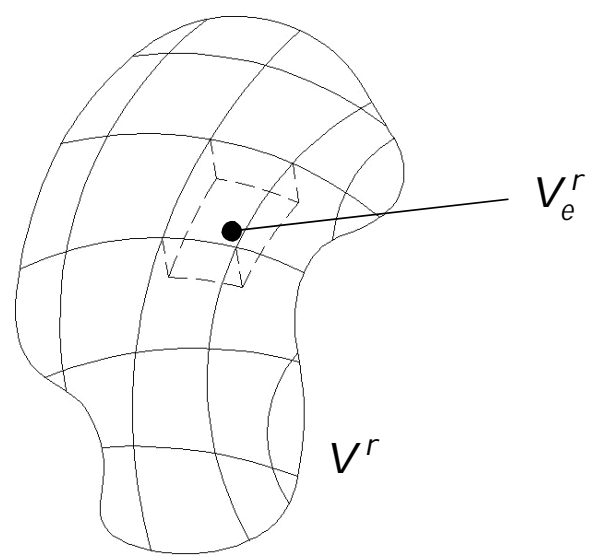

(a)

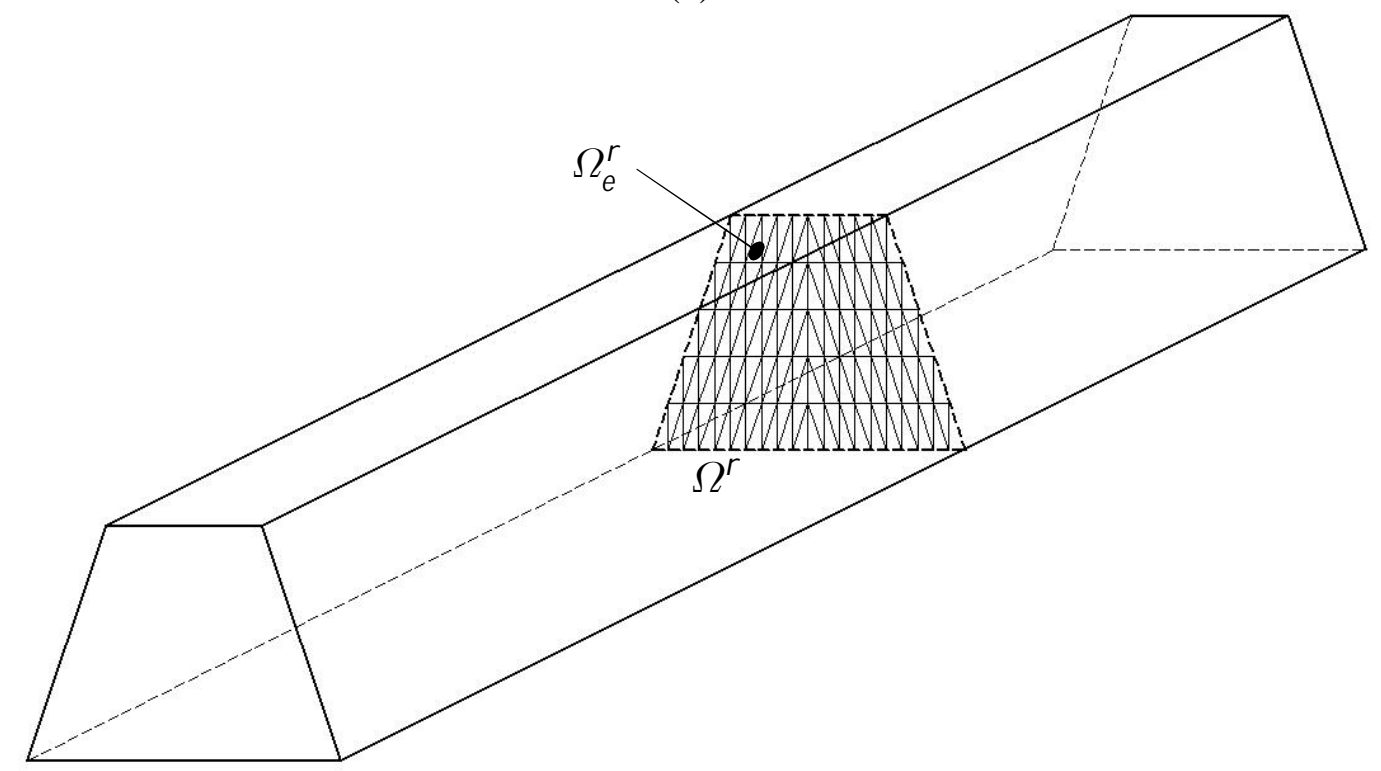

(b)

Figura 15 - Discretização do sólidos: (a) tridimensional; (b) em EPD. 
A partir desta consideração, pode-se definir o domínio na configuração de referência como

$$
\mathrm{V}^{\mathrm{r}}=\mathrm{UV}_{\mathrm{e}}^{\mathrm{r}} \text { ou } \Omega^{\mathrm{r}}=\bigcup \Omega_{\mathrm{e}}^{\mathrm{r}} \text {. }
$$

Para o sólido em EPD, considere um elemento triangular de seis nós, plano, sendo sua numeração de nós e sistema local apresentados na Figura 16. Um domínio bidimensional pode ser facilmente discretizado com elementos triangulares sem muitos problemas. Uma malha composta por estes elementos tende a não gerar erros significativos e isso é essencial durante a solução de problemas com elementos finitos.

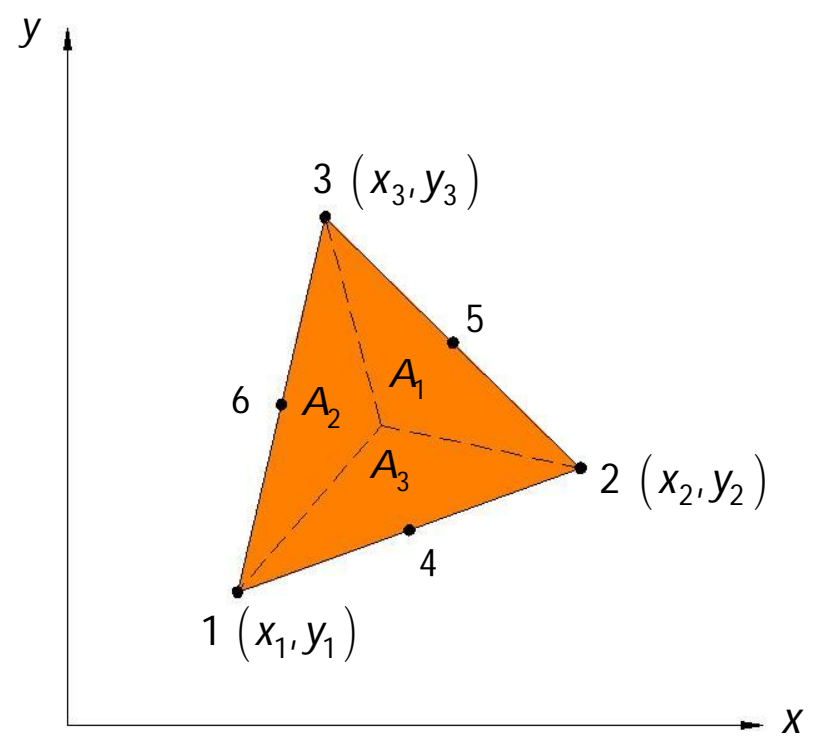

Figura 16 - Elemento triangular de seis nós.

Define-se o vetor dos graus de liberdade do nó “i”, denominado $(i=1, \ldots, 6)$, como sendo

$$
\mathbf{p}_{\mathrm{i}}=\mathbf{u}_{\mathrm{i}}
$$

sendo $\mathbf{u}_{\mathrm{i}}$ o vetor deslocamento do nó “i”. Este elemento apresenta graus de liberdade de deslocamento em todos os nós e, portanto pode-se se utilizar funções quadráticas completas para interpolar os deslocamentos no seu interior. Essa consideração é baseada na necessidade de o número de termos da função polinomial ser igual ao número de nós do elemento. Assim, ao observar o triângulo de Pascal (Figura 17), percebe-se que se trata de um caso de funções quadráticas completas. 


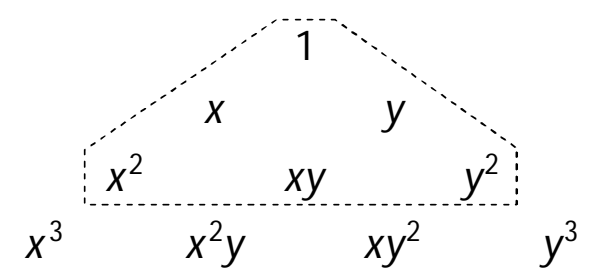

Figura 17 - Triangulo de Pascal - 2D.

As funções de interpolação quadráticas $\mathrm{N}_{\mathrm{i}}$ podem ser escritas utilizando-se as chamadas coordenadas de área $A_{i}$, a partir das funções auxiliares $L_{i}=A_{i} / A, i=1,2,3$. Adota-se $A$ como a área total do elemento e $A_{i}$ como as áreas parciais indicadas na Figura 16 (já apresentada).

Em coordenadas cartesianas, tem-se:

$$
\begin{aligned}
& L_{i}(x, y)=\frac{1}{2 A}\left(a_{i}+b x+c_{i} y\right), i=1,2,3, c o m \\
& a_{1}=x_{2} y_{3}-x_{3} y_{2}, b_{1}=y_{2}-y_{3}, c_{1}=x_{3}-x_{2} \\
& a_{2}=x_{3} y_{1}-x_{1} y_{3}, b_{2}=y_{3}-y_{1}, c_{2}=x_{1}-x_{3} \\
& a_{3}=x_{1} y_{2}-x_{2} y_{1}, b_{3}=y_{1}-y_{2}, c_{3}=x_{2}-x_{1}
\end{aligned}
$$

A Tabela 1 ilustra os valores de $A_{i}$ e $L_{i}$ em cada nó e apresenta as expressões de $\mathrm{N}_{\mathrm{i}}$.

Tabela 1 - Funções de interpolação do elemento triangular de seis nós.

\begin{tabular}{c|c|c|c|c|c|c|c}
\hline $\mathrm{i}$ & $\mathrm{A}_{1}$ & $\mathrm{~A}_{2}$ & $\mathrm{~A}_{3}$ & $\mathrm{~L}_{1}(\mathrm{x}, \mathrm{y})$ & $\mathrm{L}_{2}(\mathrm{x}, \mathrm{y})$ & $\mathrm{L}_{3}(\mathrm{x}, \mathrm{y})$ & $\mathrm{N}_{\mathrm{i}}$ \\
\hline 1 & 1 & 0 & 0 & 1 & 0 & 0 & $\mathrm{~L}_{1}\left(\mathrm{~L}_{1}-1\right)$ \\
2 & 0 & 1 & 0 & 0 & 1 & 0 & $\mathrm{~L}_{2}\left(\mathrm{~L}_{2}-1\right)$ \\
3 & 0 & 0 & 1 & 0 & 0 & 1 & $\mathrm{~L}_{3}\left(2 \mathrm{~L}_{3}-1\right)$ \\
4 & $\frac{1}{2} \mathrm{~A}$ & $\frac{1}{2} \mathrm{~A}$ & 0 & $1 / 2$ & $1 / 2$ & 0 & $4 \mathrm{~L}_{1} \mathrm{~L}_{2}$ \\
5 & 0 & $\frac{1}{2} \mathrm{~A}$ & $\frac{1}{2} \mathrm{~A}$ & 0 & $1 / 2$ & $1 / 2$ & $4 \mathrm{~L}_{2} \mathrm{~L}_{3}$ \\
6 & $\frac{1}{2} \mathrm{~A}$ & 0 & $\frac{1}{2} \mathrm{~A}$ & $1 / 2$ & 0 & $1 / 2$ & $4 \mathrm{~L}_{1} \mathrm{~L}_{3}$ \\
\hline
\end{tabular}

Adaptado de: BELYTSCHKO \& FISH (2007).

O elemento assim construído é aqui chamado de T6. O vetor que agrupa os seus graus de liberdade é definido como 


$$
\mathbf{p}_{\mathrm{e}}=\left[\begin{array}{c}
\mathbf{p}_{1} \\
\mathbf{p}_{2} \\
\vdots \\
\mathbf{p}_{6}
\end{array}\right],
$$

sendo o campo de deslocamentos no seu interior determinado através de

$$
\mathbf{u}=\mathbf{N} \mathbf{p}_{\mathrm{e}}
$$

onde $\mathbf{N}$ é a matriz que agrupa as funções de interpolação. Esta matriz é definida da seguinte forma

$$
\mathbf{N}=\left[\begin{array}{llllll}
\mathrm{N}_{1} \mathbf{I} & \mathrm{N}_{2} \mathbf{I} & \mathrm{N}_{3} \mathbf{I} & \mathrm{N}_{4} \mathbf{I} & \mathrm{N}_{5} \mathbf{I} & \mathrm{N}_{6} \mathbf{I}
\end{array}\right] .
$$

Utilizando o Método de Galerkin, os deslocamentos virtuais $\delta \mathbf{u}$ no interior do elemento podem ser aproximados com as mesmas funções $\mathbf{N}_{\mathrm{i}}$ :

$$
\delta \mathbf{u}=\mathbf{N} \delta \mathbf{p}_{\mathrm{e}},
$$

sendo $\delta \mathbf{p}_{\mathrm{e}}$ o vetor dos deslocamentos virtuais nodais do elemento.

Introduzindo-se (104) e (106) na expressão da forma fraca (equação (32)), e tomando-se partido de (100), pode-se reescrever o equilíbrio do sólido da seguinte forma

$$
\sum_{\mathrm{e}=1}^{\mathrm{n}_{\mathrm{e}}} \int_{\mathrm{V}_{\mathrm{e}}^{\mathrm{r}}} \boldsymbol{\tau}_{\mathrm{i}} \cdot \boldsymbol{\Delta}_{\mathrm{i}} \mathbf{N} \delta \mathbf{p}_{\mathrm{e}} \mathrm{d} \mathrm{V}^{\mathrm{r}}-\sum_{\mathrm{e}=1}^{\mathrm{n}_{\mathrm{e}}}\left[\int_{\mathrm{V}_{\mathrm{e}}^{\mathrm{r}}} \mathbf{b}^{r} \cdot \mathbf{N} \delta \mathbf{p}_{\mathrm{e}} \mathrm{d} \mathrm{V}^{r}+\int_{\mathrm{S}_{\mathrm{e}}^{\mathrm{r}}} \overline{\mathbf{t}}^{\mathrm{r}} \cdot \mathbf{N} \delta \mathbf{p}_{\mathrm{e}} \mathrm{d} \mathrm{S}^{\mathrm{r}}\right]=0, \forall \delta \mathbf{p}_{\mathrm{e}}, \text { (107) }
$$

onde $n_{e}$ é o número de elementos utilizados na discretização do domínio. Os integrandos desta expressão não dependem da coordenada longitudinal $x_{3}^{r}$ por conta das hipóteses do EPD. Assim, as integrais acima podem ser feitas no domínio bidimensional $\Omega^{r}$, e seus resultados multiplicados pelo comprimento total do sólido na direção longitudinal. Portanto, pode-se reescrever (107) como

$\sum_{\mathrm{e}=1}^{\mathrm{n}_{\mathrm{d}}} \int_{\Omega_{\mathrm{e}}^{\mathrm{r}}}\left(\boldsymbol{\Delta}_{\alpha} \mathbf{N}\right)^{\top} \boldsymbol{\tau}_{\alpha} \mathrm{d} \Omega^{\mathrm{r}} \cdot \delta \mathbf{p}_{\mathrm{e}}-\sum_{\mathrm{e}=1}^{\mathrm{n}_{\mathrm{e}}}\left[\int_{\Omega_{\mathrm{e}}^{\mathrm{r}}} \mathbf{N}^{\top} \mathbf{b}^{\mathrm{r}} \mathrm{d} \Omega^{\mathrm{r}}+\int_{\Gamma_{\mathrm{e}}^{\mathrm{r}}} \mathbf{N}^{\top} \overline{\mathbf{t}}^{\mathrm{r}} \mathrm{d} \Gamma^{\mathrm{r}}\right] \cdot \delta \mathbf{p}_{\mathrm{e}}=0, \forall \delta \mathbf{p}_{\mathrm{e}},(108)$

onde $\Gamma_{\mathrm{e}}^{\mathrm{r}}$ é a parte do elemento "e" que pertence ao contorno $\Gamma^{\mathrm{r}}$ de $\Omega^{\mathrm{r}}$. Essa expressão motiva as seguintes definições

$$
\begin{aligned}
& \mathbf{P}_{\text {int }}^{\mathbf{e}}=\int_{\Omega_{\mathrm{e}}^{\mathrm{r}}}\left(\boldsymbol{\Delta}_{\alpha} \mathbf{N}\right)^{\top} \boldsymbol{\tau}_{\alpha} \mathrm{d} \Omega^{\mathrm{r}} \mathrm{e} \\
& \mathbf{P}_{\text {ext }}^{\mathbf{e}}=\int_{\Omega_{\mathrm{e}}^{\mathrm{e}}}^{\mathrm{r}} \mathbf{N}^{\top} \mathbf{b}^{\mathrm{r}} \mathrm{d} \Omega^{\mathrm{r}}+\int_{\Gamma_{\mathrm{e}}^{\mathrm{r}}} \mathbf{N}^{\top} \overline{\mathbf{t}}^{\mathrm{r}} \mathrm{d} \Gamma^{\mathrm{r}} .
\end{aligned}
$$


Chama-se $\mathbf{P}_{\text {int }}^{\mathbf{e}}$ de vetor dos esforços internos nodais de um elemento e $\mathbf{P}_{\text {ext }}^{\mathbf{e}}$ de vetor dos esforços externos nodais de um elemento. Portanto, tem-se

$$
\sum_{\mathrm{e}=1}^{\mathrm{n}_{\mathrm{e}}} \mathbf{P}_{\mathrm{int}}^{\mathrm{e}} \cdot \delta \mathbf{p}_{\mathrm{e}}-\sum_{\mathrm{e}=1}^{\mathrm{n}_{\mathrm{e}}} \mathbf{p}_{\mathrm{ext}}^{\mathrm{e}} \cdot \delta \mathbf{p}_{\mathrm{e}}=0, \forall \delta \mathbf{p}_{\mathrm{e}} .
$$

Os graus de liberdade nodais de todo o sólido podem ser agrupados em um vetor $\mathbf{r}$, de onde o vetor dos graus de liberdade do elemento pode ser extraído, conforme abaixo

$$
\mathbf{p}_{\mathrm{e}}=\mathbf{A}_{\mathrm{e}} \mathbf{r}
$$

sendo $\mathbf{A}_{\mathrm{e}}$ a chamada matriz de conectividade do elemento "e". Esta matriz $\mathbf{A}_{\mathrm{e}}$ armazena as posições dos graus de liberdade do elemento nas numerações para os sistemas local e global. Da mesma forma, pode-se reescrever o vetor dos deslocamentos virtuais nodais do elemento como

$$
\delta \mathbf{p}_{\mathrm{e}}=\mathbf{A}_{\mathrm{e}} \delta \mathbf{r} .
$$

A partir das equações (110) e (112), pode-se escrever

$$
\left(\sum_{\mathrm{e}=1}^{\mathrm{n}_{\mathrm{e}}} \mathbf{A}_{\mathrm{e}}^{\top} \mathbf{P}_{\mathrm{int}}^{\mathrm{e}}-\sum_{\mathrm{e}=1}^{\mathrm{n}_{\mathrm{e}}} \mathbf{A}_{\mathrm{e}}^{\top} \mathbf{P}_{\mathrm{ext}}^{\mathrm{e}}\right) \cdot \delta \mathbf{r}=0, \forall \delta \mathbf{r},
$$

sendo definido o vetor dos esforços internos nodais do sólido como

$$
\mathbf{R}_{\text {int }}=\sum_{\mathrm{e}=1}^{\mathrm{n}_{\mathrm{e}}} \mathbf{A}_{\mathrm{e}}^{\top} \mathbf{P}_{\mathrm{int}}^{\mathrm{e}} \mathrm{e}
$$

o vetor dos esforços externos nodais como

$$
\mathbf{R}_{\text {ext }}=\sum_{\mathrm{e}=1}^{\mathrm{n}_{\mathrm{e}}} \mathbf{A}_{\mathrm{e}}^{\top} \mathbf{P}_{\mathrm{ext}}^{\mathrm{e}} .
$$

Tem-se então que

$$
\left(\mathbf{R}_{\text {int }}-\mathbf{R}_{\text {ext }}\right) \cdot \delta \mathbf{r}=0, \forall \delta \mathbf{r}
$$

de onde resulta o seguinte sistema de equações algébricas não lineares

$$
\mathbf{R}(\mathbf{r})=\mathbf{R}_{\text {int }}-\mathbf{R}_{\text {ext }}=\mathbf{o}
$$

onde $\mathbf{R}(\mathbf{r})$ é denominado o vetor das forças nodais desbalanceadas.

A solução deste sistema de equações algébricas não lineares deve ser feita por métodos aproximados, e aqui se opta pelo Método de Newton. Neste, utilizam-se os primeiros termos da expansão da Série de Taylor como uma aproximação do vetor das forças 
desbalanceadas, ou seja,

$$
\mathbf{R}(\mathbf{r}) \approx \mathbf{R}\left(\mathbf{r}_{0}\right)+\left.\frac{\partial \mathbf{R}}{\partial \mathbf{r}}\right|_{\mathbf{r}_{0}}\left(\mathbf{r}-\mathbf{r}_{0}\right)
$$

Esta aproximação nada mais é do que uma linearização de $\mathbf{R}(\mathbf{r})$ em torno de $\mathbf{r}_{0}$, onde este é conhecido. Portanto, (117) pode ser reescrita da seguinte forma

$$
\mathbf{R}\left(\mathbf{r}_{0}\right)+\left.\frac{\partial \mathbf{R}}{\partial \mathbf{r}}\right|_{\mathbf{r}_{0}}\left(\mathbf{r}-\mathbf{r}_{0}\right)=\mathbf{o}
$$

onde se pode definir

$$
\begin{gathered}
\mathbf{K}\left(\mathbf{r}_{0}\right)=\left.\frac{\partial \mathbf{R}}{\partial \mathbf{r}}\right|_{\mathbf{r}_{0}} \mathrm{e} \\
\boldsymbol{\delta}=\mathbf{r}-\mathbf{r}_{0}
\end{gathered}
$$

Assim, a equação (119) pode ser reescrita como

$$
\mathbf{K}\left(\mathbf{r}_{0}\right) \boldsymbol{\delta}=-\mathbf{R}\left(\mathbf{r}_{0}\right)
$$

onde $\mathbf{K}$ é a chamada matriz de rigidez do sólido. O sistema apresentado na equação (122) é linear, e é o sistema de equações a ser resolvido, onde a incógnita a ser determinada é $\delta$. Conhecido o $\boldsymbol{\delta}$, tem-se $\mathbf{r}$ através da expressão (121).

A Figura 18, apresentada a seguir, demonstra a rotina a ser seguida durante a implementação em elementos finitos para aplicar o Método de Newton.

1. $\mathrm{k}=0$, conhece-se $\mathbf{r}_{0}$.

2. Resolução da equação: $\mathbf{K}\left(\mathbf{r}_{\mathrm{k}}\right) \boldsymbol{\delta}=-\mathbf{R}\left(\mathbf{r}_{\mathrm{k}}\right) \rightarrow$ obtém-se $\boldsymbol{\delta}$.

3. $\mathbf{r}_{\mathrm{k}+1}=\mathbf{r}_{\mathrm{k}}+\boldsymbol{\delta}, \mathrm{k}=\mathrm{k}+1$.

4. Se $\frac{\left\|\mathbf{R}\left(\mathbf{r}_{\mathrm{k}+1}\right)\right\|}{\left\|\mathbf{R}\left(\mathbf{r}_{0}\right)\right\|}<$ valor de tolerância admitido, a solução está determinada. Se não, retorna-se ao passo $\mathrm{n}^{\circ} 2$.

Figura 18 - Visão geral do método de Newton.

A aplicação do Método de Newton requer que se conheça a expressão da matriz de rigidez do sólido:

$$
\mathbf{K}=\frac{\partial \mathbf{R}}{\partial \mathbf{r}}=\frac{\partial}{\partial \mathbf{r}}\left(\mathbf{R}_{\text {int }}(\mathbf{r})-\mathbf{R}_{\text {ext }}(\mathbf{r})\right)
$$

de onde, ao se considerar apenas carregamentos conservativos, tem-se 


$$
\mathbf{K}=\frac{\partial \mathbf{R}_{\text {int }}(\mathbf{r})}{\partial \mathbf{r}}=\frac{\partial}{\partial \mathbf{r}}\left(\sum_{\mathrm{e}=1}^{\mathrm{n}_{\mathrm{e}}} \mathbf{A}_{\mathrm{e}}^{\top} \mathbf{P}_{\mathrm{int}}^{\mathrm{e}}\right)=\sum_{\mathrm{e}=1}^{\mathrm{n}_{\mathrm{e}}} \mathbf{A}_{\mathrm{e}}^{\top} \frac{\partial}{\partial \mathbf{r}}\left(\int_{\Omega_{\mathrm{e}}^{\mathrm{r}}}\left(\boldsymbol{\Delta}_{\alpha} \mathbf{N}\right)^{\top} \boldsymbol{\tau}_{\alpha} \mathrm{d} \Omega^{\mathrm{r}}\right)
$$

Sendo $\tau_{\mathrm{i}}=\hat{\tau}_{\mathrm{i}}\left(\hat{\gamma}_{\mathrm{i}}\left(\hat{\mathbf{p}}_{\mathrm{e}}(\mathbf{r})\right)\right)$ (ver expressões de $\boldsymbol{\tau}_{\mathrm{i}}$ no capítulo 2 ), tem-se

$$
\mathbf{K}=\sum_{\mathrm{e}=1}^{\mathrm{n}_{\mathrm{e}}} \mathbf{A}_{\mathrm{e}}^{\top} \int_{\Omega_{\mathrm{e}}^{\mathrm{r}}}\left(\boldsymbol{\Delta}_{\alpha} \mathbf{N}\right)^{\top} \frac{\partial \boldsymbol{\tau}_{\alpha}}{\partial \gamma_{\alpha}} \frac{\partial \boldsymbol{\gamma}_{\alpha}}{\partial \mathbf{p}_{\mathrm{e}}} \frac{\partial \mathbf{p}_{\mathrm{e}}}{\partial \mathbf{r}} \mathrm{d} \Omega^{\mathrm{r}}
$$

Lembrando que $\mathbf{C}_{\alpha \beta}=\partial \tau_{\alpha} / \partial \gamma_{\beta}$, e com a ajuda de

$$
\begin{gathered}
\frac{\partial \boldsymbol{\gamma}_{\alpha}}{\partial \mathbf{p}_{\mathrm{e}}}=\boldsymbol{\Delta}_{\alpha} \mathbf{N} \mathrm{e} \\
\frac{\partial \mathbf{p}_{\mathrm{e}}}{\partial \mathbf{r}}=\mathbf{A}_{\mathrm{e}},
\end{gathered}
$$

tem-se

$$
\mathbf{K}=\sum_{\mathrm{e}=1}^{\mathrm{n}_{\mathrm{e}}} \mathbf{A}_{\mathrm{e}}^{\top}\left(\int_{\Omega_{\mathrm{e}}^{\mathrm{r}}}\left(\boldsymbol{\Delta}_{\alpha} \mathbf{N}\right)^{\top} \mathbf{C}_{\alpha \beta}\left(\boldsymbol{\Delta}_{\alpha} \mathbf{N}\right) \mathrm{d} \Omega^{\mathrm{r}}\right) \mathbf{A}_{\mathrm{e}}
$$

Pode-se definir a matriz de rigidez do elemento como

$$
\mathbf{k}_{\mathrm{e}}=\int_{\Omega_{\mathrm{e}}^{\mathrm{r}}}\left(\boldsymbol{\Delta}_{\alpha} \mathbf{N}\right)^{\mathrm{T}} \mathbf{C}_{\alpha \beta}\left(\boldsymbol{\Delta}_{\alpha} \mathbf{N}\right) \mathrm{d} \Omega^{\mathrm{r}}
$$

A matriz de rigidez do sólido pode então ser reescrita como

$$
\mathbf{K}=\sum_{\mathrm{e}=1}^{\mathrm{n}_{\mathrm{e}}} \mathbf{A}_{\mathrm{e}}^{\top} \mathbf{k}_{\mathrm{e}} \mathbf{A}_{\mathrm{e}}
$$

As grandezas $\mathbf{R}(\mathbf{r})$ e $\mathbf{k}_{\mathrm{e}}$ são obtidas através de integrações numéricas, utilizando-se três pontos de integração nos domínios $\Omega_{\mathrm{e}}^{r}$.

A seguir, serão apresentados os exemplos de validação da implementação das expressões acima no programa PEFSYS.

\subsection{VALIDAÇÃO DA IMPLEMENTAÇÃO EM ELEMENTOS FINITOS}

A implementação em elementos finitos foi desenvolvida em duas etapas. $\mathrm{Na}$ primeira etapa foi realizada a programação do elemento T6 para a equação constitutiva do material hiperelástico de Kirchhoff-Saint Venant com estado plano de deformação. A segunda 
etapa consistiu na implementação da função de fluência do modelo viscoelástico de KelvinVoigt na formulação anterior.

Houve dificuldade para encontrar exemplos de estado plano de deformação na literatura para validação da implementação. A seguir serão validadas as implementações da primeira etapa através de dois problemas. Estes serão analisados em linearidade e não linearidade geométrica.

O primeiro exemplo foi proposto por Mesquita (2002) e consiste em um cilindro de parede espessa (espessura de $25,4 \mathrm{~cm}$ ) composto por um único material e submetido a uma pressão interna p (Figura 19). Este exemplo pode ser considerado um “benchmark”, pois sua solução analítica é simples e facilmente encontrada na literatura.

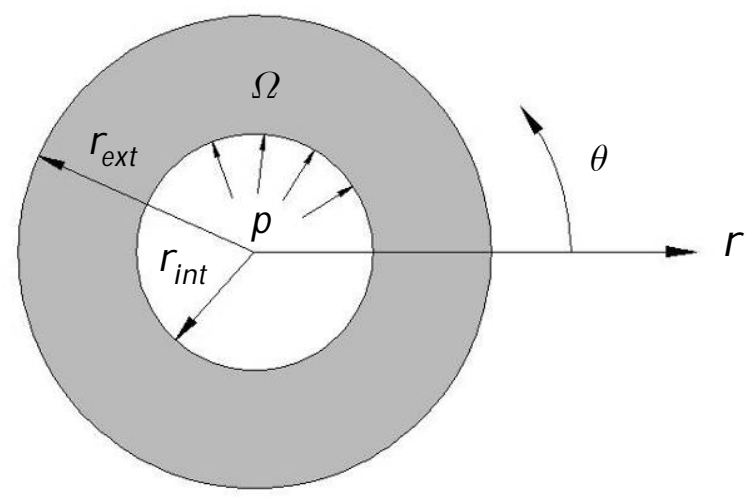

$$
\begin{gathered}
r_{\text {ext }}=50,8 \mathrm{~cm} \text { e } r_{\text {int }}=25,4 \mathrm{~cm} \\
\mathrm{E}=35 \mathrm{kgf} / \mathrm{cm}^{2} \\
\nu=0,4 \\
\mathrm{p}=7,031 \mathrm{kgf} / \mathrm{cm}^{2}
\end{gathered}
$$

Figura 19 - Exemplo 1: características geométricas e propriedades do material.

Flügge (1967) apresenta uma solução analítica para esse exemplo via Teoria Linear da Elasticidade, obtendo para o deslocamento no sentido do eixo $r$ a expressão

$$
u=\frac{p(1+\nu) r_{\text {int }}^{2}}{E\left(r_{\text {ext }}^{2}-r_{\text {int }}^{2}\right)}\left[(1-2 \nu) r+\frac{r_{\text {ext }}^{2}}{r}\right]
$$

Esta solução contempla uma função que apenas é dependente do valor adotado para o raio $r$. Assim, aplicam-se os valores de $r_{\text {int }}$ e $r_{\text {ext }}$ da Figura 19 na equação (131), juntamente com o valor de $r$, e obtém-se os deslocamentos de $10,000894 \mathrm{~cm}$ para $r=25,4 \mathrm{~cm} \mathrm{e} 5,714797 \mathrm{~cm}$ para $r=50,8 \mathrm{~cm}$.

Para obter a solução numérica via MEF, como este exemplo apresenta simetria, apenas um quarto do cilindro foi discretizado. A Figura 20(a) mostra as condições de contorno essenciais e naturais aplicadas e as Figura 20(b)-(e) apresentam as quatro malhas de elementos finitos utilizadas para a validação da implementação. As malhas propostas com $6 \times$ 3 divisões nas faces, posteriormente $12 \times 6$ divisões, $24 \times 12$ divisões e $48 \times 24$ divisões nas 
faces apresentam um crescente número de elementos e, principalmente, atendem ao aspecto de que cada malha mais refinada contém a malha anterior. Assim, isto permite uma análise de convergência adequada dos valores de deslocamento. Serão analisados os deslocamentos dos pontos A, B, C e D em cada malha conforme mostra a Figura 20(a), sendo comparados à solução analítica apresentada anteriormente.

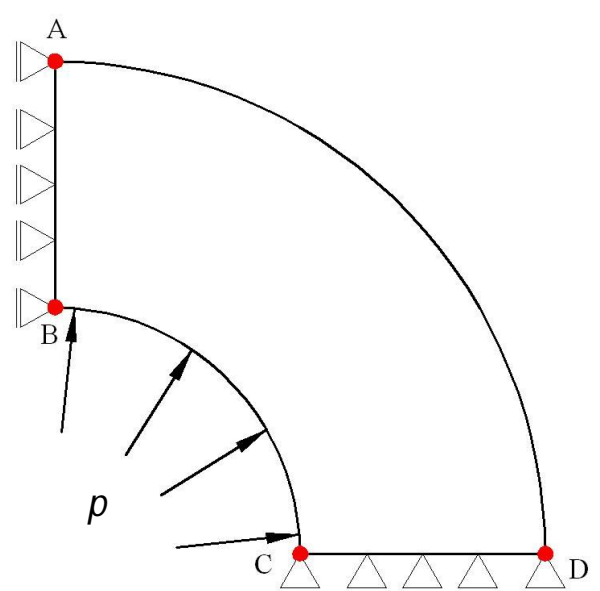

(a)

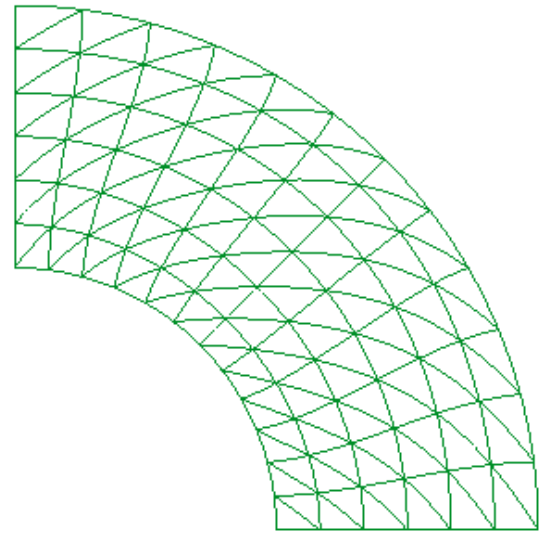

(c)

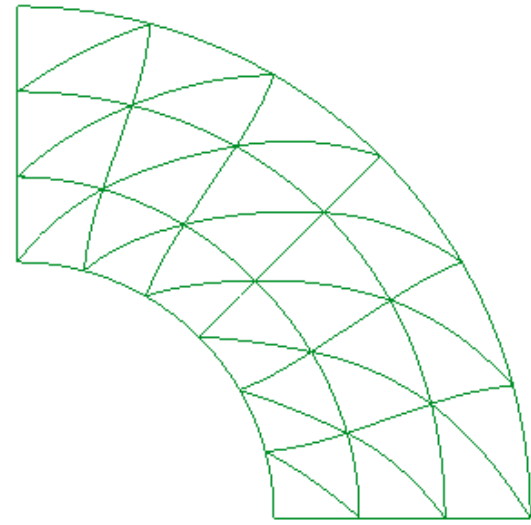

(b)

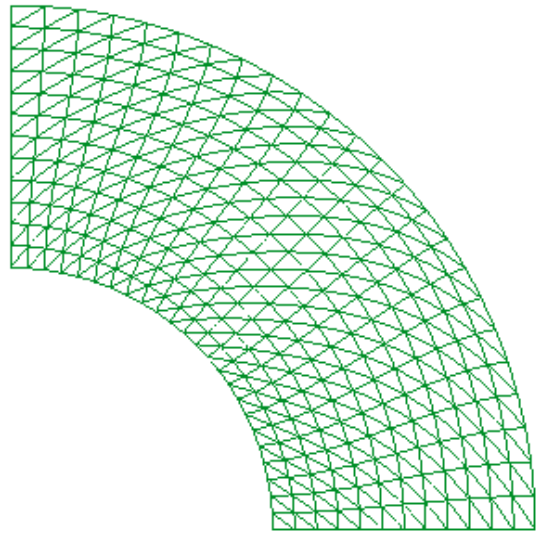

(d)

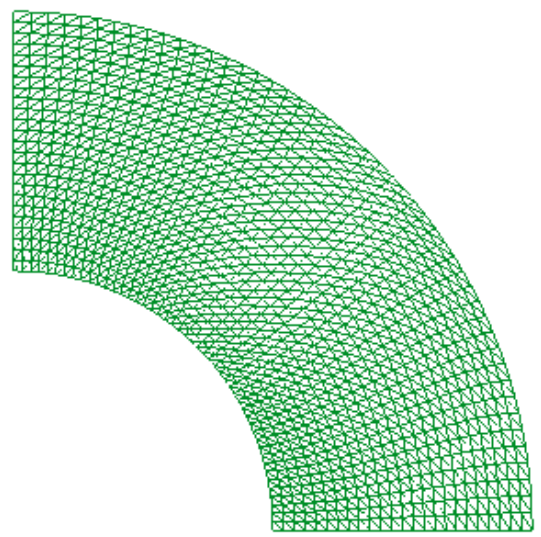

(e)

Figura 20 - Exemplo 1: (a) condições de contorno; (b) malha de elementos finitos com $6 \times 3$ divisões nas faces; (c) malha de elementos finitos com $12 \times 6$ divisões nas faces; (d) malha de elementos finitos com $24 \times 12$ divisões nas faces; (e) malha de elementos finitos com $48 \times 24$ divisões nas faces. 
Os resultados numéricos obtidos para linearidade geométrica foram organizados na Tabela 2 juntamente com a solução analítica calculada através da equação (131).

Tabela 2 - Resultados obtidos para o Exemplo 1 - Solução Numérica sob linearidade geométrica.

\begin{tabular}{c|c|c|c|c|c}
\hline \multirow{2}{*}{ Ponto } & \multicolumn{5}{|c}{ Deslocamento (cm) } \\
\cline { 2 - 6 } & $\begin{array}{c}\text { Solução Analítica } \\
\text { (Flügge) }\end{array}$ & Malha 6x3 & Malha 12x6 & $\begin{array}{c}\text { Malha } \\
24 \times 12\end{array}$ & $\begin{array}{c}\text { Malha } \\
48 \times 24\end{array}$ \\
\hline A & 5,714797 & 5,714826 & 5,715054 & 5,715074 & 5,716110 \\
B & 10,000894 & 10,09864 & 10,06968 & 10,03955 & 10,02235 \\
C & 10,000894 & 10,04295 & 10,04344 & 10,02703 & 10,01543 \\
D & 5,714797 & 5,635853 & 5,696358 & 5,709531 & 5,713035 \\
\hline
\end{tabular}

Os resultados apresentados na tabela acima podem ser considerados satisfatórios ao serem comparados com a solução analítica, mesmo para a malha de elementos finitos com $6 \times 3$ divisões nas faces. Ressalta-se que a ausência de simetria das malhas de elementos finitos propostas gerou uma diferença entre os resultados encontrados para pontos de simetria do exemplo em questão.

A Figura 21apresenta o campo de deslocamentos na direção do eixo X e Figura 22 o campo de deslocamentos na direção do eixo Y obtidos para a malha de elementos finitos com $48 \times 24$ divisões nas faces.

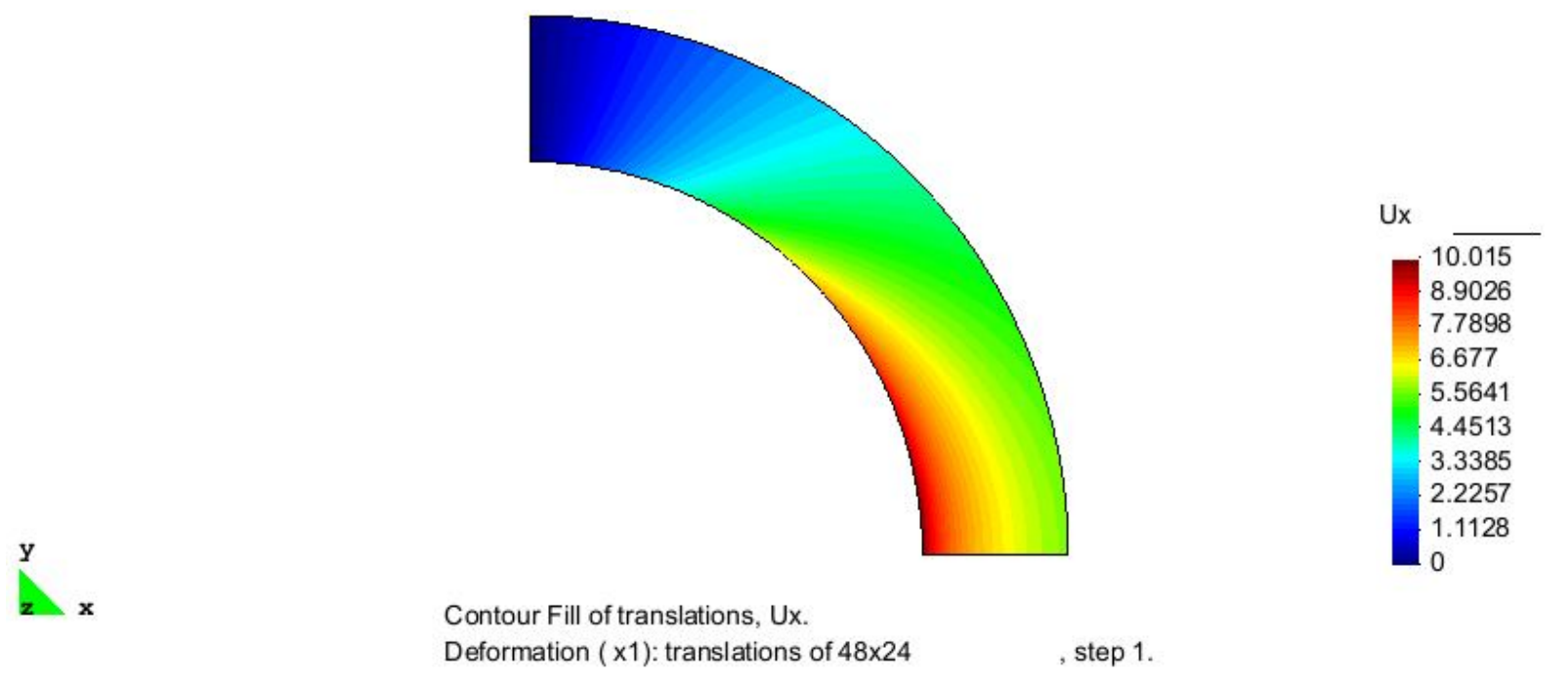

Figura 21 - Exemplo 1: Campo de deslocamentos na direção do eixo X (componente horizontal) obtido para a malha $48 \times 24$ divisões nas faces (linearidade geométrica). 
y

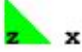

Deformation ( $x 1$ ): translations of $48 \times 24$

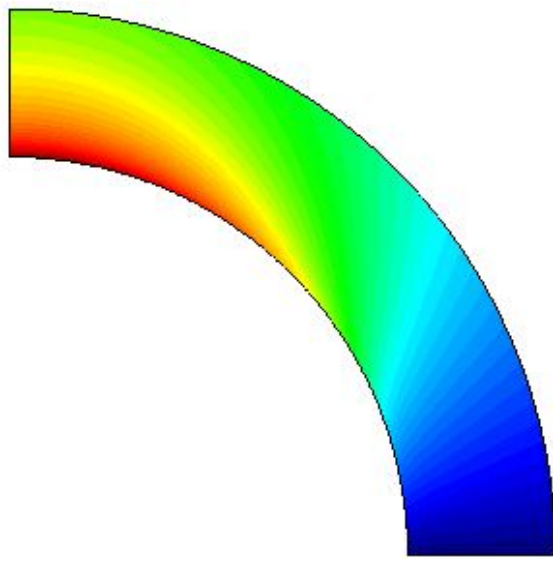

Uy

Figura 22 - Exemplo 1: Campo de deslocamentos na direção do eixo Y (componente vertical) obtido para a malha $48 \times 24$ divisões nas faces (linearidade geométrica).

Os resultados numéricos obtidos para não linearidade geométrica estão apresentados na Tabela 3. Ressalta-se que em todas as malhas na análise em não linearidade geométrica aparece uma divergência no Método de Newton (apresentado no item 4.1) quando o carregamento atinge cerca de $80 \%$ de seu valor final. Isto pode ter ocorrido devido ao fato de a função energia de deformação específica do material de Kirchhoff - Saint Venant (equação (75)) não ser policonvexa segundo Ciarlet (1988 apud CAMPELLO; PIMENTA; WRIGGERS, 2003). Isto implica em uma possível inexistência de solução para problemas de valor de contorno quando as deformações forem grandes. Observa-se a seguir que as deformações apresentadas são da ordem de $15 \%$ nos níveis de carregamento apresentados na Tabela 3, o que representa um valor suficientemente elevado para causar problemas desta natureza. Estas limitações podem ser evitadas ao utilizar um material policonvexo como o material Neo-Hookiano de Ciarlet-Simo (CAMPELLO; PIMENTA; WRIGGERS, 2003). Assim, os valores apresentados na tabela a seguir correspondem ao último nível de carga convergido. Observou-se que a taxa de convergência do Método de Newton obtida para cada nível de carga convergido foi quadrática. 
Tabela 3 - Resultados obtidos para o Exemplo 1 - Solução numérica sob não linearidade geométrica.

\begin{tabular}{c|c|c|c|c}
\hline \multirow{2}{*}{ Ponto } & \multicolumn{4}{|c}{ Deslocamento $(\mathrm{cm})$} \\
\cline { 2 - 5 } & $\begin{array}{c}\text { Malha 6x3 } \\
(94,55 \% \mathrm{p})\end{array}$ & $\begin{array}{c}\text { Malha 12x6 } \\
(81,22 \% \mathrm{p})\end{array}$ & $\begin{array}{c}\text { Malha 24x12 } \\
(80,55 \% \mathrm{p})\end{array}$ & $\begin{array}{c}\text { Malha 48x24 } \\
(79,09 \% \mathrm{p})\end{array}$ \\
\hline A & 4,285392 & 3,834725 & 3,810992 & 3,746254 \\
B & 9,052028 & 7,833751 & 7,791043 & 7,607005 \\
C & 11,47608 & 7,966914 & 7,835410 & 7,605411 \\
D & 4,242059 & 3,796976 & 3,800917 & 3,739942 \\
\hline
\end{tabular}

Os campos de deslocamentos para a malha de elementos finitos com $48 \times 24$ divisões estão apresentados na Figura 23.

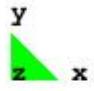

Y

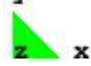

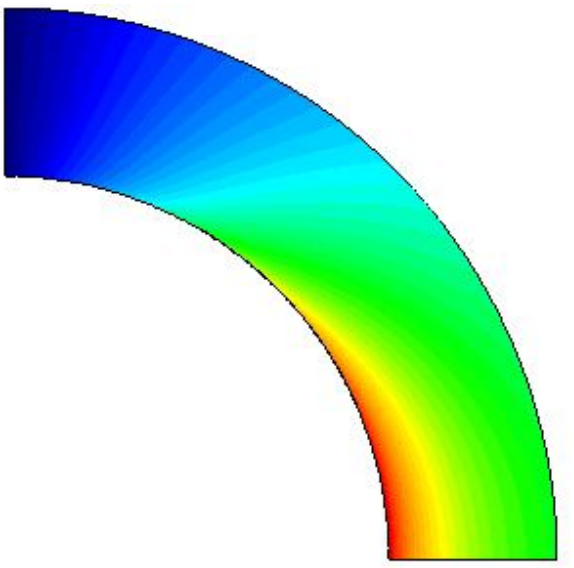

Ux 7.6054 6.7604 5.9153 5.0703

4.2252

3.3802

2.5351

1.6901

0.84505

step 5

Contour Fill of translations, Ux.

Deformation ( $x 1$ ): translations of $48 \times 24$, step 5 .

(a)

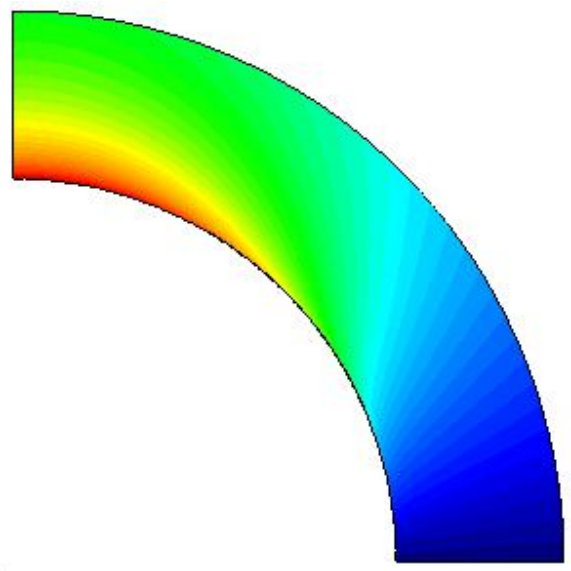

Uy 7.6073 6.762 5.9168 5.0715 4.2263 3.381 2.5358 1.6905 0.84525

step 5

Contour Fill of translations, Uy.

Deformation ( $x 1$ ): translations of $48 \times 24$, step 5 .

(b)

Figura 23 - Exemplo 1: Campo de deslocamentos obtido para a malha com $48 \times 24$ divisões nas faces (não linearidade geométrica) - (a) Deslocamentos na direção do eixo X / (b) Deslocamentos na direção eixo $\mathrm{Y}$. 
O segundo exemplo utilizado para validação foi proposto por Batthi (2006) e consiste em um sólido com $20 \mathrm{~m}$ de largura e $5 \mathrm{~m}$ de altura com carga distribuída q aplicada em 10m centrais da face superior. A geometria do modelo e as propriedades do material são apresentadas na Figura 24.

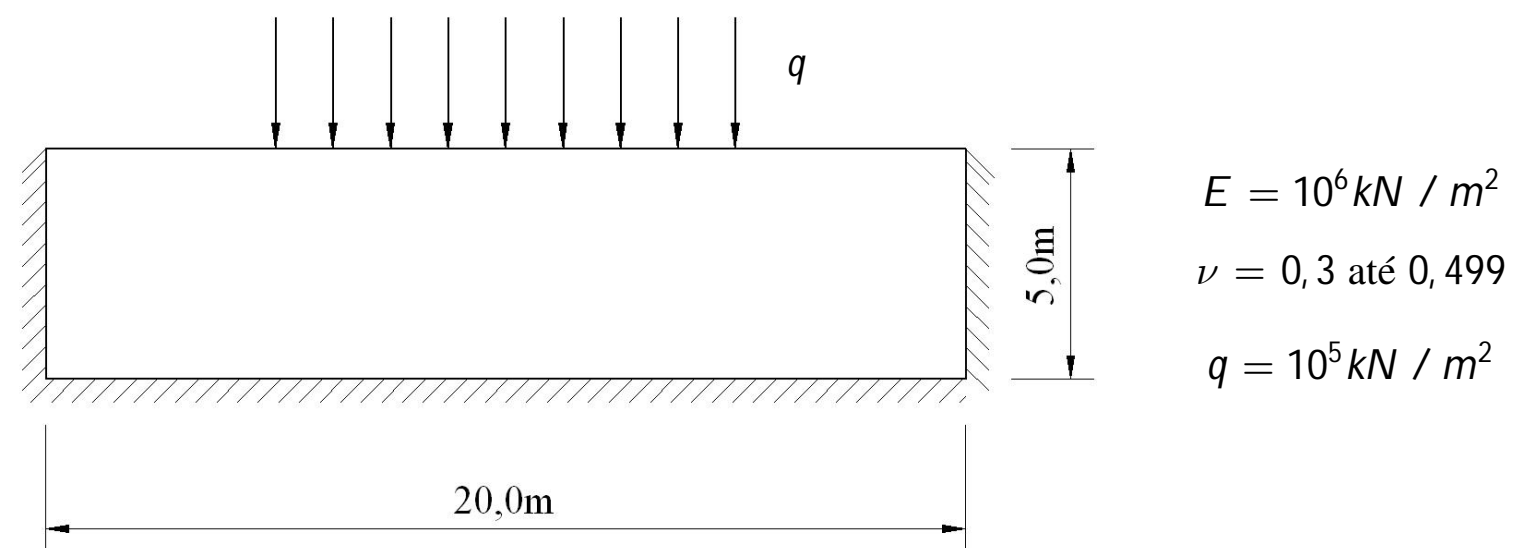

Figura 24 - Modelo 2: características geométricas e propriedades do material.

Este exemplo apresenta simetria, portanto, metade do domínio foi discretizado. A Figura 25-(a) mostra as condições de contorno essenciais e naturais aplicadas e o ponto A em que serão analisados os deslocamentos. Diversos valores foram considerados para o coeficiente de Poisson. $\mathrm{O}$ sólido foi discretizado empregando-se cinco malhas progressivamente refinadas, mantendo-se a idéia de que cada nova malha contém a malha anterior (Figura 25(b)-(f)). 


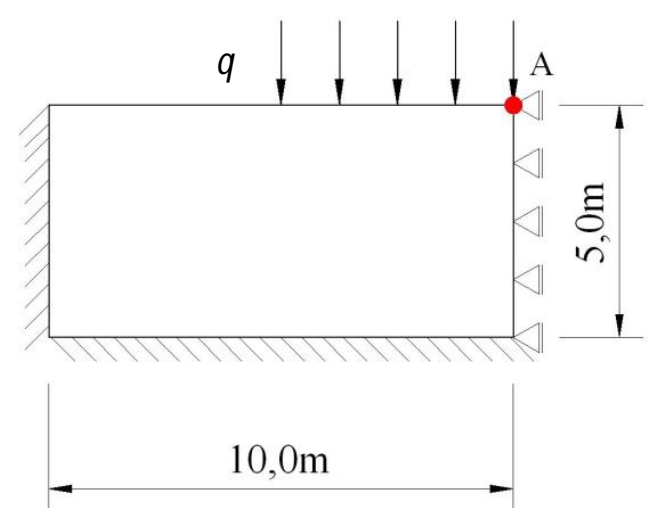

(a)

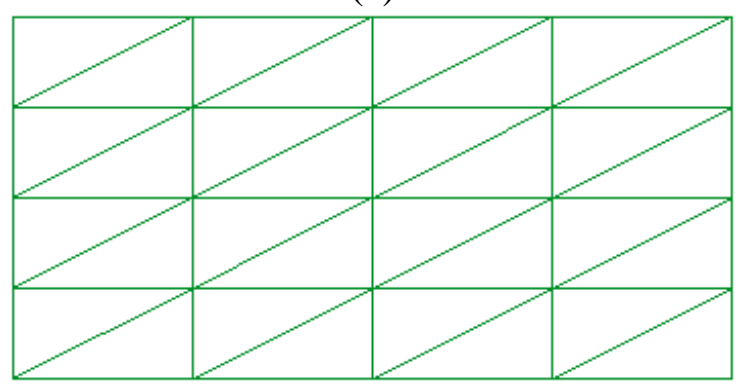

(c)

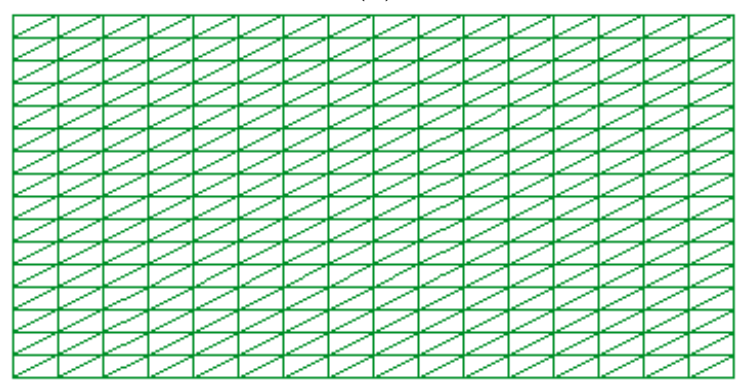

(e)

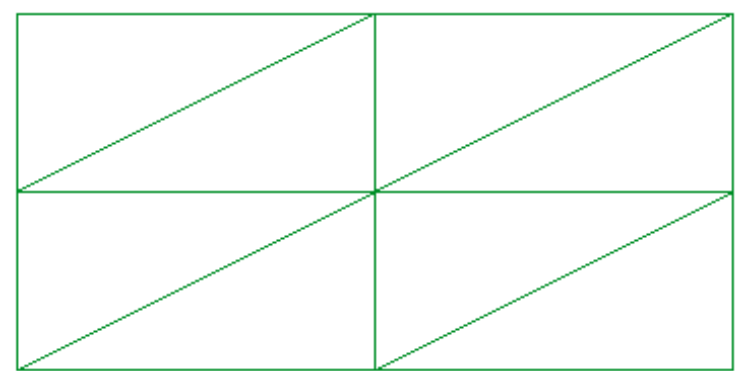

(b)

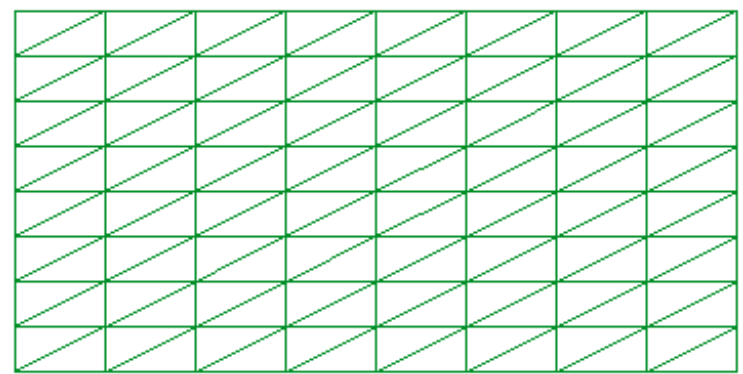

(d)

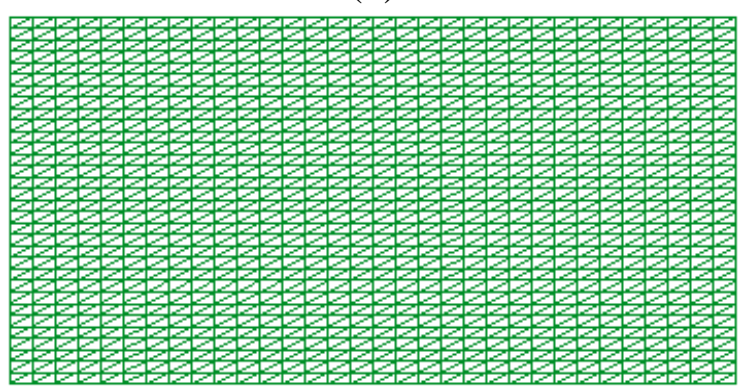

(f)

Figura 25 - Exemplo 2: (a) condições de contorno; (b) malha de elementos finitos com $2 \times 2$ divisões nas faces; (c) malha de elementos finitos com $4 \times 4$ divisões nas faces; (d) malha de elementos finitos com $8 \times$ 8 divisões nas faces; (e) malha de elementos finitos com $16 \times 16$ divisões nas faces; (f) malha de elementos finitos com $32 \times 32$ divisões nas faces.

A solução numérica apresentada por Batthi (2006) também considera as condições de simetria, empregando uma malha de $4 \times 4$ elementos quadrangulares bilineares com integração completa.

Os deslocamentos verticais do ponto A obtidos para todas as malhas de elementos finitos determinados sob linearidade geométrica estão dispostos na Tabela 4. 
Tabela 4 - Resultados obtidos para o Exemplo 2 - Solução numérica sob linearidade geométrica.

\begin{tabular}{|c|c|c|c|c|c|c|}
\hline \multirow{2}{*}{$\begin{array}{l}\text { Coeficiente } \\
\text { de Poisson }\end{array}$} & \multirow{2}{*}{$\begin{array}{c}\text { Deslocamento } \\
\text { vertical - } \\
\text { Batthi (2006) }\end{array}$} & \multicolumn{5}{|c|}{ Deslocamento vertical do ponto A (m) } \\
\hline & & Malha 2x2 & Malha $4 x 4$ & Malha $8 x 8$ & $\begin{array}{l}\text { Malha } \\
16 \times 16 \\
\end{array}$ & $\begin{array}{l}\text { Malha } \\
32 \times 32 \\
\end{array}$ \\
\hline 0,30 & $-0,39269$ & $-0,3940735$ & $-0,3880942$ & $-0,3877937$ & $-0,3878072$ & $-0,3878096$ \\
\hline 0,35 & $-0,345359$ & $-0,3483328$ & $-0,3417469$ & $-0,3414183$ & $-0,3414482$ & $-0,3414551$ \\
\hline 0,40 & $-0,284731$ & $-0,2909084$ & $-0,2830236$ & $-0,2826251$ & $-0,2827030$ & $-0,2827271$ \\
\hline 0,45 & $-0,203696$ & $-0,2185059$ & $-0,2083933$ & $-0,2077614$ & $-0,2079884$ & $-0,2080738$ \\
\hline 0,49 & $-0,0897658$ & $-0,1450605$ & $-0,1344189$ & $-0,1323172$ & $-0,1328189$ & $-0,1330705$ \\
\hline 0,499 & $-0,0150392$ & $-0,1231209$ & $-0,1161252$ & $-0,1133131$ & $-0,1135578$ & $-0,1138062$ \\
\hline
\end{tabular}

Os campos de deslocamentos sob linearidade geométrica para malha de elementos finitos com $32 \times 32$ divisões nas faces são apresentados a seguir.

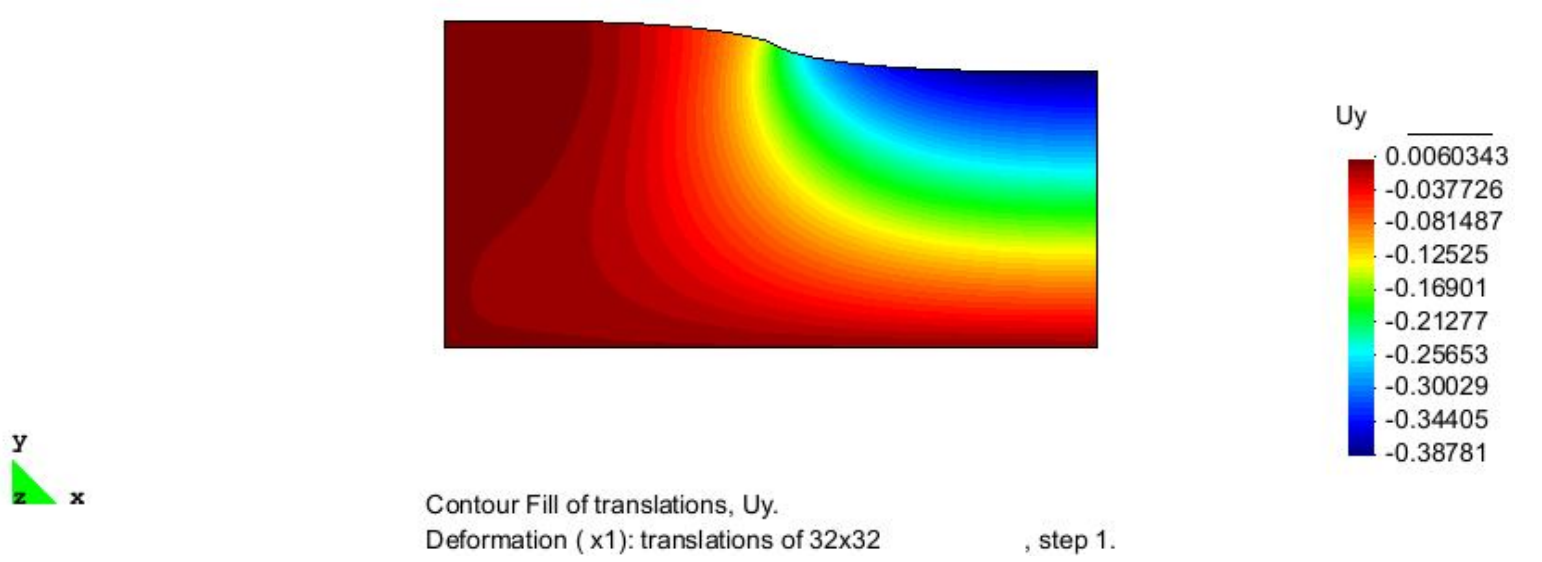

Figura 26 - Exemplo 2: Campo de deslocamentos obtido para a malha com $32 \times 32$ divisões nas faces (linearidade geométrica) e $\nu=0,30$ - Deslocamentos na direção Y.

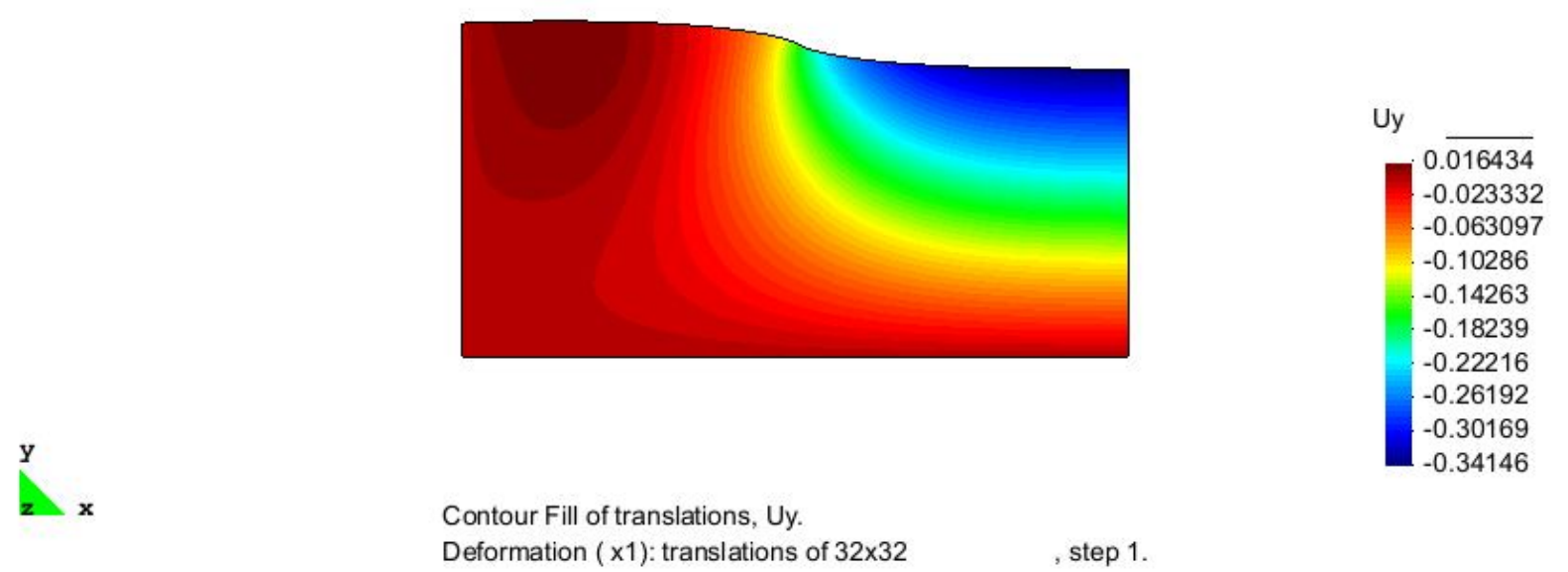

Figura 27 - Exemplo 2: Campo de deslocamentos obtido para a malha com $32 \times 32$ divisões nas faces (linearidade geométrica) e $\nu=0,35$ - Deslocamentos na direção Y. 


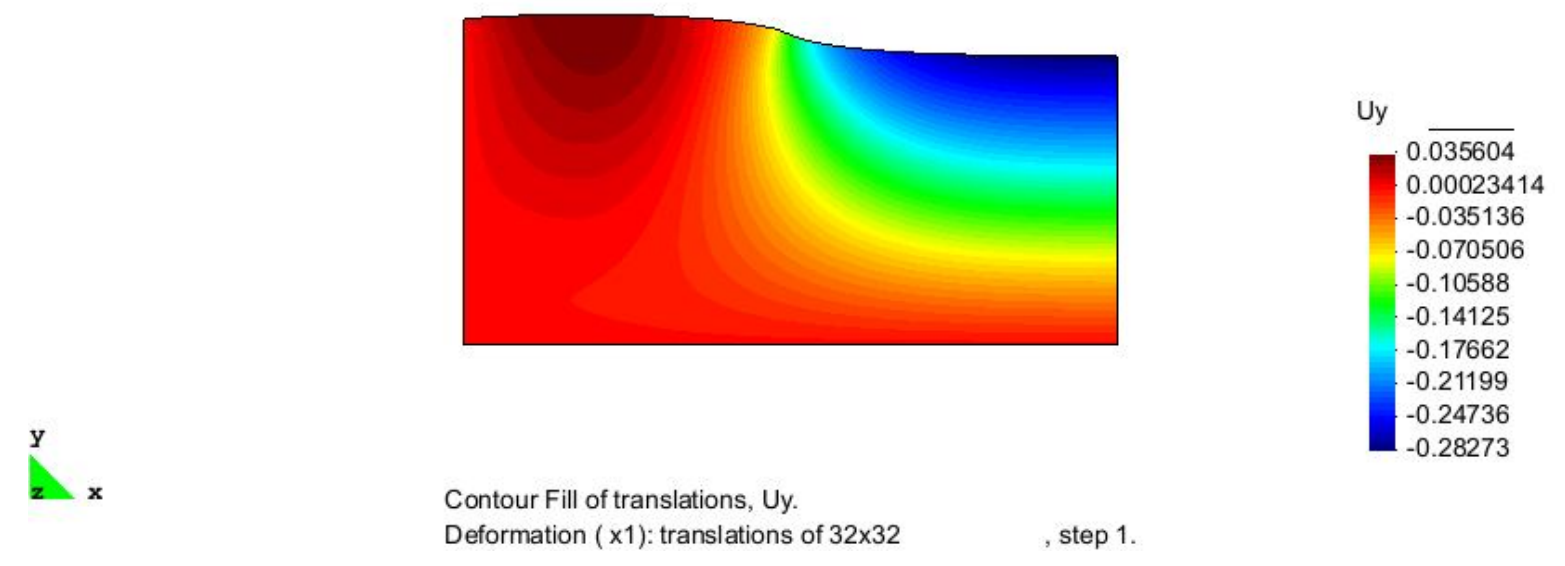

Figura 28 - Exemplo 2: Campo de deslocamentos obtido para a malha com $32 \times 32$ divisões nas faces (linearidade geométrica) e $\nu=0,40$ - Deslocamentos na direção Y.

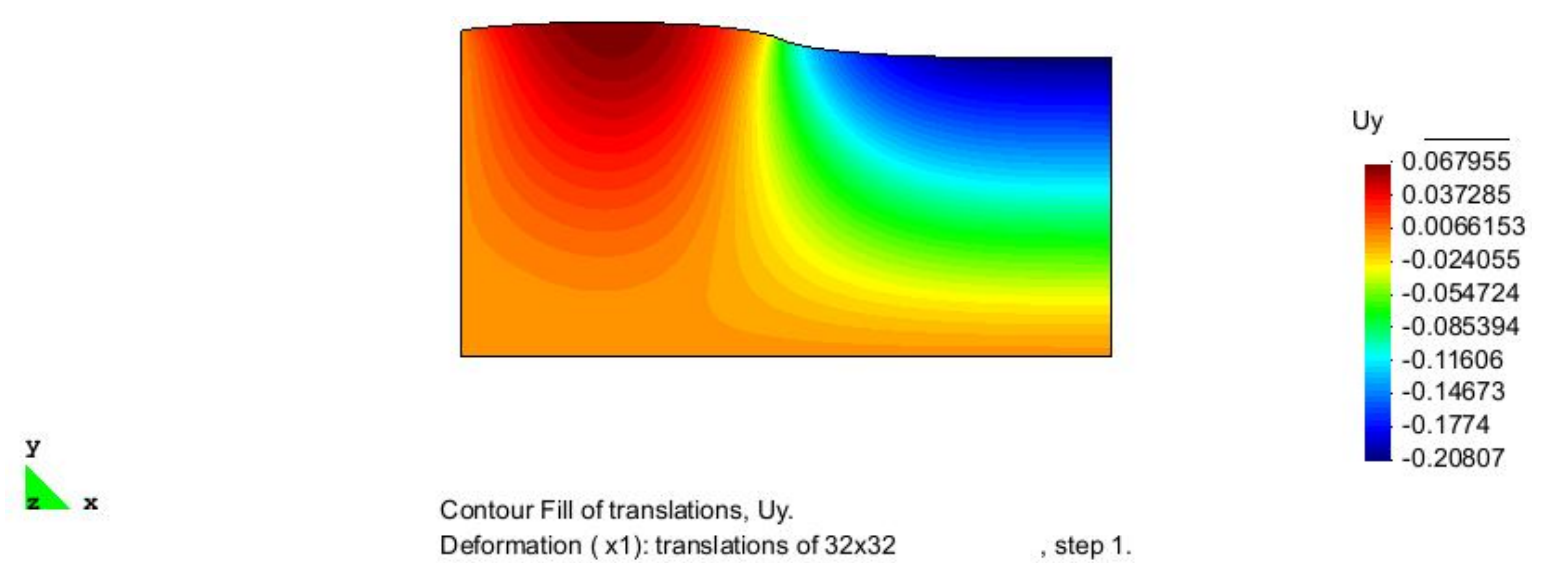

Figura 29 - Exemplo 2: Campo de deslocamentos obtido para a malha com $32 \times 32$ divisões nas faces (linearidade geométrica) e $\nu=0,45$ - Deslocamentos na direção Y.

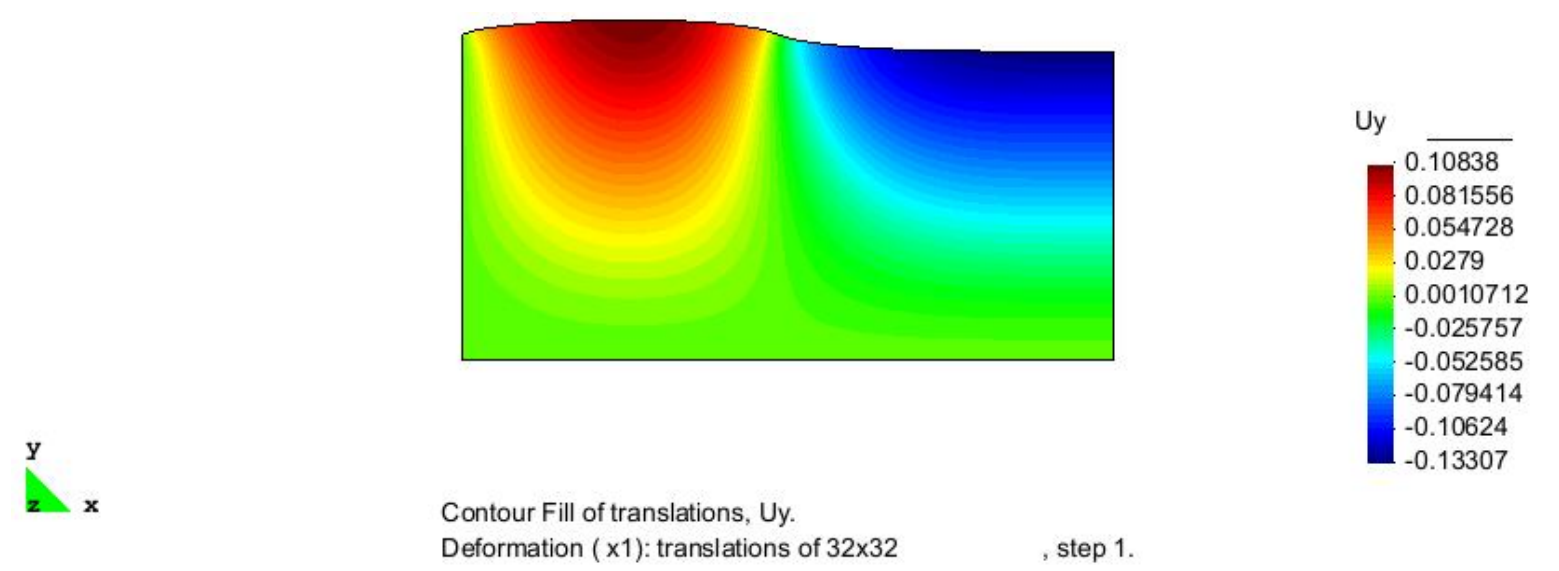

Figura 30 - Exemplo 2: Campo de deslocamentos obtido para a malha com $32 \times 32$ divisões nas faces (linearidade geométrica) e $\nu=0,49$ - Deslocamentos na direção Y. 


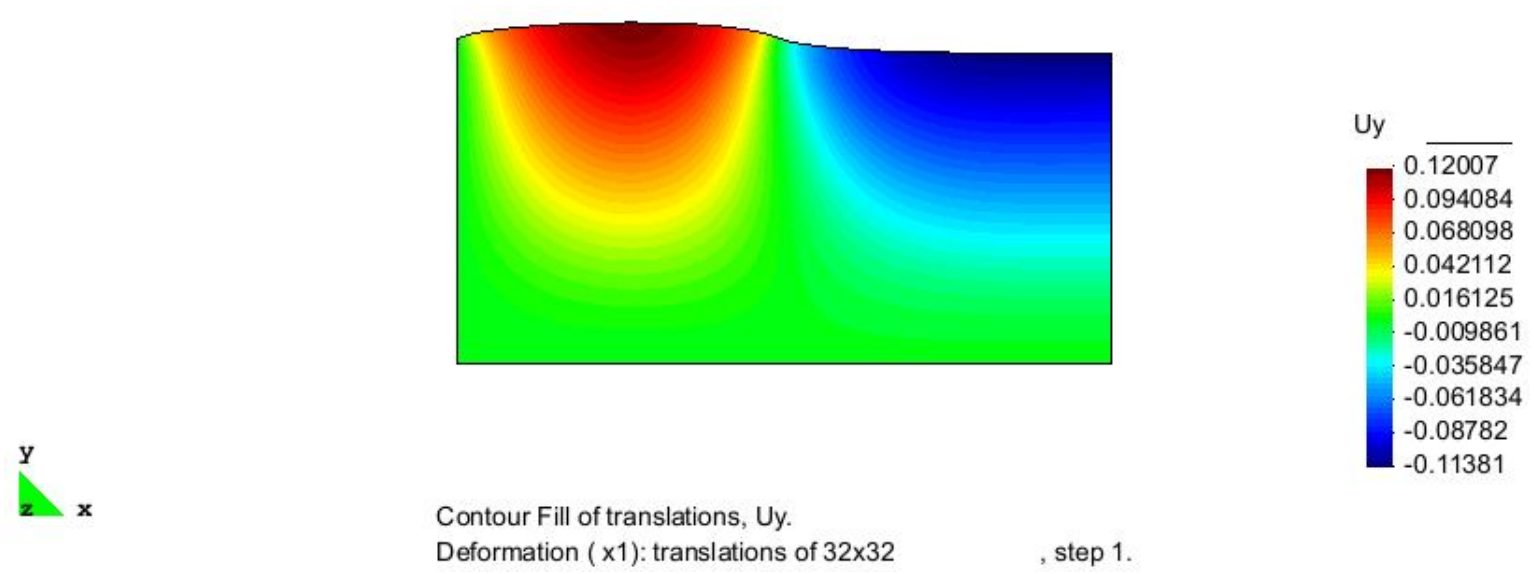

Figura 31 - Exemplo 2: Campo de deslocamentos obtido para a malha com $32 \times 32$ divisões nas faces (linearidade geométrica) e $\nu=0,499$ - Deslocamentos na direção Y.

Na Tabela 5 são apresentados os valores obtidos na análise sob não linearidade geométrica. Neste exemplo também se observou que a taxa de convergência nas iterações do Método de Newton é sempre quadrática quadrática.

Tabela 5 - Resultados obtidos para o Exemplo 2 - Solução numérica sob não linearidade geométrica.

\begin{tabular}{c|c|c|c|c|c}
\hline \multirow{2}{*}{$\begin{array}{c}\text { Coeficiente } \\
\text { de Poisson }\end{array}$} & \multicolumn{5}{|c}{ Deslocamento vertical do ponto A (m) } \\
\cline { 2 - 6 } & Malha 2x2 & Malha 4x4 & Malha 8x8 & $\begin{array}{c}\text { Malha } \\
16 \times 16\end{array}$ & $\begin{array}{c}\text { Malha } \\
32 \times 32\end{array}$ \\
\hline 0,30 & $-0,4760354$ & $-0,4634756$ & $-0,4615351$ & $-0,4614823$ & $-0,4614735$ \\
0,35 & $-0,4158148$ & $-0,4030335$ & $-0,4009873$ & $-0,4009836$ & $-0,4009854$ \\
0,40 & $-0,3437150$ & $-0,3302180$ & $-0,3279018$ & $-0,3279941$ & $-0,3280248$ \\
0,45 & $-0,2577300$ & $-0,2434255$ & $-0,2403174$ & $-0,2406382$ & $-0,2407579$ \\
0,49 & $-0,1749134$ & $-0,1637587$ & $-0,1578304$ & $-0,1584012$ & $-0,1587324$ \\
0,499 & $-0,1517170$ & $-0,1448549$ & $-0,1381026$ & $-0,1382584$ & $-0,1385310$ \\
\hline
\end{tabular}

Observa-se que os deslocamentos obtidos com a análise sob não linearidade geométrica são maiores que os obtidos na análise sob linearidade geométrica e que o resultado numérico apresentado por Batthi (2006). Ressalta-se que grandes deformações também são observadas, sobretudo, para os modelos com menor coeficiente de Poisson.

O campo de deslocamentos sob não linearidade geométrica para malha de elementos finitos com $32 \times 32$ divisões nas faces são apresentados a seguir, sem nenhum fator de escala nas configurações deformadas. 


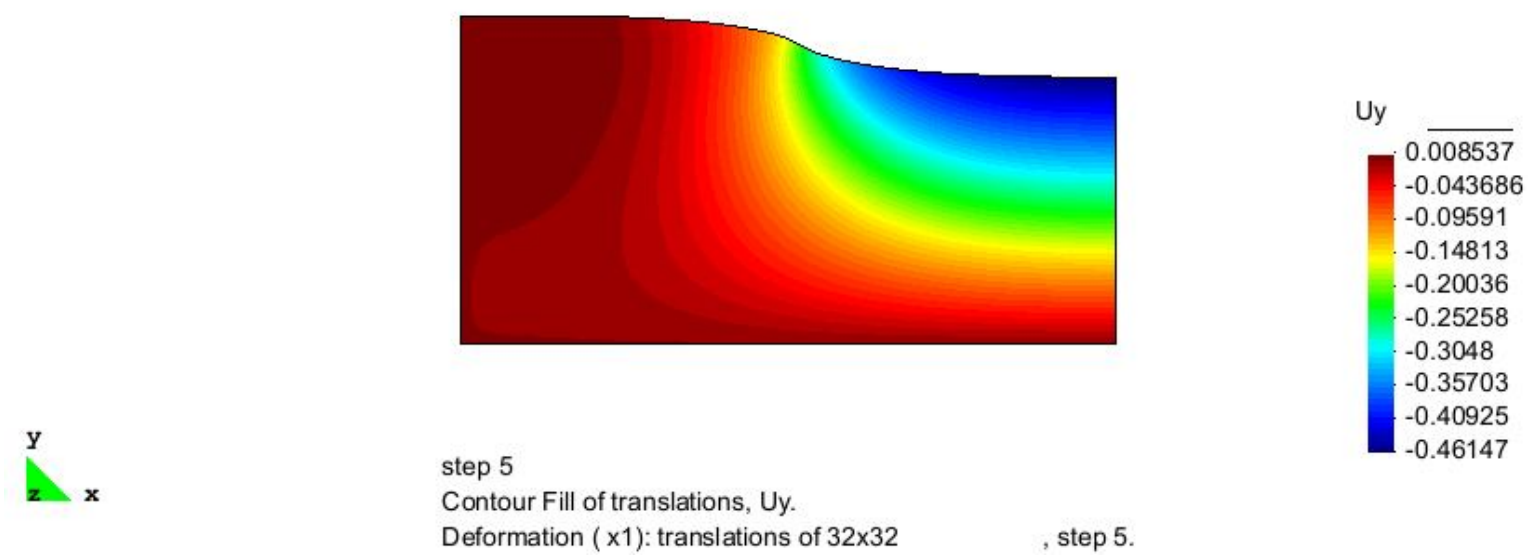

Figura 32 - Exemplo 2: Campo de deslocamentos obtido para a malha com $32 \times 32$ divisões nas faces (não linearidade geométrica) e $\nu=0,30$ - Deslocamentos na direção Y.

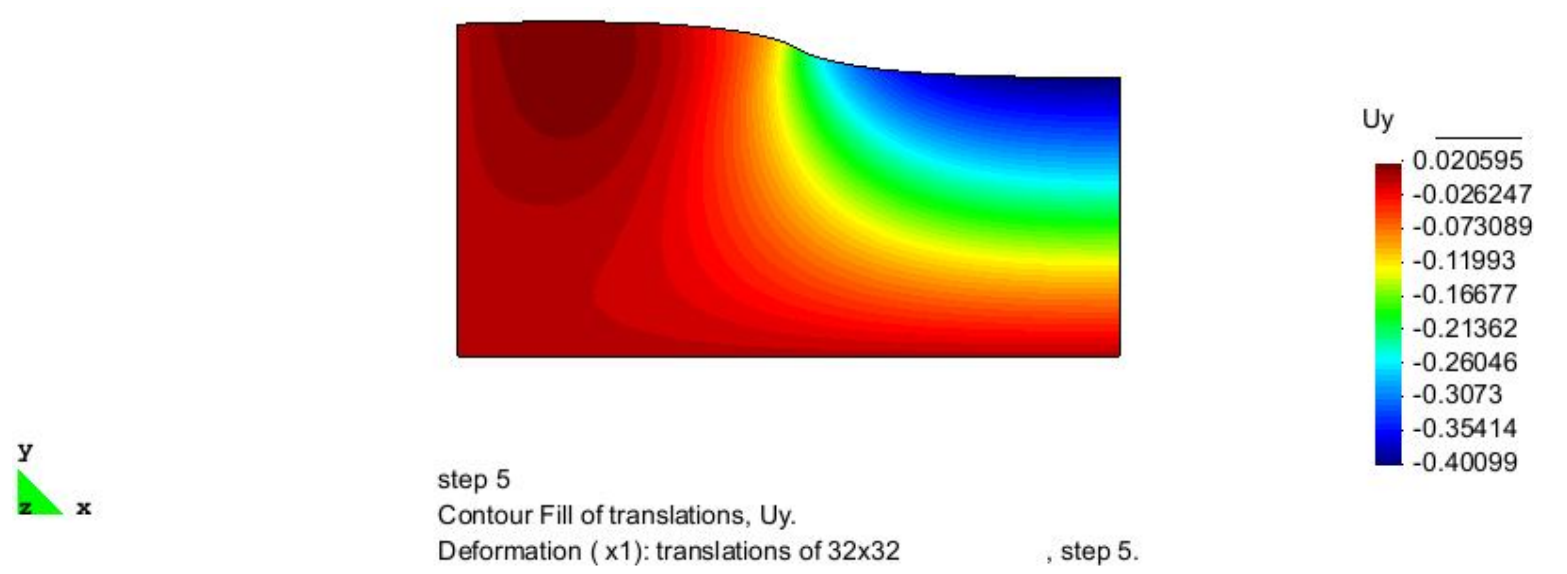

Figura 33 - Exemplo 2: Campo de deslocamentos obtido para a malha com $32 \times 32$ divisões nas faces (não linearidade geométrica) e $\nu=0,35$ - Deslocamentos na direção Y.

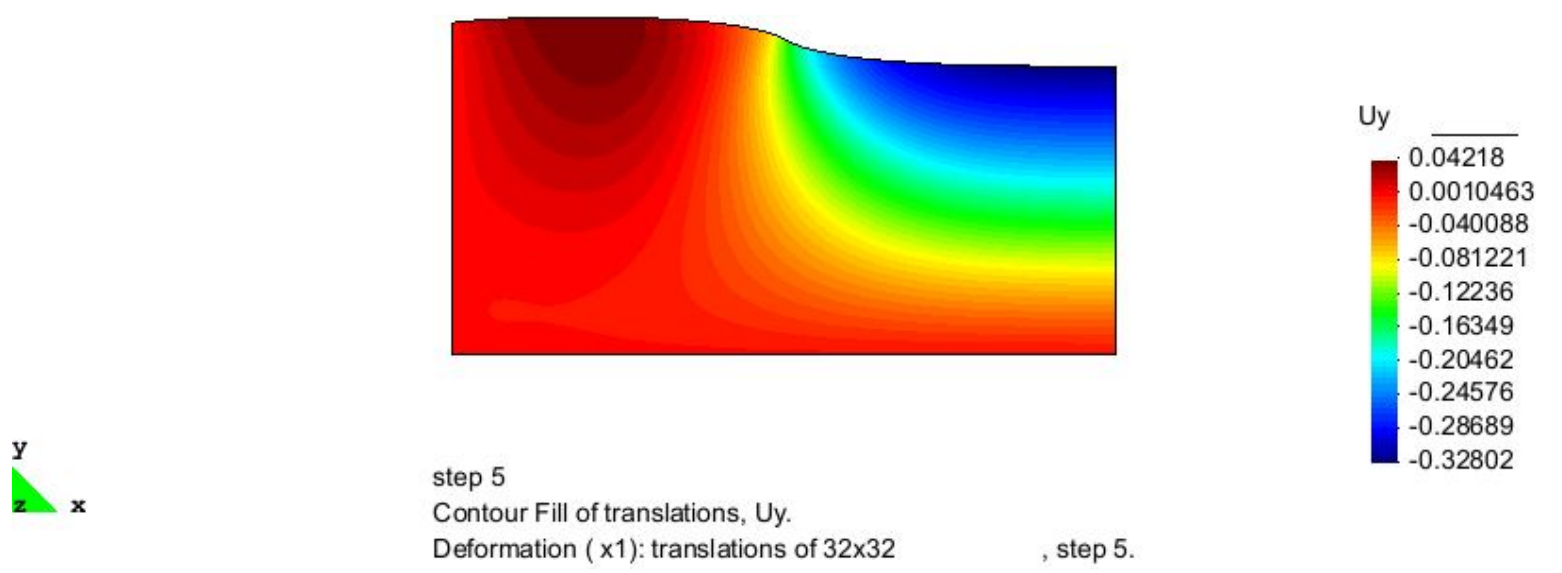

Figura 34 - Exemplo 2: Campo de deslocamentos obtido para a malha com $32 \times 32$ divisões nas faces (não linearidade geométrica) e $\nu=0,40$ - Deslocamentos na direção Y. 


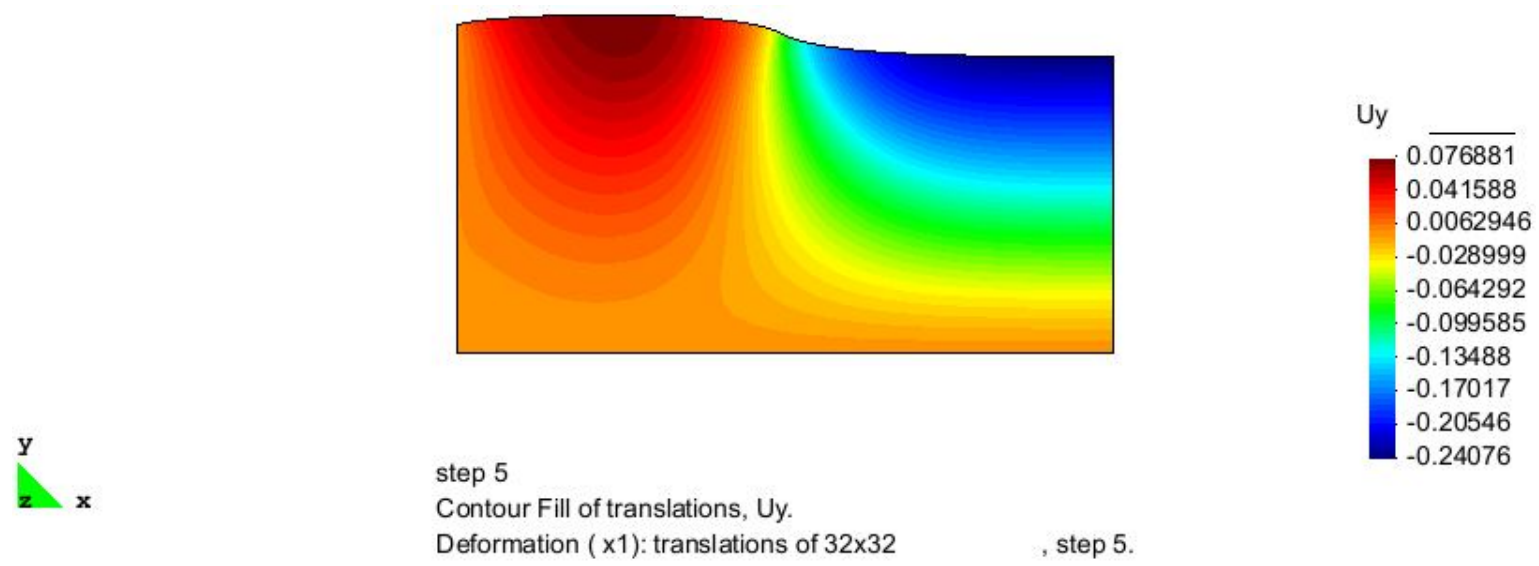

Figura 35 - Exemplo 2: Campo de deslocamentos obtido para a malha com $32 \times 32$ divisões nas faces (não linearidade geométrica) e $\nu=0,45$ - Deslocamentos na direção Y.

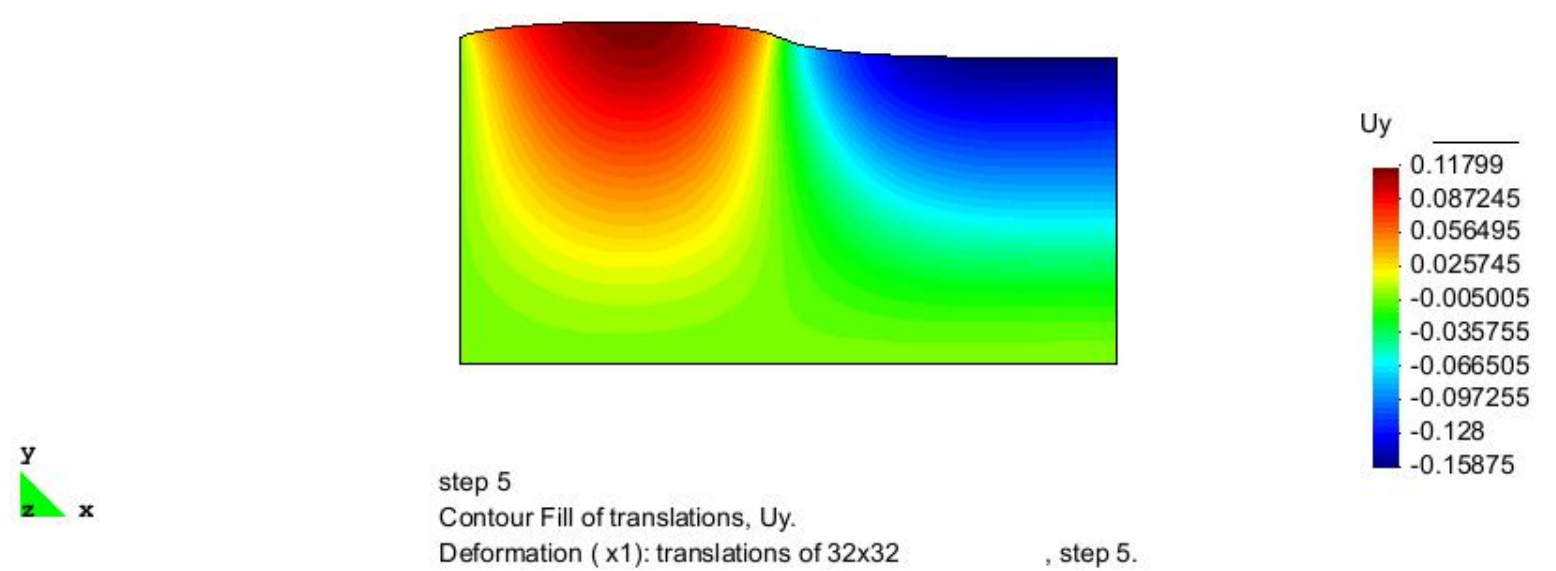

Figura 36 - Exemplo 2: Campo de deslocamentos obtido para a malha com $32 \times 32$ divisões nas faces (não linearidade geométrica) e $\nu=0,49$ - Deslocamentos na direção Y.

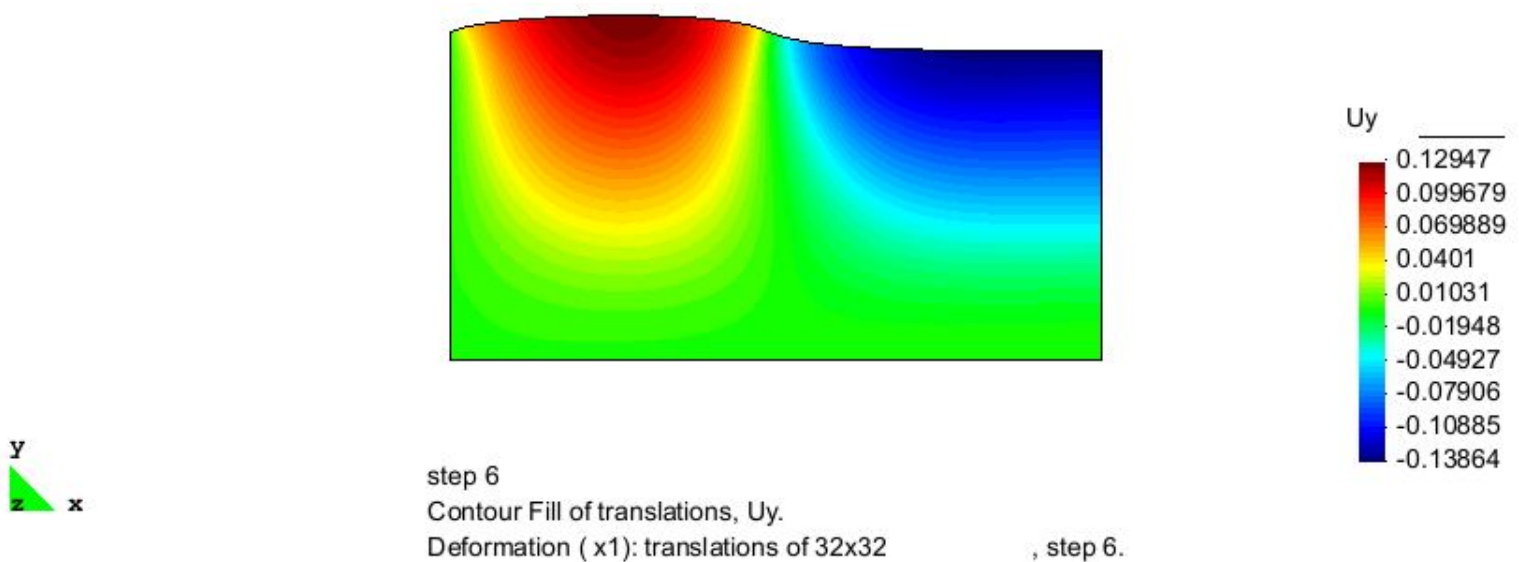

Figura 37 - Exemplo 2: Campo de deslocamentos obtido para a malha com $32 \times 32$ divisões nas faces (não linearidade geométrica) e $\nu=0,499$ - Deslocamentos na direção Y.

Para alguns problemas em estado plano de deformação, é difícil obter a solução 
através do Método de Elementos Finitos para coeficientes de Poisson próximo de 0,50 (material tendendo a ser incompressível). O motivo está em determinadas condições de contorno e no módulo de compressibilidade K ("bulk modulus"), pois K tende a infinito quando $\nu$ tende a 0,50. Sendo este o caso deste exemplo. A diferença entre os valores encontrados na análise sob linearidade geométrica e os resultados numéricos de referência existe devido ao tipo de elemento utilizado. O elemento utilizado por Batthi (2006) apresenta travamento quando $\nu$ assume valores como 0,49 e 0,499; já o elemento T6 mostra-se livre deste fenômeno.

Conclui-se que os resultados obtidos para os dois exemplos apresentados são satisfatórios em relação aos valores encontrados na literatura. Lembra-se da dificuldade de encontrar outros exemplos em EPD na literatura. Assim, pode-se, a seguir, validar a segunda etapa da implementação.

A implementação do modelo viscoelástico de Kelvin-Voigt no programa PEFSYS foi aferida através dos três exemplos propostos a seguir.

O exemplo 3 (Figura 38) apresenta as mesmas características geométricas do exemplo 1, porém as propriedades atribuídas são correspondentes a um material viscoelástico do tipo Kelvin-Voigt e os deslocamentos serão determinados ao longo do tempo.

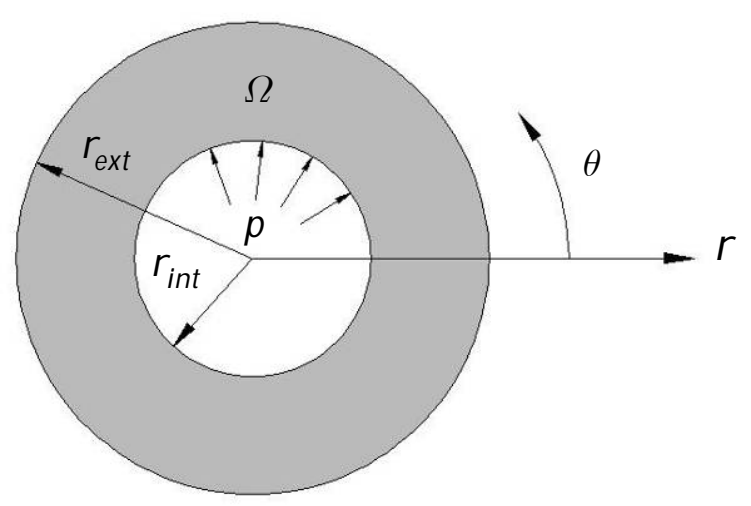

$$
\begin{gathered}
r_{\text {ext }}=50,8 \mathrm{~cm} \mathrm{e} r_{\text {int }}=25,4 \mathrm{~cm} \\
\mathrm{E}=35 \mathrm{kgf} / \mathrm{cm}^{2} \\
\nu=0,40 \\
\eta=249,99975 \frac{\mathrm{kgf}}{\mathrm{cm}^{2}} \cdot \mathrm{dia} \\
\mathrm{p}=7,031 \mathrm{kgf} / \mathrm{cm}^{2}
\end{gathered}
$$

Figura 38 - Exemplo 3: características geométricas e propriedades do material.

Este cilindro será discretizado considerando novamente as condições de simetria com uma malha de elementos finitos com 16x6 divisões nas faces (Figura 39) conforme Oliveira (2009) propôs ao utilizar o programa ADINA. Este autor utilizou uma malha composta por elementos isoparamétricos de 9 nós, porém este resolveu o problema como um caso do estado plano de tensão. Este autor não faz comentário sobre a utilização ou não de parâmetros materiais equivalentes para simular o EPD. 


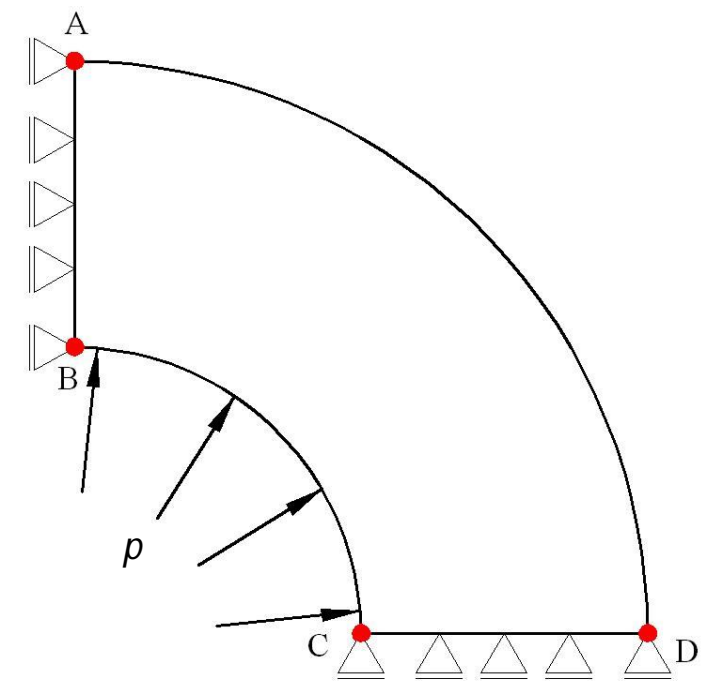

(a)

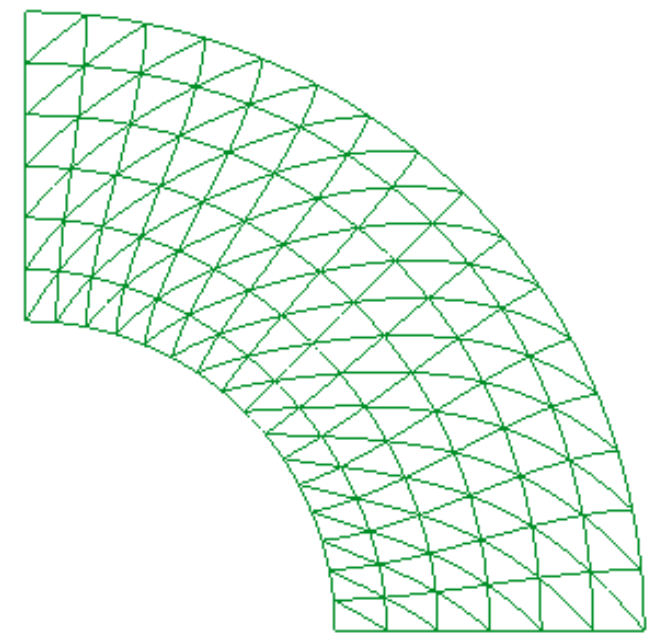

(b)

Figura 39 - Exemplo 3: (a) condições de contorno; (b) malha de elementos finitos com $16 \times 6$ divisões nas faces.

Os resultados numéricos em linearidade geométrica serão comparados com os valores obtidos pela equação (131) ao aplicar o módulo de elasticidade aparente na fluência (equação (87)) para certo instante $t$. Para $r=50,8 \mathrm{~cm}$, a solução de referência é $5,714778 \mathrm{~cm}$ para o instante $\mathrm{t}=90$ dias. Obteve-se aqui os resultados numéricos de $5,715442 \mathrm{~cm} \mathrm{e}$ $5,704280 \mathrm{~cm}$ para os pontos A e D, respectivamente. Para $r=25,4 \mathrm{~cm}$, o deslocamento obtido com a equação (131) com $E(t)$ é de $10,000861 \mathrm{~cm}$ para o mesmo instante já definido; os resultados numéricos obtidos com a presente implementação são 10,045120 e 10,032180cm para os pontos B e C, respectivamente. Oliveira (2009) obteve um deslocamento de $10.000149 \mathrm{~cm}$ com a plataforma MEC e $10,004700 \mathrm{~cm}$ com o programa ADINA para o ponto C. Como o autor não apresenta os resultados para os demais pontos, optou-se por não comparar os resultados obtidos ao longo do tempo por ele com os aqui apresentados. Os resultados numéricos ao longo do tempo em linearidade geométrica são apresentados no Gráfico 1 (pontos A e D) e no Gráfico 2 (pontos B e C), juntamente com a solução de referência. Observa-se que todas as curvas são visualmente coincidentes. 


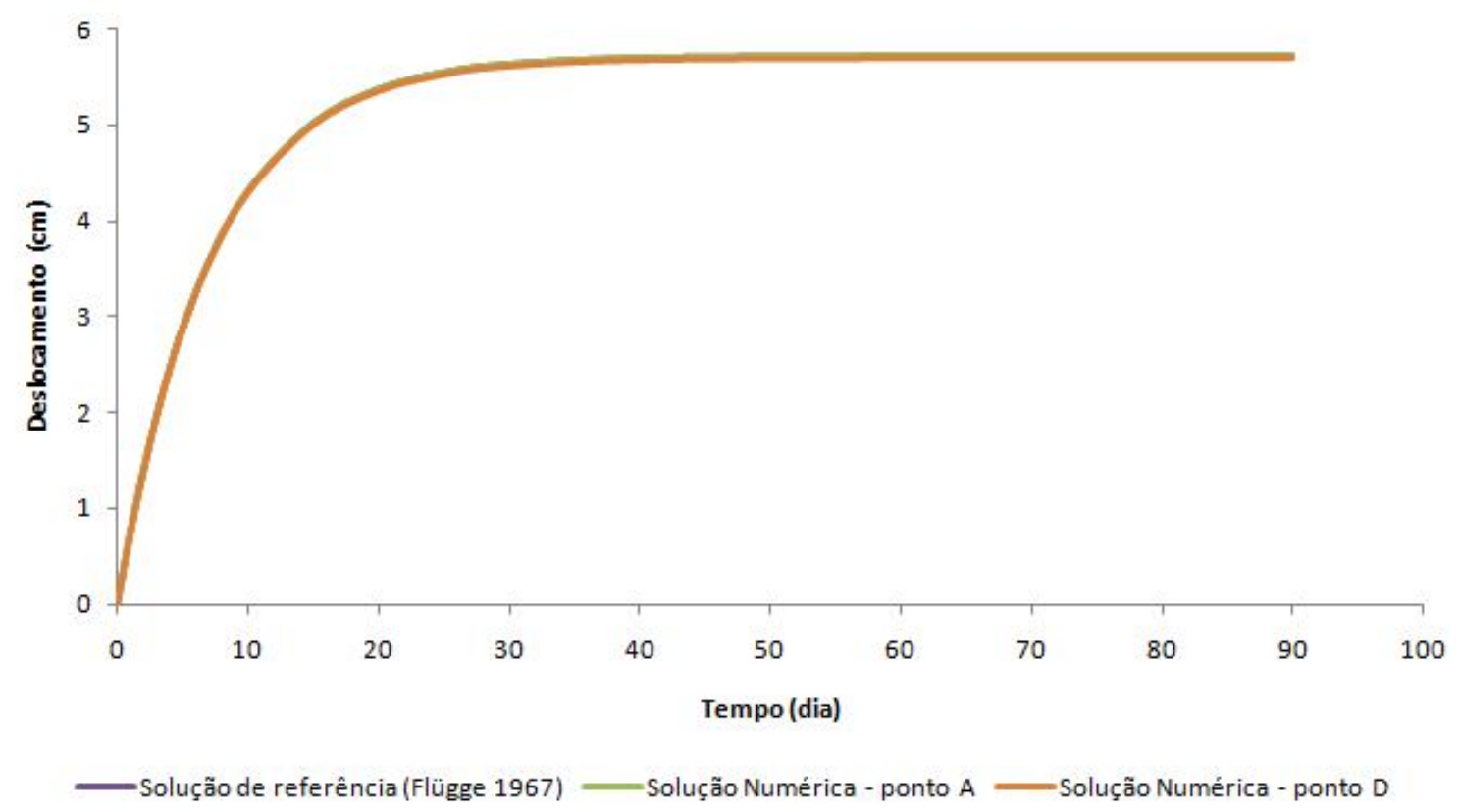

Gráfico 1 - Exemplo 3: deslocamentos dos pontos A e D (linearidade geométrica).

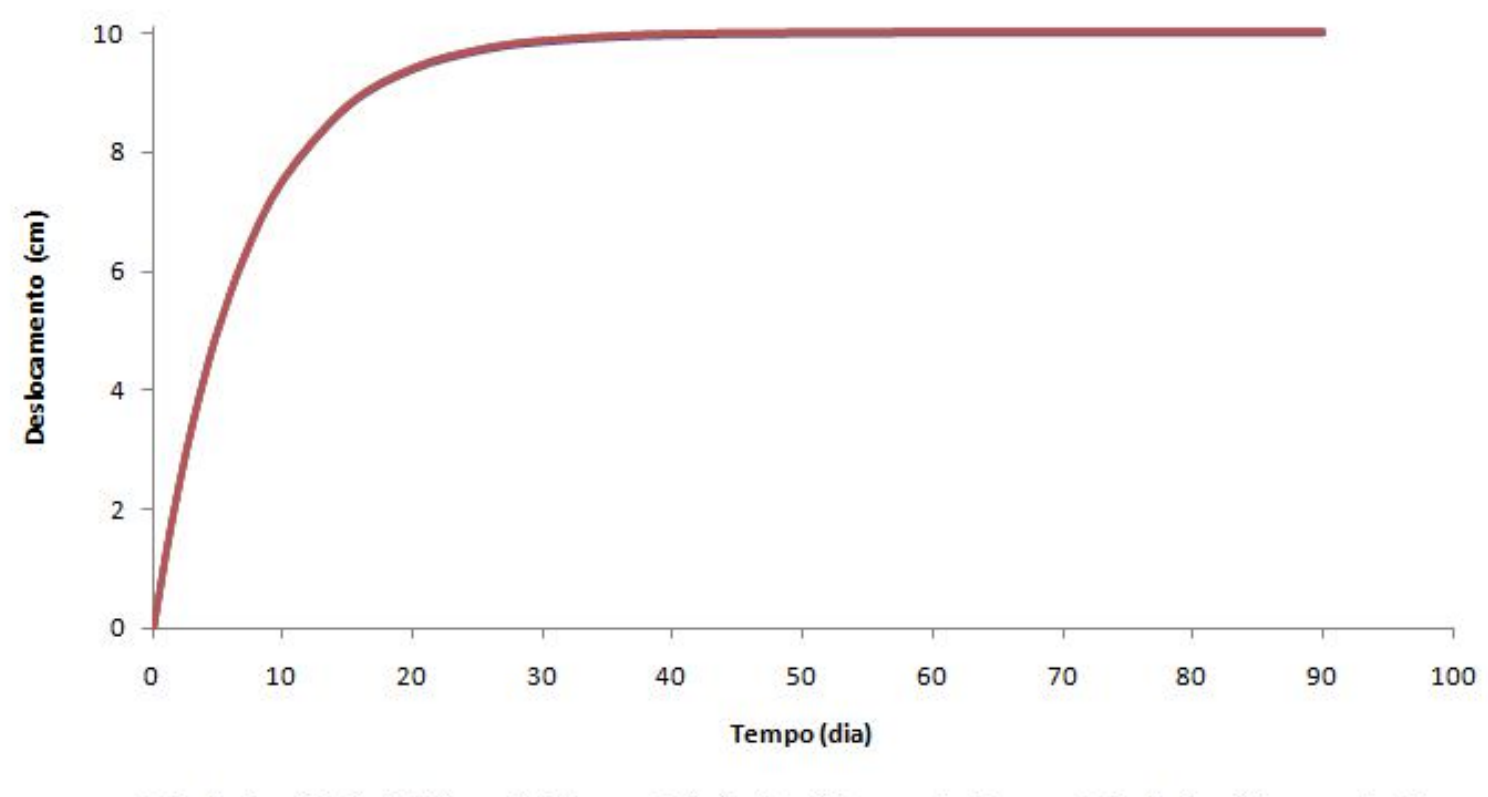

- Solução de referência (Flügge 1967) - Solução Numérica - ponto B — Solução Numérica - ponto C

Gráfico 2 - Exemplo 3: deslocamentos dos pontos B e C (linearidade geométrica).

Os resultados numéricos em linearidade geométrica podem ser considerados satisfatórios ao serem comparados com a solução analítica. Novamente, a ausência de simetria da malha de elementos finitos proposta justifica a diferença (embora mínima) entre os resultados encontrados para pontos de simetria do modelo em questão. O campo de deslocamentos do cilindro no instante $t=90$ dias está apresentado na Figura 40. 


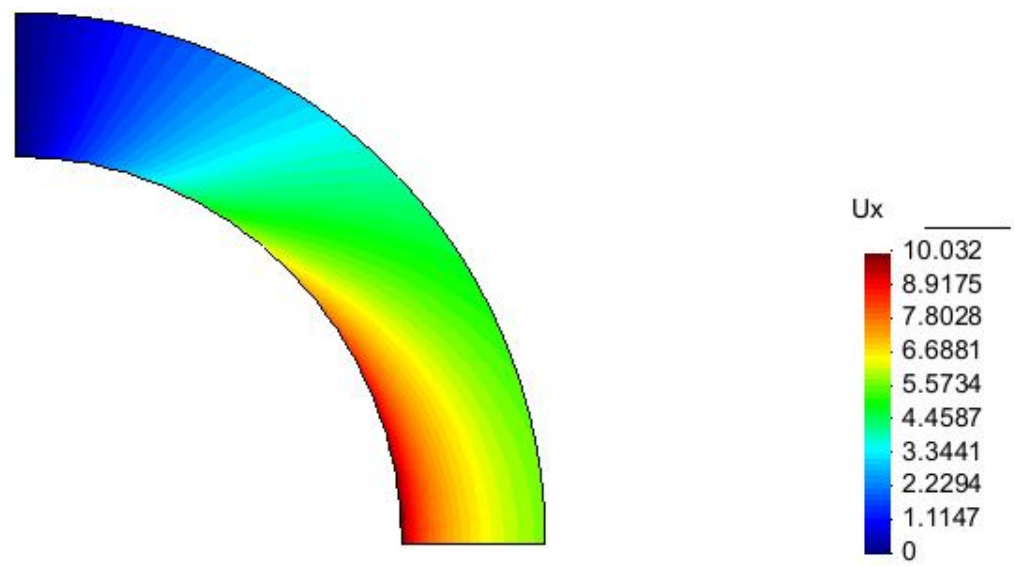

Contour Fill of translations, Ux.

Deformation ( $\mathrm{x} 1)$ : translations of $16 \mathrm{x} 6 \quad$, step 1 .

(a)

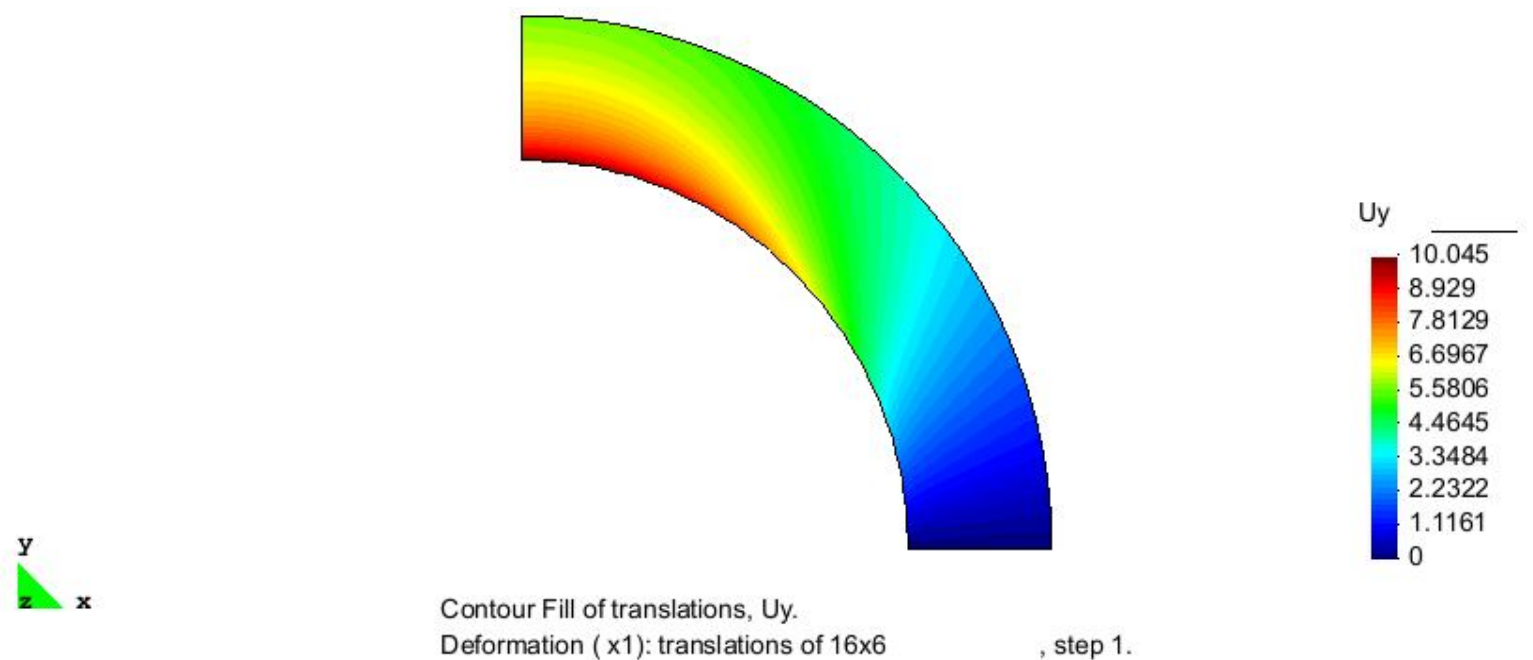

(b)

Figura 40 - Exemplo 3: Campo de deslocamentos obtido para a malha com $16 \times 6$ divisões nas faces no instante $\mathrm{t}=90$ dias (linearidade geométrica) - (a) Deslocamentos na direção do eixo $\mathrm{X} /$ (b) Deslocamentos na direção do eixo Y.

O mesmo exemplo 3 foi analisado também em não linearidade geométrica. Como já justificado anteriormente no exemplo 1, os valores numéricos obtidos não equivalem à totalidade do carregamento aplicado p. Neste caso, será calculado para 81,81\% de p. Observou-se uma taxa de convergência do Método de Newton quadrática durante a análise. Deslocamentos obtidos para o instante $\mathrm{t}=90$ dias: $3,860634 \mathrm{~cm}$ (Ponto $\mathrm{A}$ ); $7,878023 \mathrm{~cm}$ (Ponto B); 8,017452cm (Ponto C) e 3,831406cm (Ponto D). Os resultados numéricos em função do tempo são apresentados no Gráfico 3. Os campos de deslocamentos do cilindro neste caso estão apresentados na Figura 41 e Figura 42. 


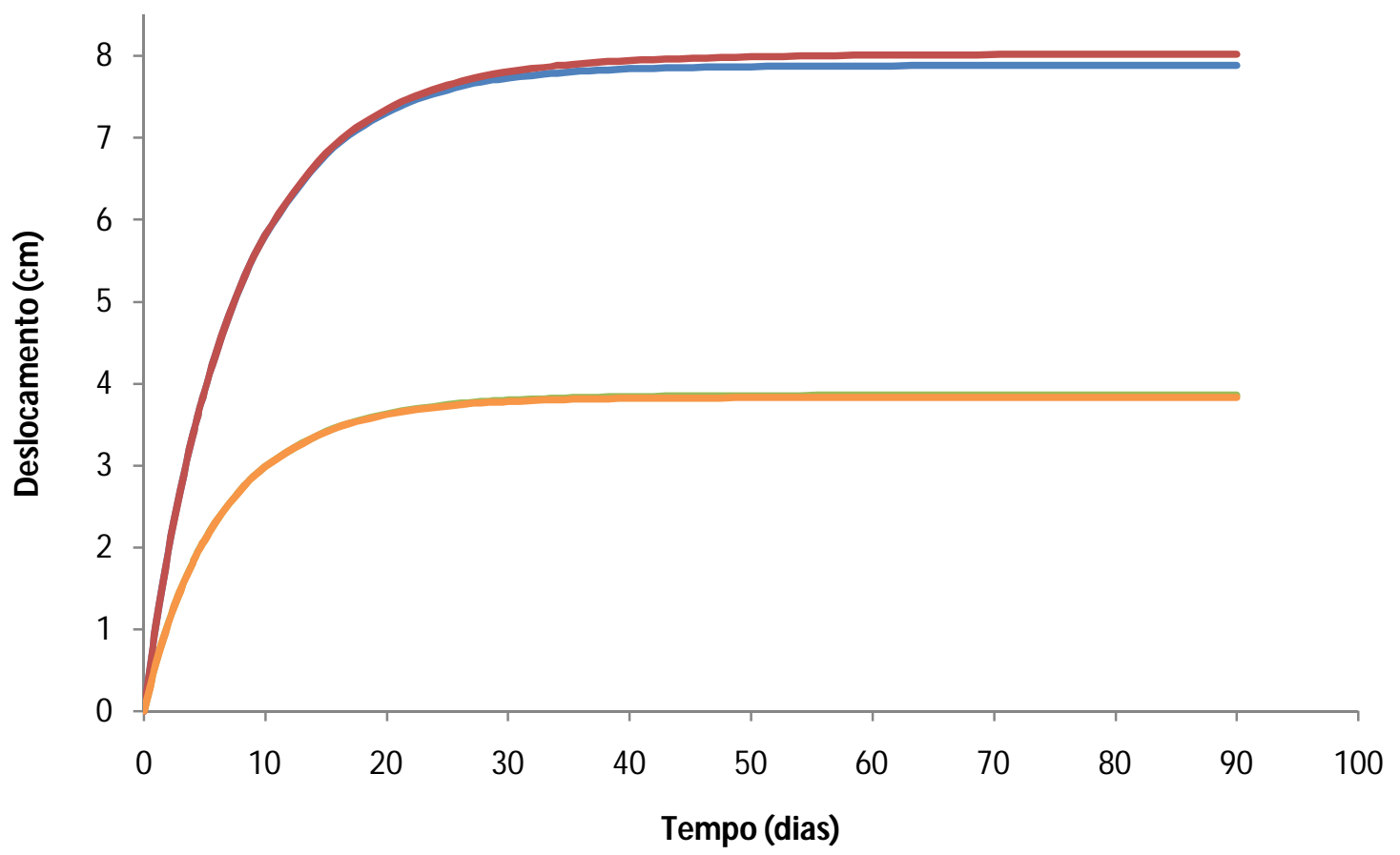

- Solução Numérica - ponto A —Solução Numérica - ponto B

Solução Numérica - ponto $C \longrightarrow$ Solução Numérica - ponto $D$

Gráfico 3 - Exemplo 3: deslocamentos em função do tempo (não linearidade geométrica).

y

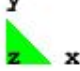

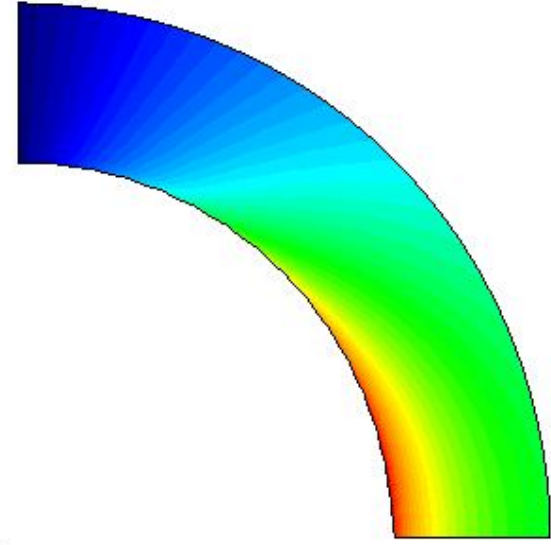

step 5

Contour Fill of translations, Ux.

Deformation ( $x 1$ ): translations of $16 \times 6$
Ux

8.0175

7.1266

6.2358

5.345

4.4541

3.5633

2.6725

1.7817

0.89083

Figura 41 - Exemplo 3: Campo de deslocamentos na direção do eixo X obtido para a malha com $16 \times 6$ divisões nas faces no instante $t=90$ dias (não linearidade geométrica). 


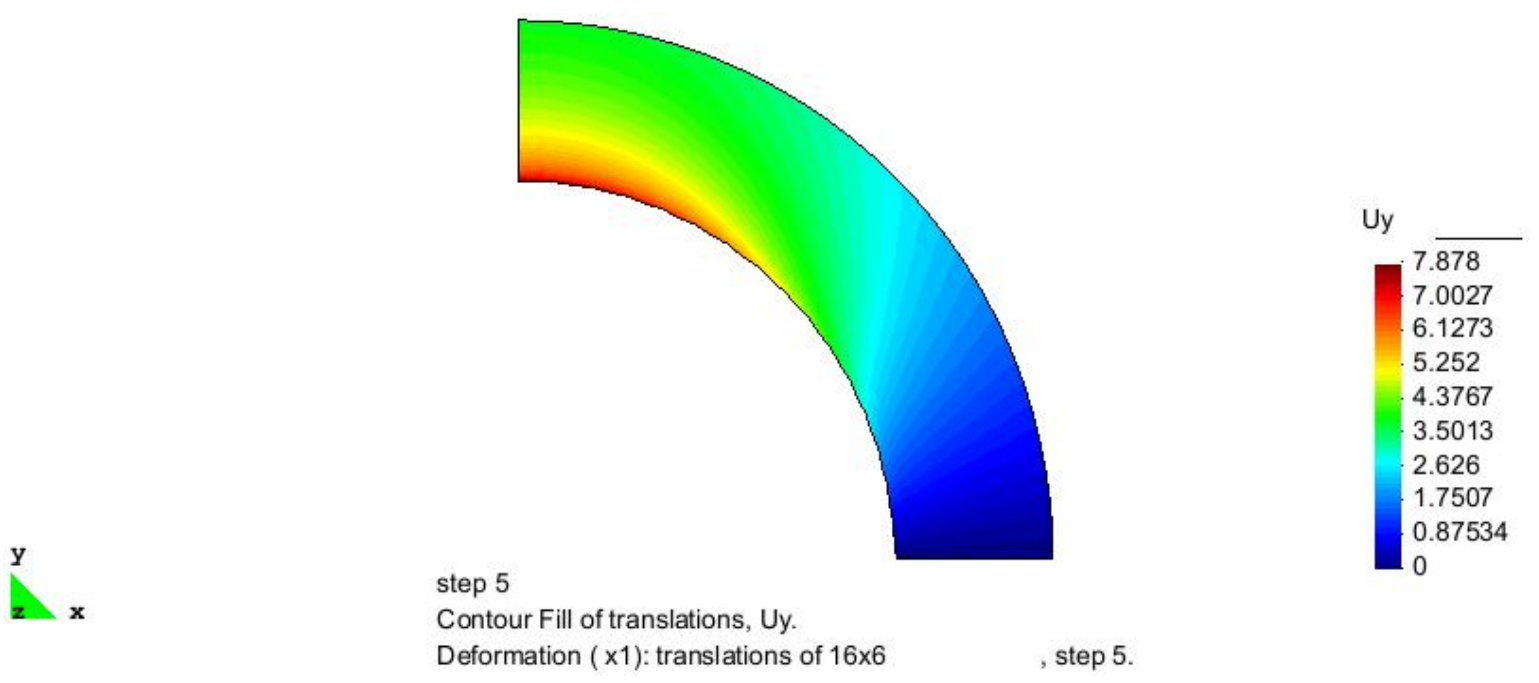

Figura 42 - Exemplo 3: Campo de deslocamentos na direção do eixo Y obtido para a malha com $16 \times 6$ divisões nas faces no instante $t=90$ dias (não linearidade geométrica).

O exemplo 4 foi proposto por Flügge (1967) e consiste em um cilindro de parede espessa composto por dois materiais e submetido a uma pressão interna (Figura 43). Um dos materiais já é conhecido (o mesmo do exemplo 3). O material que recobre o primeiro é considerado infinitamente rígido. Segundo o autor, devido à rigidez deste segundo material, sua deformação poderá ser desprezada. Assim, tudo se passa como se o cilindro fosse constituído apenas pelo material interno, sendo a fronteira externa deste último indeslocável.

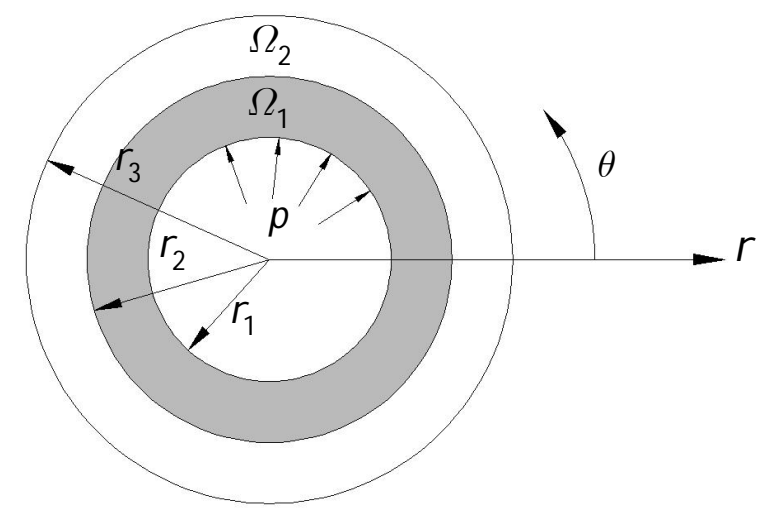

$$
\begin{gathered}
r_{1}=25,4 \mathrm{~cm}, r_{2}=38,1 \mathrm{~cm} \mathrm{e} \\
r_{3}=50,8 \mathrm{~cm} \\
E_{1}=35 \mathrm{kgf} / \mathrm{cm}^{2} \\
\nu_{1}=0,40 \\
\eta_{1}=249,99975 \frac{\mathrm{kgf}}{\mathrm{cm}^{2}} \cdot \mathrm{dia} \\
\mathrm{E}_{2} \rightarrow \infty \\
\mathrm{p}=7,031 \mathrm{kgf} / \mathrm{cm}^{2}
\end{gathered}
$$

Figura 43 - Exemplo 4: características geométricas e propriedades do material.

Nessas condições, uma solução de referência via Teoria Linear da Elasticidade proposta por Flügge (1967) para o deslocamento radial de um ponto é dada por

$$
\mathrm{u}=\frac{\mathrm{p}(1+\nu)(1-2 \nu) \mathrm{r}_{\text {ext }} \mathrm{r}_{\text {int }}^{2}}{\mathrm{E}_{1}\left[(1-2 \nu) \mathrm{r}_{\text {ext }}^{2}+\mathrm{r}_{\text {int }}^{2}\right]}\left(\frac{\mathrm{r}_{\text {ext }}}{\mathrm{r}}-\frac{\mathrm{r}}{\mathrm{r}_{\text {ext }}}\right),
$$


com $r_{\text {int }}=25,4 \mathrm{~cm}$ e $r_{\text {ext }}=38,1 \mathrm{~cm}$. Esta equação apresentada não pode ser considerada uma solução analítica como no Exemplo 3, pois devido às condições de contorno deste exemplo o campo de tensões depende não só das características geométrica, mas também do coeficiente de Poisson. Como no exemplo 3, a solução de referência admitindo material viscoelástico será determinada a partir da solução elástica, substituindo $E_{1}$ pelo módulo de elasticidade aparente na fluência, $\mathrm{E}_{1}(\mathrm{t})$.

Este exemplo apresenta simetria. Assim, um quarto do cilindro foi discretizado. A Figura 44 mostra as condições de contorno essenciais e naturais aplicadas e a malha de elementos finitos utilizada, de $16 \times 3$ divisões nas faces. A malha é proposta desta forma, pois apenas metade da espessura será discretizada já que o segundo material poderá ser simulado através das condições de contorno impostas. Por simplicidade, o carregamento $p$ foi aplicado com valores igualmente distribuídos em todos os nós da face interna do cilindro.

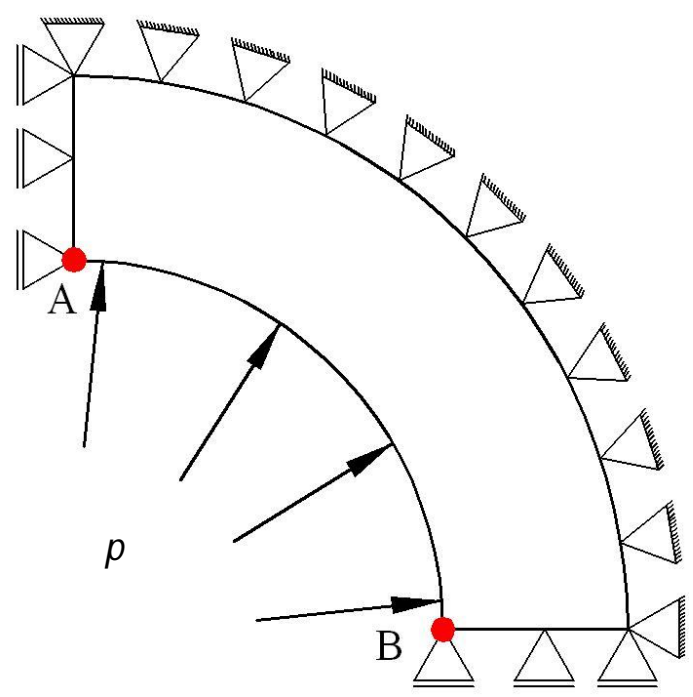

(a)

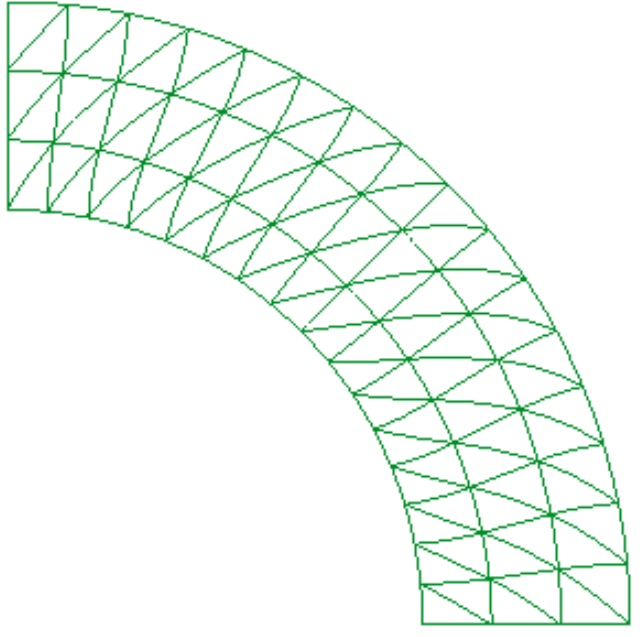

(b)

Figura 44 - Exemplo 4: (a) condições de contorno; (b) malha de elementos finitos com 16×3 divisões.

A solução de referência para o exemplo 4 foi tomada a partir da equação (132) no instante $\mathrm{t}=120$ dias, e para os pontos A e B vale $1,231637 \mathrm{~cm}$. Utilizando-se o PEFSYS, obteve-se em linearidade geométrica $1,278505 \mathrm{~cm}$ (Ponto A) e $1,273421 \mathrm{~cm}$ (Ponto B). No Gráfico 4 são apresentados os deslocamentos em função do tempo dos dois pontos analisados e da solução de referência. 


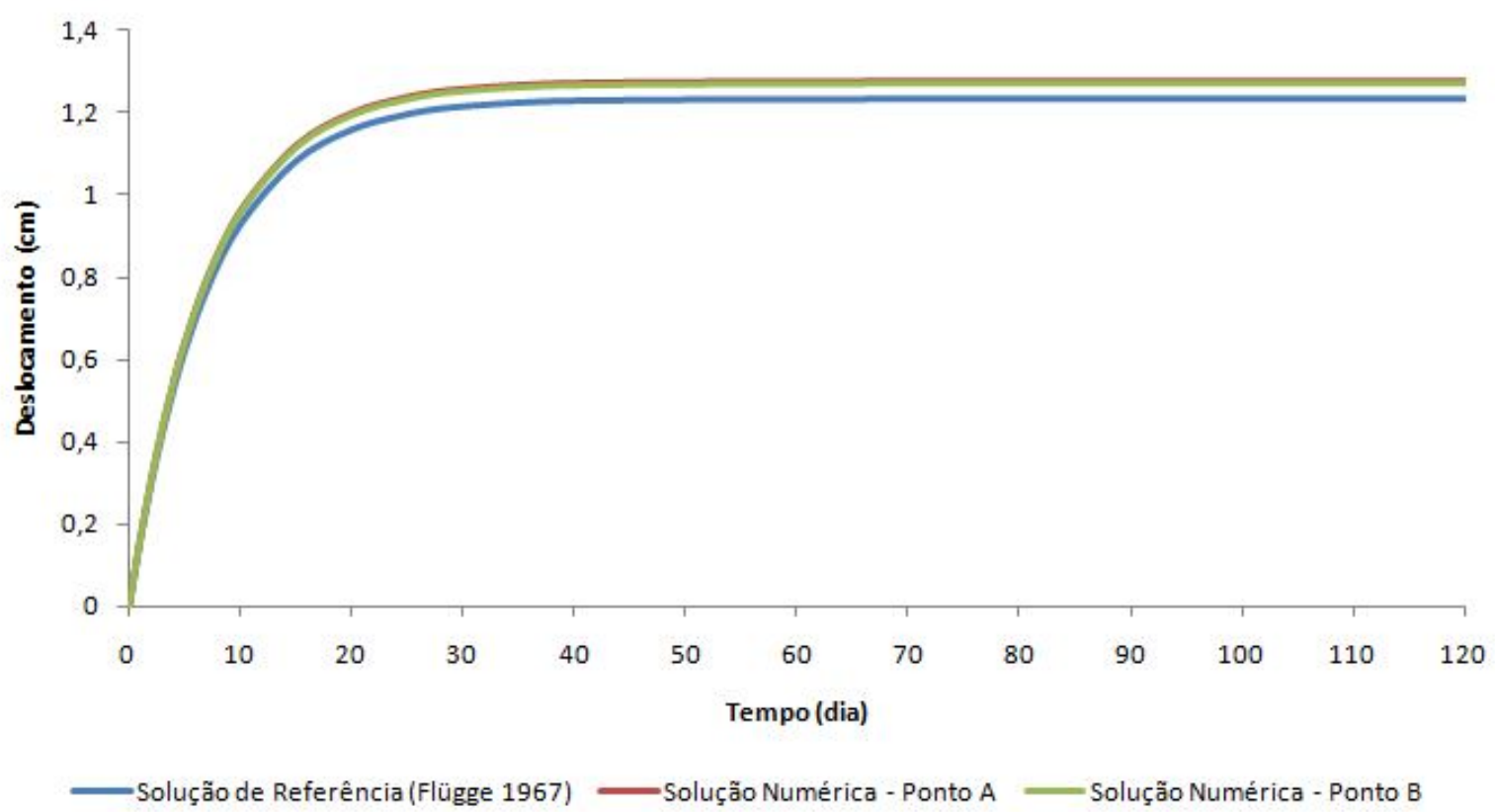

Gráfico 4 - Exemplo 4: deslocamentos em função do tempo (linearidade geométrica).

Os valores apresentados para o exemplo 4 são considerados satisfatórios ao serem comparados com a solução de referência, já que se trata de uma malha de elementos finitos com três divisões na espessura do cilindro. Novamente, ressalta-se que a ausência de simetria da malha de elementos finitos gerou uma pequena diferença entre os resultados encontrados para os pontos A e B. O campo de deslocamentos do exemplo 4 no instante $\mathrm{t}=$ 120dias está apresentado a seguir.

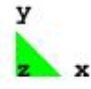

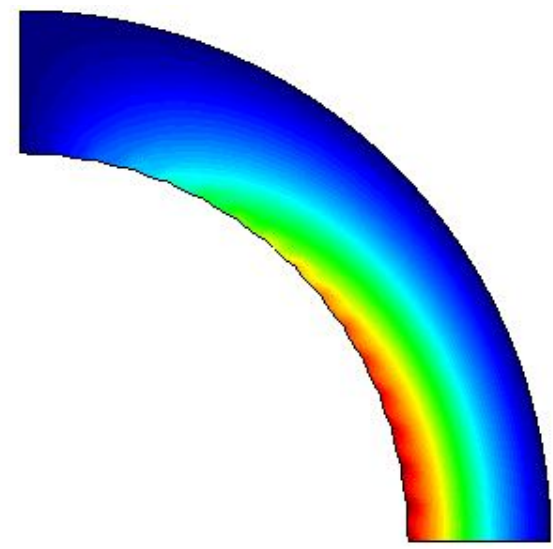

Contour Fill of translations, Ux.

Deformation ( $x 1$ ): translations of $16 \times 3$

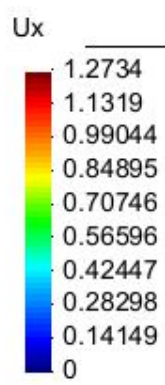

, step 1.

Figura 45 - Exemplo 4: Campo de deslocamentos na direção do eixo $\mathrm{X}$ obtido para a malha com $16 \times 3$ divisões nas faces no instante $t=120$ dias (linearidade geométrica). 

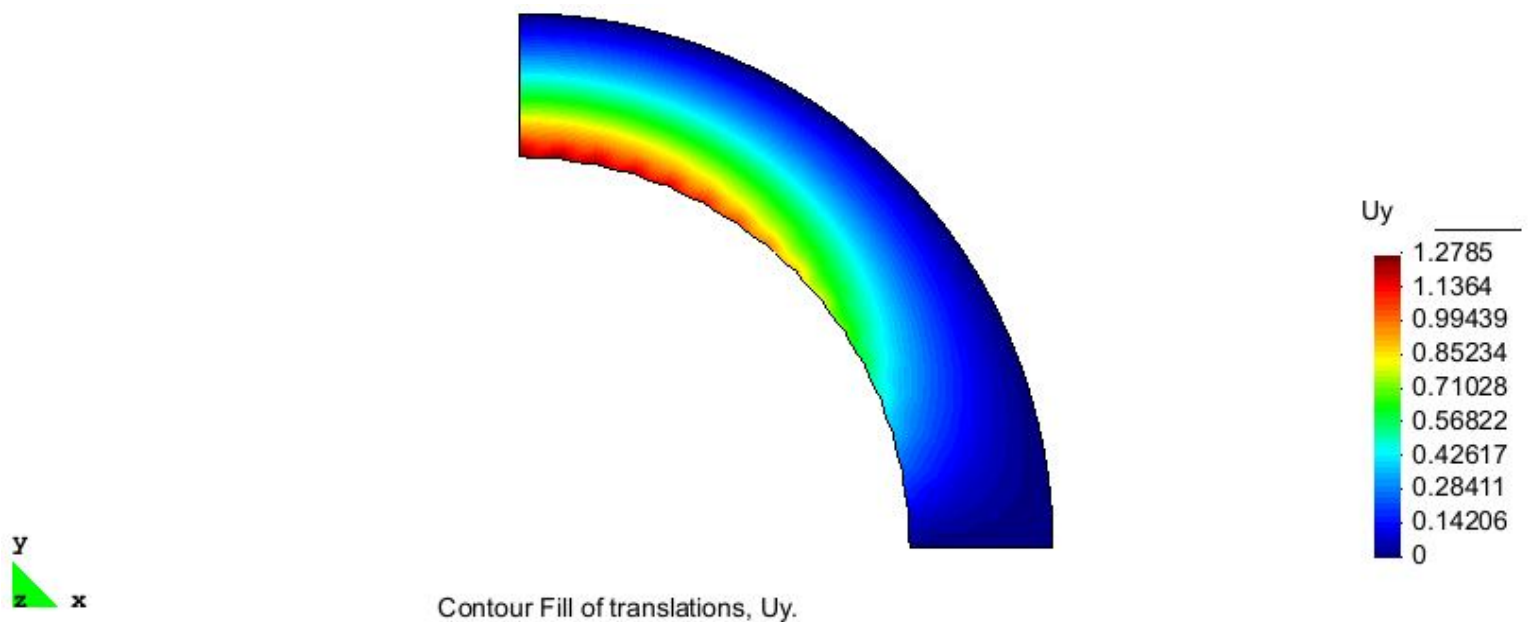

Contour Fill of translations, Uy.

Deformation ( $x 1$ ): translations of $16 \times 3 \quad$, step 1.

Figura 46 - Exemplo 4: Campo de deslocamentos na direção do eixo Y obtido para a malha com $16 \times 3$ divisões nas faces no instante $t=120$ dias (linearidade geométrica).

Os resultados numéricos sob não linearidade geométrica para o instante $\mathrm{t}=120$ dias são $1,6860420 \mathrm{~cm}$ (Ponto A) e 1,6523630cm (Ponto B). Os valores apresentados correspondem à totalidade da pressão aplicada, ou seja, para o nível total de carga houve convergência mesmo com deformações da ordem de 13\%. Observou-se que a taxa de convergência no Método de Newton é quadrática. São apresentados no Gráfico 5 os deslocamentos obtidos para os dois pontos em função do tempo.

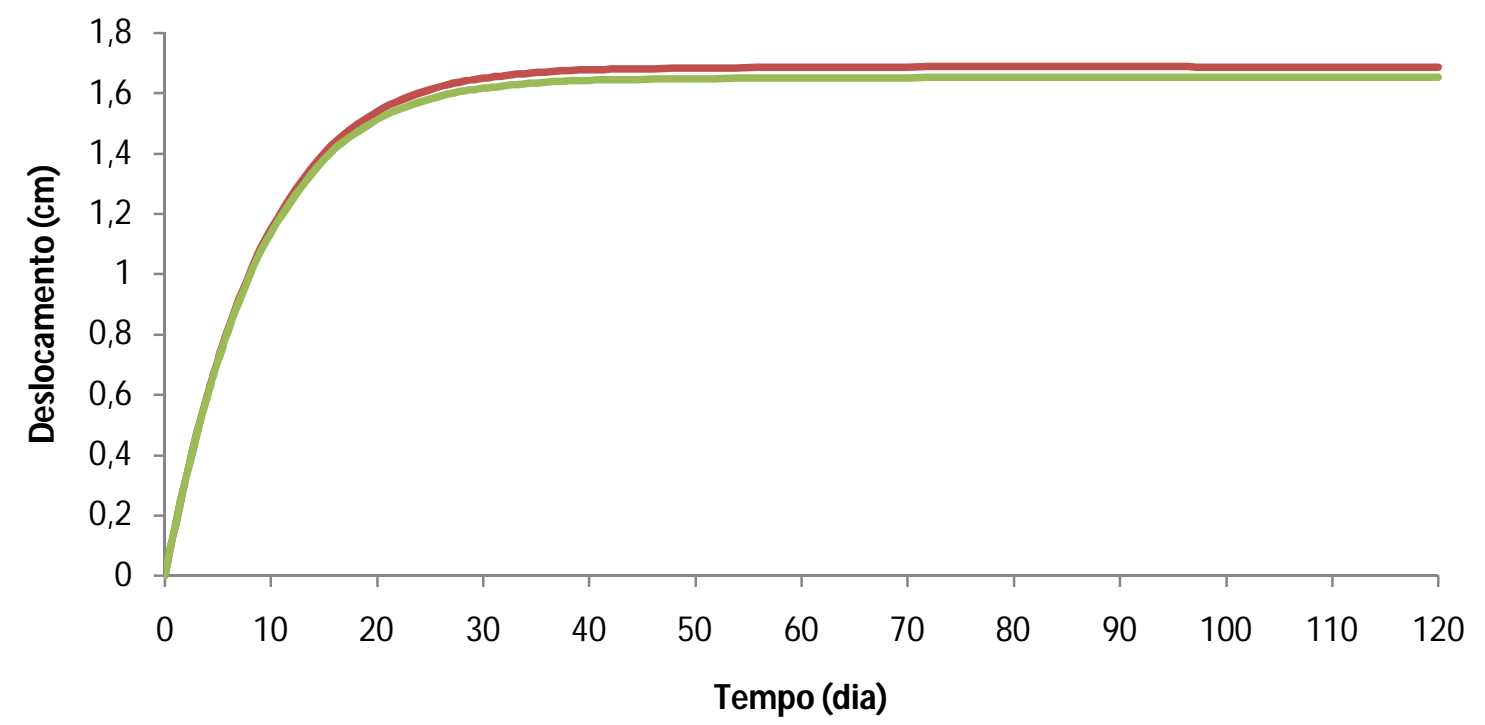

—Solução Numérica - Ponto A — Solução Numérica - Ponto B

Gráfico 5 - Exemplo 4: deslocamentos em função do tempo (não linearidade geométrica). 
O campo de deslocamentos do exemplo 4 sob não linearidade geométrica está apresentado na Figura 47. Ressalta-se que as pequenas "franjas" observadas na face interna são decorrência da aplicação simplificada do carregamento.

y

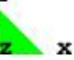

y

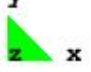

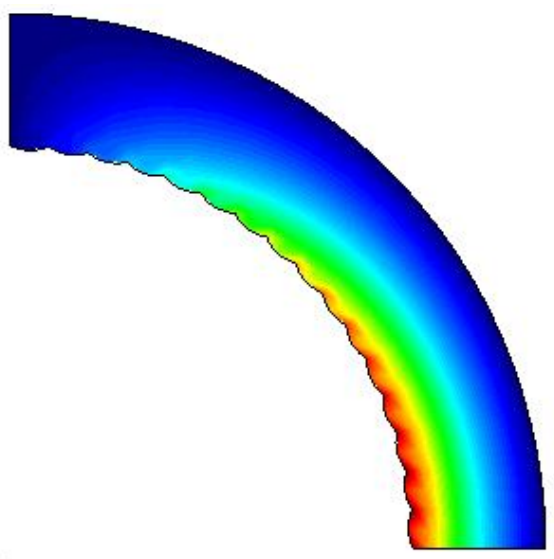

step 5

Contour Fill of translations, Ux.

Deformation ( $x 1$ ): translations of $16 \times 3$

, step 5.

(a)
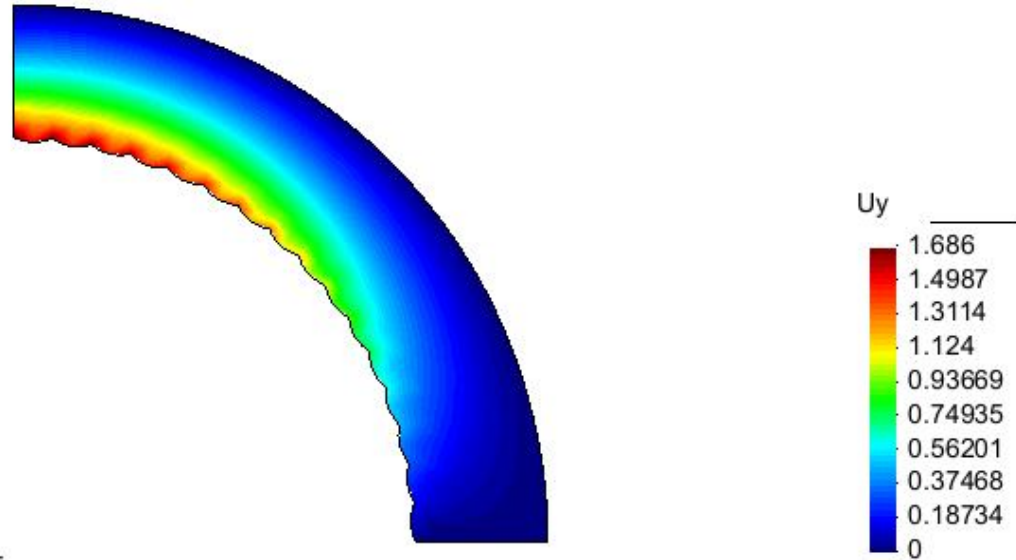

step 5

Contour Fill of translations, Uy.

Deformation ( $\mathrm{x} 1$ ): translations of $16 \times 3$

, step 5 .

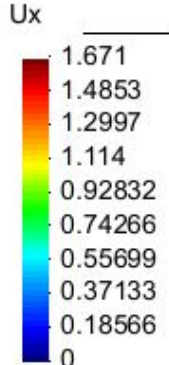

(b)

Figura 47 - Exemplo 4: Campo de deslocamentos obtido para a malha com $16 \times 3$ divisões nas faces no instante $\mathrm{t}=120$ dias (não linearidade geométrica) - (a) Deslocamentos na direção do eixo $\mathrm{X} /$ (b) Deslocamentos na direção do eixo Y.

O exemplo 5 foi proposto por Carbone (2007) e consiste em uma sapata corrida sobre o solo, esta sapata é representada por uma pressão p aplicada em 10m centrais do exemplo. As características geométricas e propriedades do solo estão apresentadas na Figura 48. 


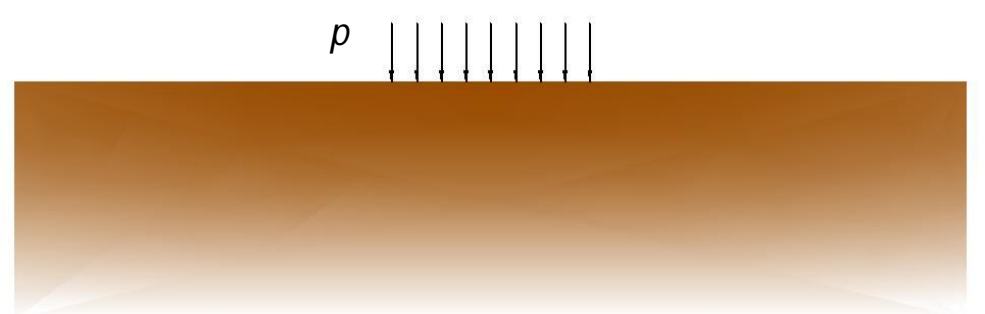

$$
\begin{gathered}
\mathrm{E}=30 \times 10^{3} \mathrm{kN} / \mathrm{m}^{2} \\
\nu=0,30 \\
\eta=279000 \frac{\mathrm{kN}}{\mathrm{m}^{2}} \cdot \mathrm{dia} \\
\mathrm{p}=46,0 \mathrm{kN} / \mathrm{m}^{2}
\end{gathered}
$$

Figura 48 - Exemplo 5: características geométricas e propriedades do material.

Este exemplo apresenta simetria. Assim, metade do sólido foi discretizado. A Figura 49 mostra as condições de contorno essenciais e naturais consideradas em Carbone (2007) e a malha de elementos finitos presentemente adotada com $24 \times 12$ divisões.

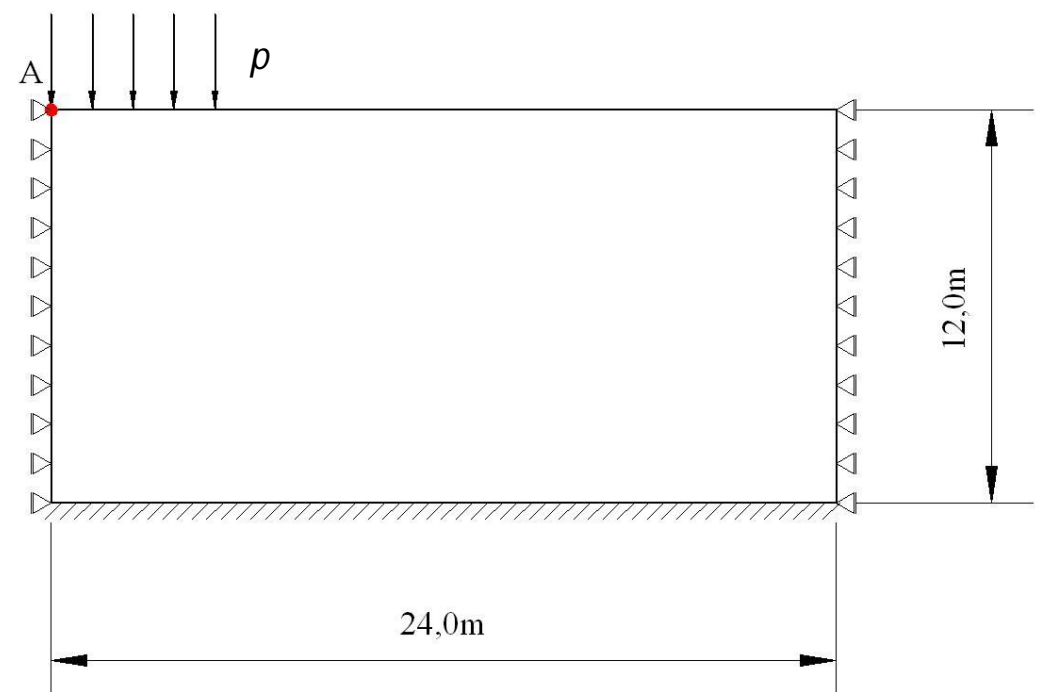

(a)

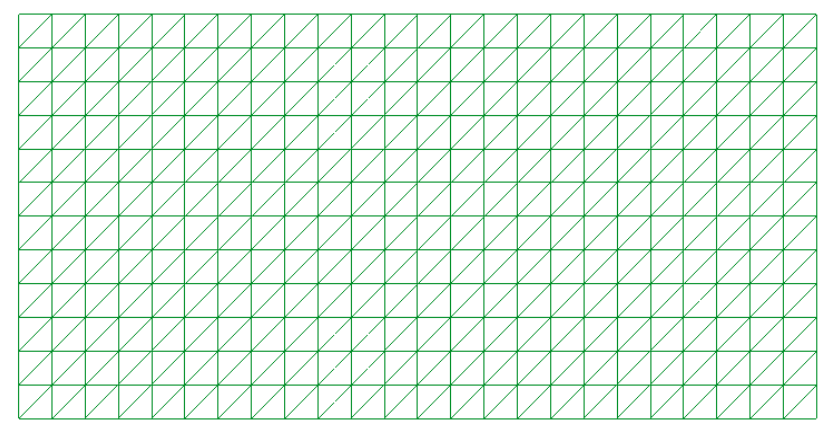

(b)

Figura 49 - Exemplo 5: (a) condições de contorno; (b) malha de elementos finitos com $24 \times 12$ divisões.

A solução numérica viscoelástica com integração de tensões obtida por Carbone (2007) a partir do Método dos Elementos de Contorno, para o deslocamento vertical do ponto $\mathrm{A}$, foi de $0,012301358 \mathrm{~m}$ no instante $\mathrm{t}=86 \mathrm{dias}$, com um passo no tempo de 2 dias. 
Obteve-se com PEFSYS um deslocamento vertical para o ponto A de $0,01231785 \mathrm{~m}$. No Gráfico 6 são apresentados os deslocamentos verticais obtidos em função do tempo para o ponto A em comparação com a de referência.

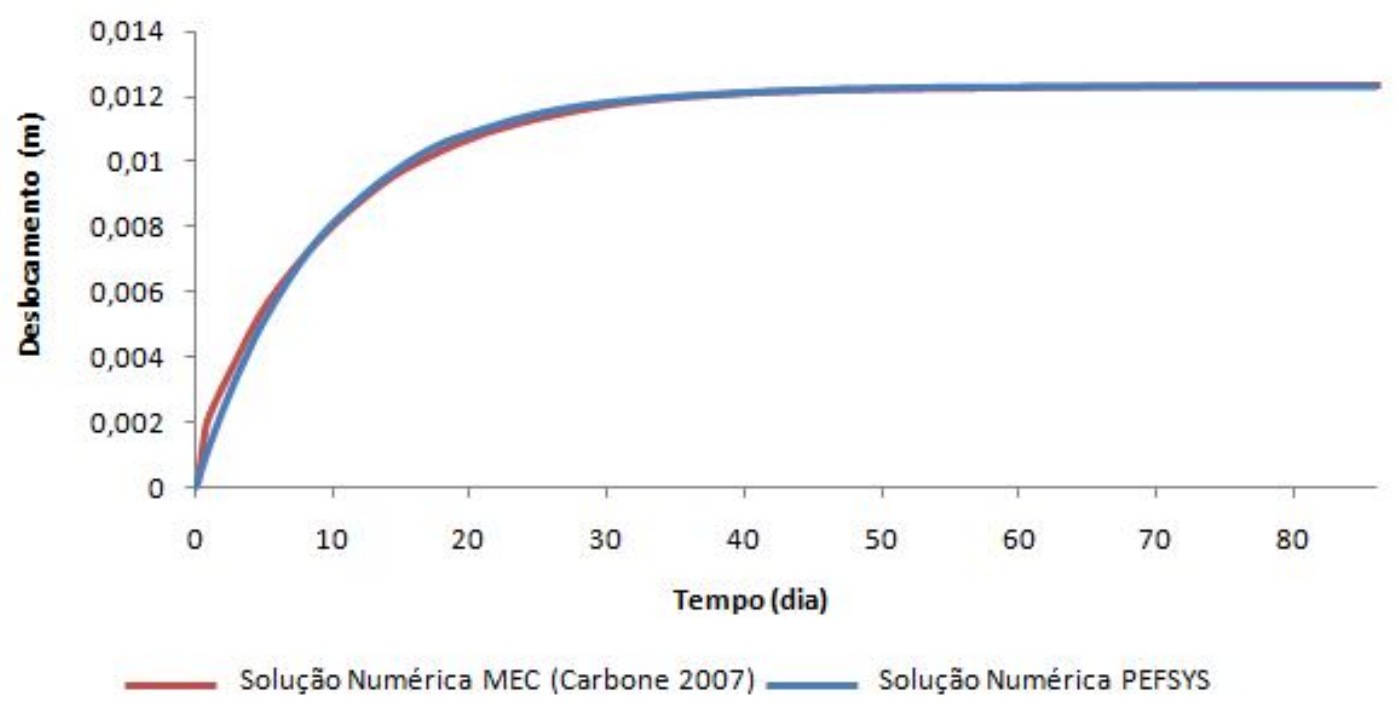

Gráfico 6 - Exemplo 5: deslocamentos verticais do ponto A em função do tempo (linearidade geométrica).

O campo de deslocamentos em linearidade geométrica na direção vertical é apresentado na Figura 50.

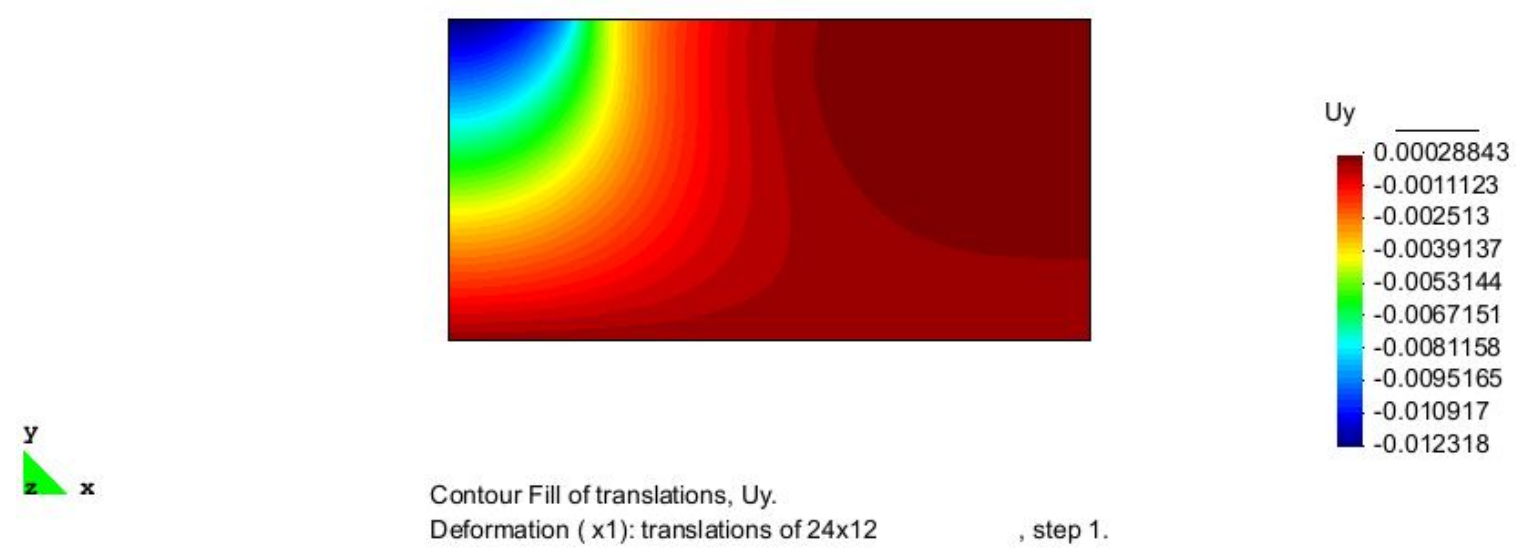

Figura 50 - Exemplo 5: Campo de deslocamentos (componente vertical) para o ponto A (linearidade geométrica).

O deslocamento obtido para o ponto $\mathrm{A}$ em não linearidade geométrica foi de 0,01234401m com uma taxa de convergência do Método de Newton quadrática. Observa-se que os valores obtidos com o PEFSYS em linearidade geométrica e não linearidade geométrica são muito próximos devido a carga aplicada neste exemplo ser muito pequena, portanto, optou-se não apresentar o deslocamento vertical do ponto A ao longo do tempo e o campo de deslocamentos verticais. 
Decidiu-se aplicar um carregamento de maior intensidade no exemplo anterior (Figura 48), sendo a pressão p de 4600,0kN / $\mathrm{m}^{2}$ a que o maciço está submetido.

Obteve-se com PEFSYS um deslocamento vertical para o ponto A de 1,770707m. Observou-se que a taxa de convergência no Método de Newton é quadrática. No Gráfico 7 são apresentados os deslocamentos verticais obtidos em função do tempo para o ponto A.

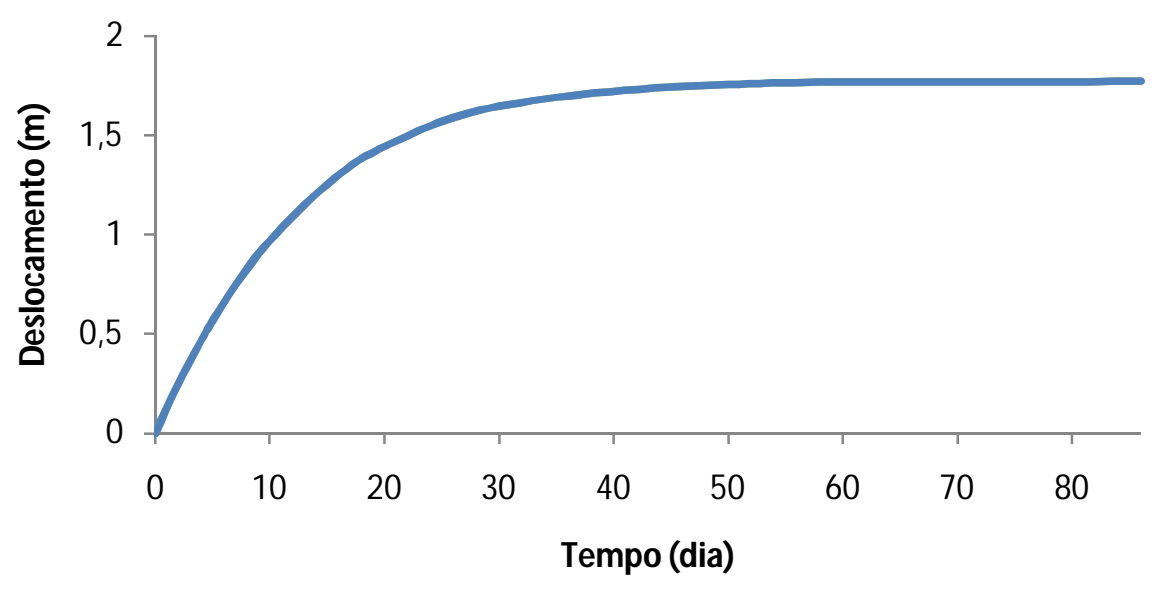

Gráfico 7 - Exemplo 5: deslocamentos verticais do ponto A em função do tempo (não linearidade geométrica).

O campo de deslocamentos em linearidade geométrica na direção vertical é apresentado na Figura 51.

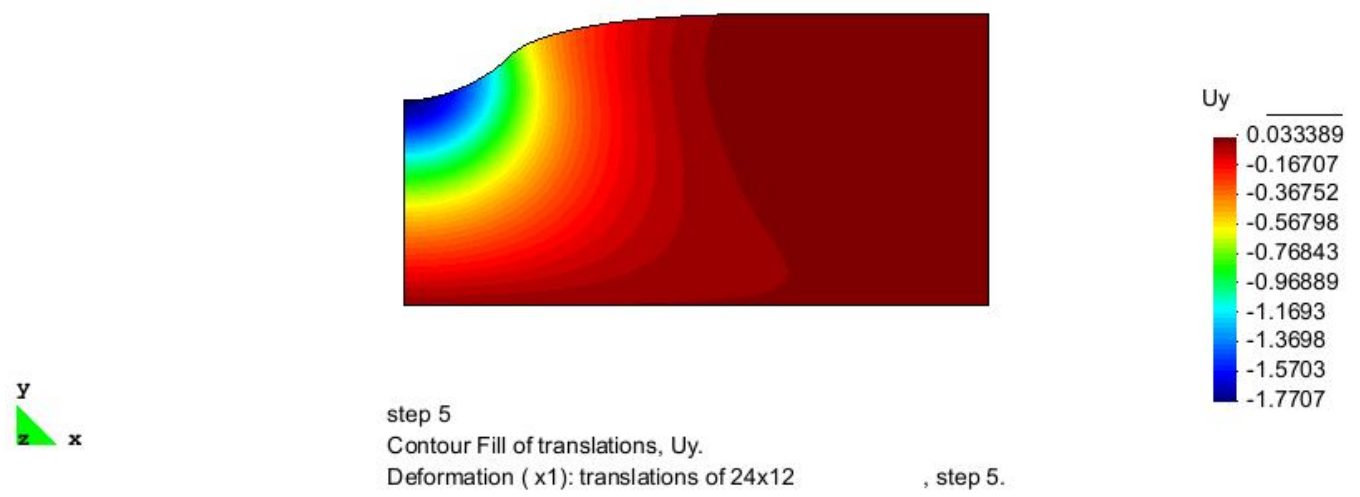

Figura 51 - Exemplo 5: Campo de deslocamentos (componente vertical) para o ponto A (não linearidade geométrica).

Conclui-se que os resultados obtidos nos exemplos com viscoelasticidade são satisfatórios em relação aos valores analíticos e de referência encontrados na literatura. Assim, pode-se prosseguir com a utilização desta implementação para análise de problemas de túneis. 


\section{APLICAÇÃO À ANÁLISE DE TÚNEIS}

A revolução industrial e o desenvolvimento dos primeiros sistemas ferroviários propiciaram a construção sistemática de túneis, iniciado na Grã-Bretanha no século XIX. O Brasil acompanhou este desenvolvimento através da construção de túneis nos estados do Rio de Janeiro e Minas Gerais por volta de 1860 para implantar a Rodovia União e Indústria e da Estrada de Ferro D. Pedro II (CELESTINO et al, 2006).

Segundo o mesmo autor, o crescimento mundial (expansão da malha de transportes rodoviária e metroferroviária, usinas hidrelétricas, mineração subterrânea, sistemas de adutoras e saneamento) proporcionou um aumento no número de obras de túneis. Com a construção do metrô de São Paulo e Rio de Janeiro houve o estabelecimento da moderna Engenharia de Túneis no Brasil, na década de 70.

Uma grande demanda por métodos que envolvessem o dimensionamento e construção de obras de túneis surgiu devido à expansão global. Entre o final do século XIX e início do século XX, tentou-se elaborar os fundamentos da Mecânica dos Túneis ao utilizar a distribuição de tensões e deslocamentos ocasionados durante a execução destas obras, e propor critérios de projeto e dimensionamento de estruturas de suporte (OLIVEIRA, 2009).

Diversos métodos e modelos têm sido propostos e utilizados para realizar a análise de problemas que envolvem túneis.

Em 1992, Celestino apresentou um novo procedimento para a análise da interação solo/rocha-estrutura, onde o maciço e o suporte possuem um comportamento dependente do tempo.

Em 2006, Gomes relatou os procedimentos utilizados durante a análise de influência de alguns parâmetros da interação solo/rocha-estrutura sobre os esforços solicitantes finais no suporte, tanto para o concreto projetado (comportamento dependente do tempo) quanto para materiais com propriedades constantes. Para o problema da quantificação de esforços solicitantes de compressão e flexão no suporte elaborou soluções adimensionais.

Dentre os trabalhos publicados aproximadamente nos últimos cinquenta anos sobre Método dos Elementos Finitos e Método de Elementos de Contorno aplicados ao estudo de túneis, citam-se King, Watson e Zienkiewicz (KING; WATSON; ZIENKIEWICZ, 1968), Venturini (VENTURINI, 1983); Golser (GOLSER, 2001); França (FRANÇA, 2006); Costa (COSTA, 2008); Freitas (FREITAS, 2008); Gomes (GOMES, 2008); Oliveira (OLIVEIRA, 
2009); Fahimifar et al (FAHIMIFAR et al, 2010) e Quim (QUIM, 2010).

Muitos trabalhos foram publicados com soluções analíticas sobre a interação entre o maciço e o suporte, dentre estes se destacam Guenot, Panet e Sulem (GUENOT; PANET; SULEM, 1987) e Huang e Pan (HUANG; PAN, 1994).

Assim serão apresentados os principais conceitos sobre métodos para análise bidimensionais de túneis, interação solo-estrutura, método executivo - NATM e modelagem computacional.

O campo de tensões e deformações durante uma escavação é de natureza tridimensional e dependente do tempo. Pode-se dividir uma visão longitudinal de um túnel em três áreas de estudo (Figura 52). A primeira área de estudo é correspondente ao maciço que permanece intacto e não sofre nenhuma influência exercida pela escavação; este pode ser analisado através de modelos bidimensionais. A região correspondente à frente de escavação e parte do interior do túnel (região esta submetida à influência da escavação realizada) tem comportamento tridimensional. E a terceira área corresponde a uma região em que o maciço e a estrutura não mais sofrem influência da frente de escavação e pode ser tratado como um problema bidimensional (PÖTTLER, 1990). Portanto, a escavação de um túnel gera influências sobre o campo de tensões e deformações do maciço impedindo uma análise bidimensional do problema em algumas seções.

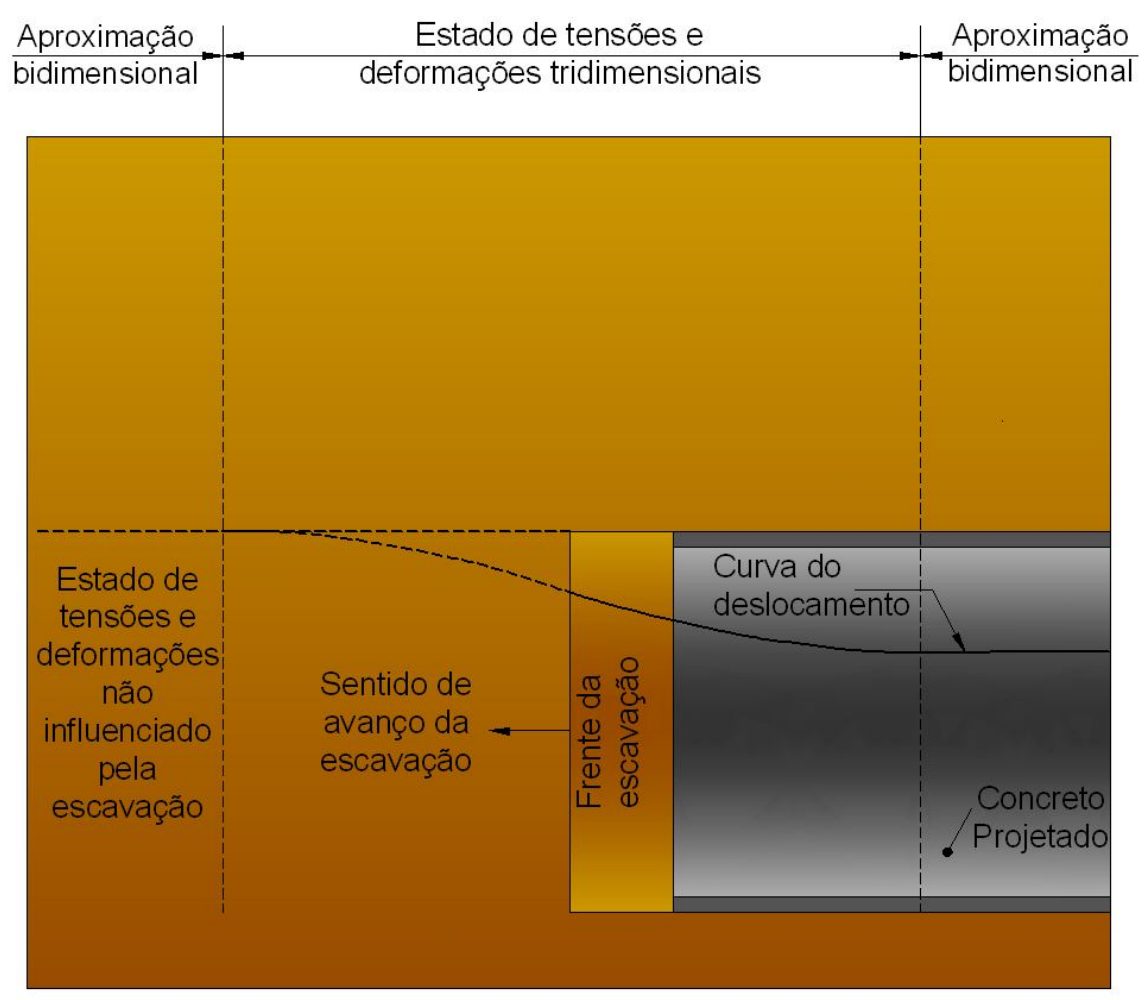

Figura 52 - Análise longitudinal de um túnel. Adaptado de: PÖTTLER (1990, p. 151) 
Apesar de ser um problema complexo, métodos foram propostos pela comunidade científica para realizar uma análise bidimensional de um túnel e determinar os campos de tensões e deformações do maciço e revestimento. O método da pressão fictícia interna, o método da redução de rigidez do núcleo e o método da redução de carregamento são brevemente comentados a seguir baseado em observações realizadas por Gomes (2006), Freitas (2008) e Quim (2010).

O método da pressão fictícia interna propõe que a escavação de túneis seja estudada em três etapas distintas através da aplicação de pressões internas fictícias. O método consiste em simular o efeito de um suporte temporário fornecido pela frente de escavação através de um modelo bidimensional submetido a uma pressão interna fictícia atuante na superfície de escavação, sendo esta pressão interna reduzida a zero durante a análise.

O método da redução de rigidez do núcleo consiste em realizar simulações numéricas bidimensionais, onde se reduz o módulo de elasticidade da região do núcleo a cada etapa de estudo. Este núcleo é delimitado pelo perímetro do futuro túnel.

O método da redução de carregamento, principalmente utilizado na Alemanha, é composto pela sobreposição de duas situações. A primeira é caracterizada pela determinação das tensões na fronteira entre a região a ser escava e o maciço. A segunda é composta pela aplicação de um suporte e a aplicação de um carregamento fictício (sem a consideração das tensões encontradas na primeira situação).

As propriedades do maciço, a forma com que ocorre a redistribuição do campo de tensões mediante as deformações ocorridas antes e depois da instalação da estrutura suporte e o tipo de método construtivo influenciam o valor da carga atuante na estrutura. Esta estimativa é um assunto ainda em estudo e objeto de pesquisadores.

Para o entendimento da interação maciço-suporte, será apresentado brevemente o método de convergência-confinamento. Há diversos outros métodos que propõem esta estimativa e alguns deles consideram o comportamento do suporte dependente do tempo. Pode-se ressaltar o método proposto por Pöttler em 1990, Celestino em 1992 e Chang em 1994.

O método de convergência-confinamento pode ser considerado uma ferramenta simples com o objetivo de auxiliar no desenvolvimento de projetos de túneis, sendo provavelmente utilizado desde a publicação realizada por Fenner em 1938 (QUIM, 2010).

O método consiste em observar as curvas características do maciço e suporte (Figura 62). Inicialmente se considera a existência de um maciço não perturbado por um túnel 
sem suporte, onde há a atuação de uma pressão interna $P_{i}$ nas paredes de mesma intensidade e com sentido oposto ao dos esforços aplicados no maciço anteriormente à escavação. Após a escavação, considera-se que haja uma redução da pressão exercida $P_{i}$ e, portanto ocorrerão deslocamentos radiais.

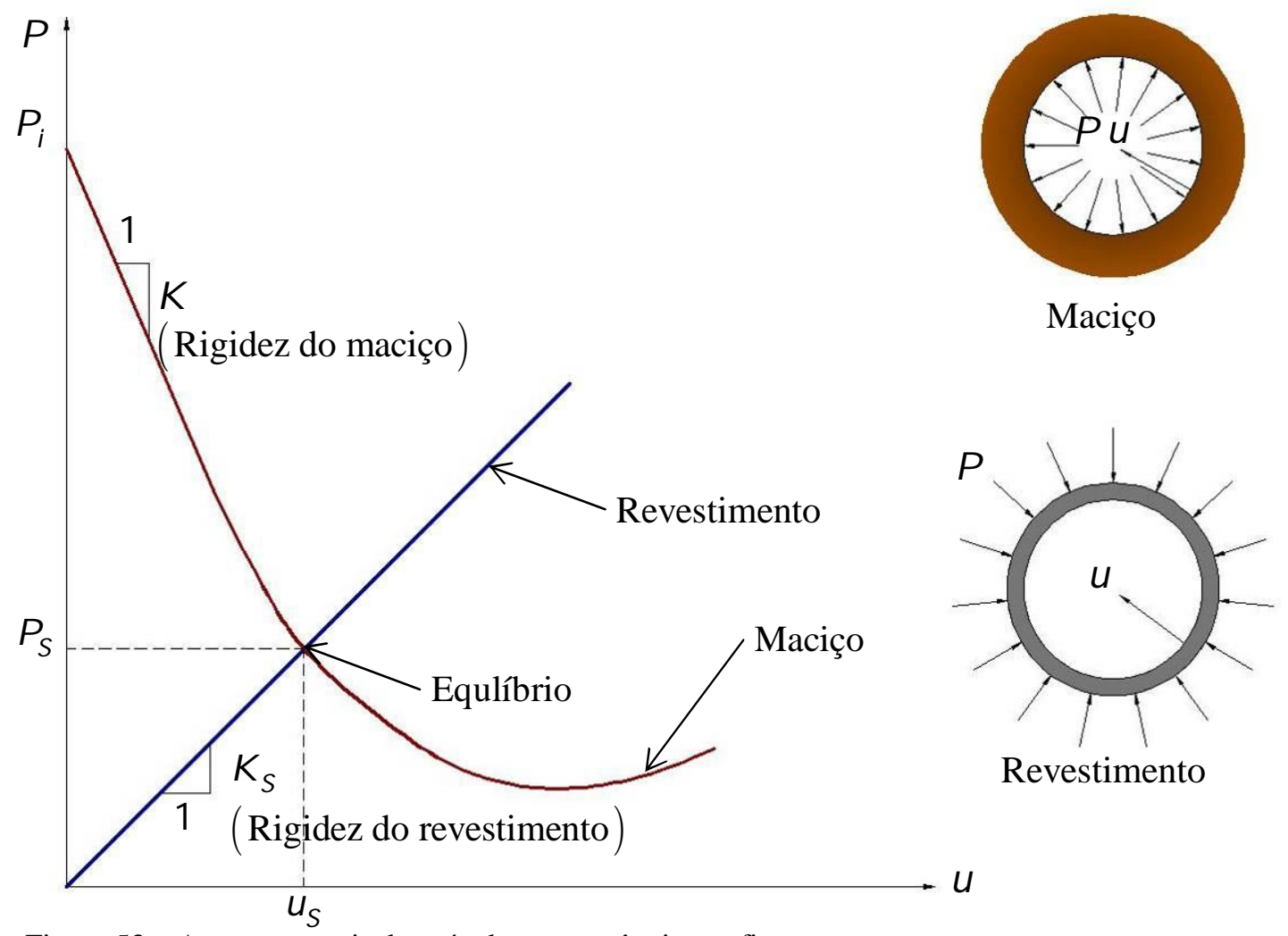

Figura 53 - Aspectos gerais do método convergência-confinamento.

A respeito do suporte, os deslocamentos radiais são proporcionais à pressão externa atuante sobre o mesmo e esta pressão é crescente devido à influência do maciço. Observa-se um ponto de equilíbrio de interação na Figura 53; este é caracterizado pelo cruzamento das curvas características do maciço e do suporte. Pode-se obter a pressão final atuante no suporte $\left(P_{s}\right)$ e o deslocamento radial final $\left(u_{s}\right)$. Ressalta-se que a inclinação das curvas características é influenciada pelas rigidezes do maciço e suporte e, portanto o ponto do equilíbrio também o é. 


\subsection{MÉTODOS EXECUTIVOS}

Há diversos métodos existentes para execução de túneis, dentre estes os considerados principais são: “shield”, “tunnel liner” (chapas de aço), “pipe jacking”, “cut and cover", e "new Austrian tunneling method" (NATM). Durante a escolha de um método executivo, o método que apresente baixos deslocamentos do maciço em direção ao interior do túnel ("fechamento") e proporcione estabilidade ao mesmo será provavelmente a melhor escolha técnica.

A seguir será descrito o método construtivo NATM a partir das seguintes referências SILVA (1997); ALY\& FARJZSRTAIN (2010). Lembra-se que o comportamento viscoelástico do concreto projeto é mais pronunciado neste método, sendo este o objetivo do trabalho.

A primeira etapa consiste em executar um travamento na face superior do túnel antes de iniciar a escavação (Fase 1-Figura 54). Assim, é realizada uma escavação em forma de ferradura (seção transversal da fase $2 \mathrm{em}$ amarelo), cambotas podem ser instaladas, no caso de solos, ou executam-se tirantes ou chumbadores, quando o material for rochoso. Posteriormente ocorre a execução do concreto projetado nas seções 1 e 2 apresentadas na figura a seguir antes que a escavação prossiga (Fase 3 -Figura 54). Executa-se o arco invertido aplicando tela e concreto projetado (Fase 3 -Figura 54, indicado na seção 3 em amarelo). Repete-se as duas primeira etapas para as seções 4 e 5 e a etapa 3 para a seção 6 apresentadas na figura. Esta repetição de etapas ocorrerá até finalizar a execução do túnel em todo o seu comprimento. 


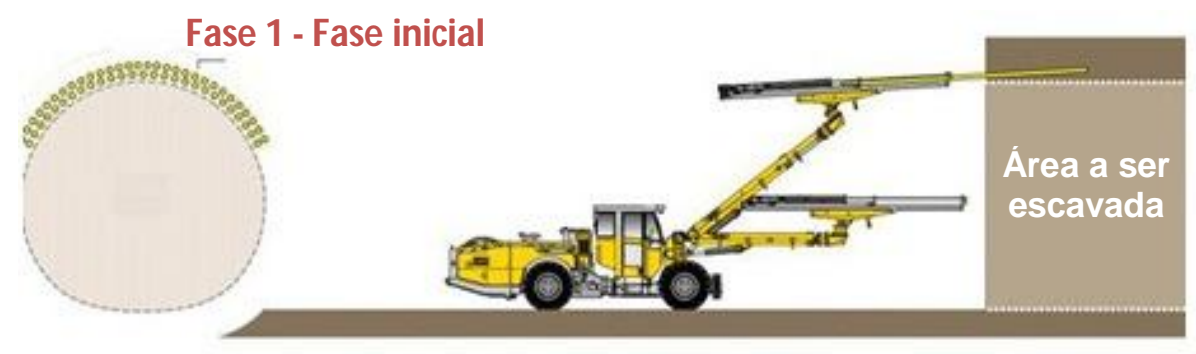

Fase 2 - Escavação parcial

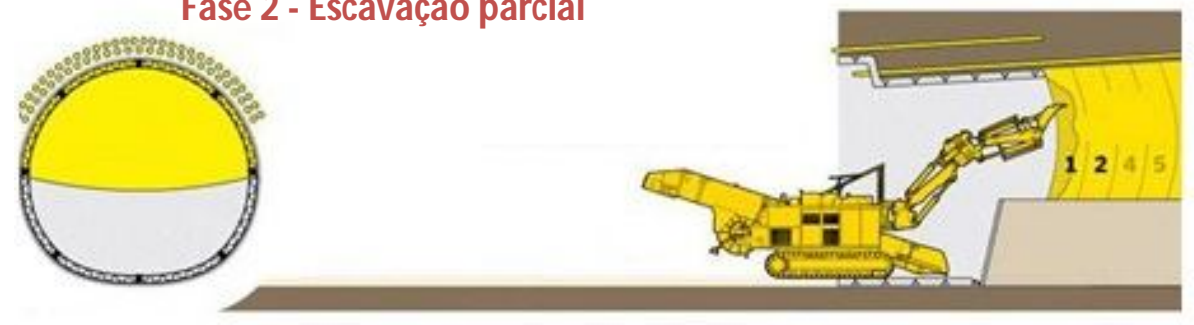

Fase 3 - Escavação do talude remanescente ("bench")

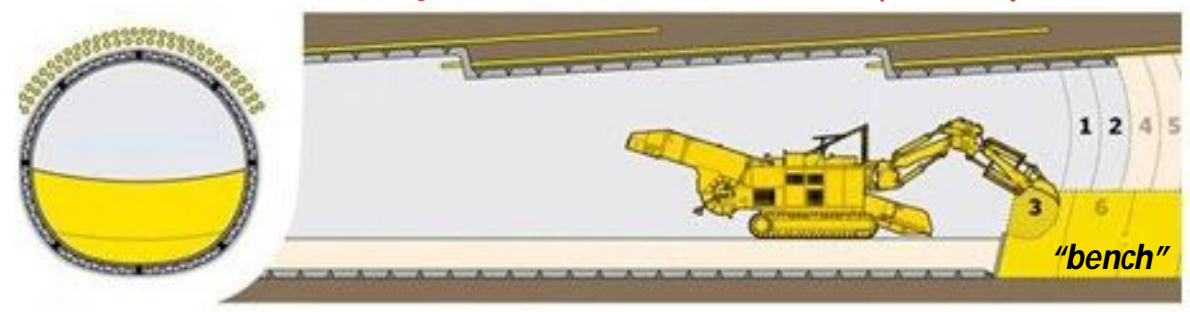

\section{Fase 4 - Túnel concluído}

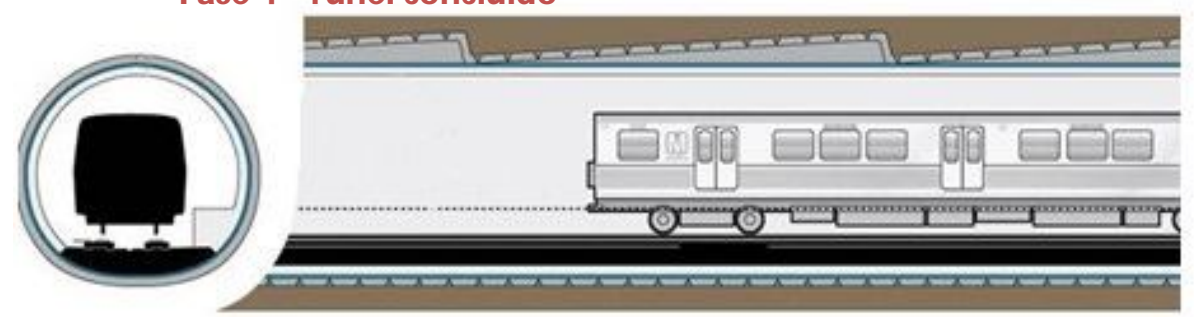

Figura 54 - Sequência executiva do método NATM Adaptado de: WASHINTON POST (2009).

A execução de uma escavação parcializada, como neste método, dependerá da coesão característica do solo. O número de divisões é dependente das propriedades do maciço (Figura 55). 


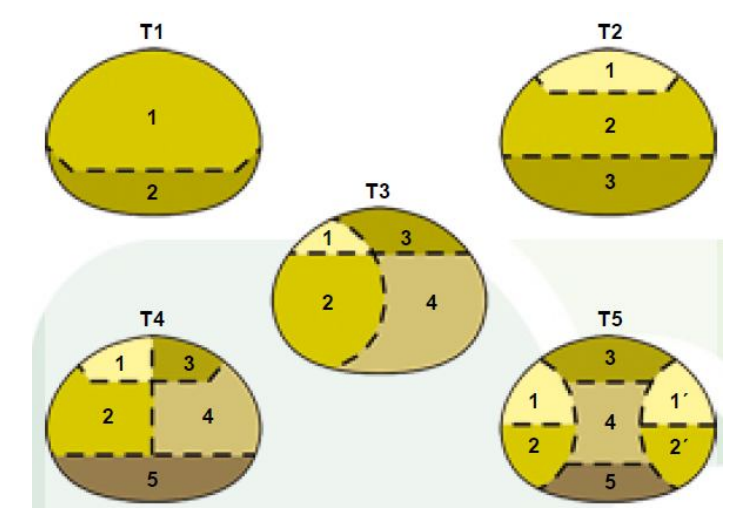

Figura 55 - Exemplo de parcialização da seção transversal de um túnel. FONTE: SOLOTRAT ENGENHARIA GEOTÉCNICA (2010)

O concreto projetado utilizado durante a execução apresenta os requisitos exigidos pelo método NATM: alta resistência inicial (evita-se o desmoronamento do maciço), alta deformabilidade (permissão do trabalho estrutural do maciço) e aplicabilidade em camadas (possibilidade de execução de reforços após a detecção de problemas com a estabilidade através de instrumentação). Ressalta-se segundo Rabcewicz (1974 apud ALY; FARJZSRTAIN, 2010) que o suporte apresenta o papel de selar a superfície exposta tão rápido quanto for possível e evitar relaxamento através da resistência superficial inicial.

Os tipos de revestimento empregados são concreto projetado e concreto moldado "in-loco". Ressalta-se que a execução do revestimento em concreto projetado permite maior economia de custo e prazos, já que este apresenta uma auto-sustentação; não é necessária a utilização de fôrmas, escoramento e desforma; permite o aumento da velocidade de concretagem e assim reduz o prazo de conclusão dos serviços.

Segundo Pelizza (1996 apud KOCHEN; RIBEIRO NETO, 2000), os objetivos da monitoração da construção de túneis rasos em solo são: controlar o comportamento do maciço durante o avanço do túnel, juntamente com a verificação das condições de segurança dos trabalhos e possíveis intervenções após a detecção das anomalias; possibilitar uma avaliação mais precisa das características do maciço (realização de retroanálises) para a determinação de medidas de estabilização e otimização de projetos. A monitoração tem a função de complementar o acompanhamento da escavação, o mapeamento geológico e a verificação de conformidades. 


\subsection{MODELAGEM COMPUTACIONAL}

A análise numérica de túneis pode ser empregada em casos em que não há solução analítica, ou em que esta solução é incompleta ou muito simplificada. Os problemas característicos para empregar a análise numérica podem apresentar condições geológicas complexas (materiais heterogêneos, anisótropos e horizontes inclinados, por exemplo), interação solo-estrutura com geometria complexa, consideração do efeito de um comportamento complexo de alguns materiais envolvendo não linearidade, plasticidade e viscosidade, consideração dos efeitos de técnicas de construções e sequência executiva, dentre outros (POTTS et al, 2002).

Há diversos métodos numéricos que podem ser utilizados para realizar uma análise (seja bidimensional ou tridimensional) de um túnel no interior de um maciço, como o método dos elementos finitos (MEF), o método dos elementos de contorno (MEC), o acoplamento entre os métodos MEF e MEC, e o métodos das diferenças finitas. A Figura 56 apresenta um exemplo da modelagem de um túnel a partir do MEF.

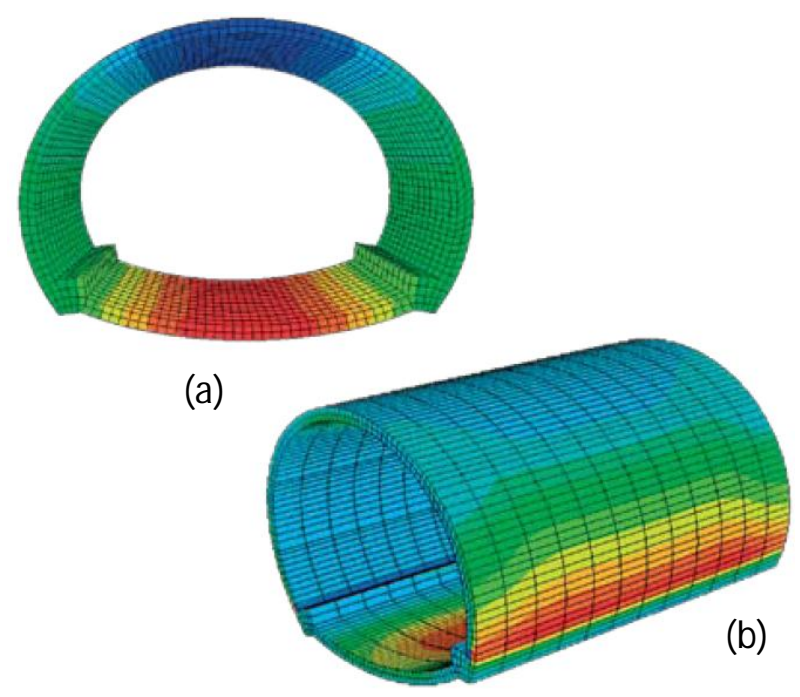

Figura 56 - Modelo de um túnel em elementos finitos: (a) vista 3-D frontal; (b) vista em perspectiva.

FONTE: MACCAFERRI INDUSTRIAL GROUP (2008, p. 4)

As análises numéricas de túneis podem ser tridimensionais, axissimétricas ou com as hipóteses do estado plano de deformação.

No caso da análise tridimensional, o método de elementos finitos é o mais utilizado. Isso se deve não apenas a dimensão do modelo, mas também à possibilidade de consideração de forma mais adequada de um material não linear e com comportamento 
dependente do tempo, simulação de uma sequência executiva e sua larga utilização na área de geotecnia (GOLSER, 2001).

As análises tridimensionais de um túnel são de alto grau de complexidade e envolvem dezenas de milhões de graus de liberdade para atingir uma boa representatividade do problema. Para reduzir o número de graus de liberdade, e com o intuito de servir como ponto de partida, este trabalho propõe uma modelagem bidimensional da estrutura de suporte do túnel e do maciço, admitindo ambos em EPD e considerando seu comportamento viscoelástico, através de análises em elementos finitos.

A análise axissimétrica é limitada pela necessidade de se tratar de um túnel com seção circular em um maciço homogêneo. Assim, este tipo de análise é recomendada para casos de túneis superficiais. Já o estado plano de deformação pode ser empregado para analisar seções transversais de túneis, onde cada estágio de escavação é simulado individualmente. Porém, problemas que envolvam a estabilidade da frente de escavação não poderão ser solucionados (POTTS et al, 2002).

Por simplicidade, o comportamento viscoelástico pode ser admitido também para o maciço, pois muitos dos materiais rochosos e solos apresentam um padrão de deformação atrasado quando submetidos a um carregamento (VENTURINI, 1983). A consideração da viscoplasticidade poderia ser mais adequada, porém foge do escopo deste trabalho.

\subsection{EXEMPLOS NUMÉRICOS}

Huang e Pan (1994) apresentam hipóteses simplificadoras para realizar a análise da interação entre maciço e estrutura. Algumas serão adotadas para propor os problemas a seguir: o maciço é composto por um número finito de materiais homogêneos e isótropos; a seção do túnel é circular; não serão considerados os efeitos da frente de escavação, sendo o estado plano de deformação considerado satisfatório para esta análise; e o suporte é considerado como um anel fechado que apresenta uma espessura constante.

A modelagem proposta para análise de uma seção transversal de um túnel será baseada na consideração de um comportamento viscoelástico do suporte e do maciço e através da aplicação do MEF. Apenas o módulo de elasticidade longitudinal será admitido dependente 
do tempo, pois conforme já explicado no capítulo 3 o coeficiente de Poisson de materiais como concreto em deformações viscosas, permanece aproximadamente constante em relação ao da deformação elástica

Os dois exemplos analisados a seguir foram propostos por Oliveira (2009) e tratados como problemas em estado plano de deformação. O primeiro exemplo é composto por um maciço homogêneo. Uma abertura em seu interior é revestida com um concreto projetado de espessura de $30 \mathrm{~cm}$. Uma edificação na superfície do maciço é simulada através da aplicação de uma pressão p (Figura 57).

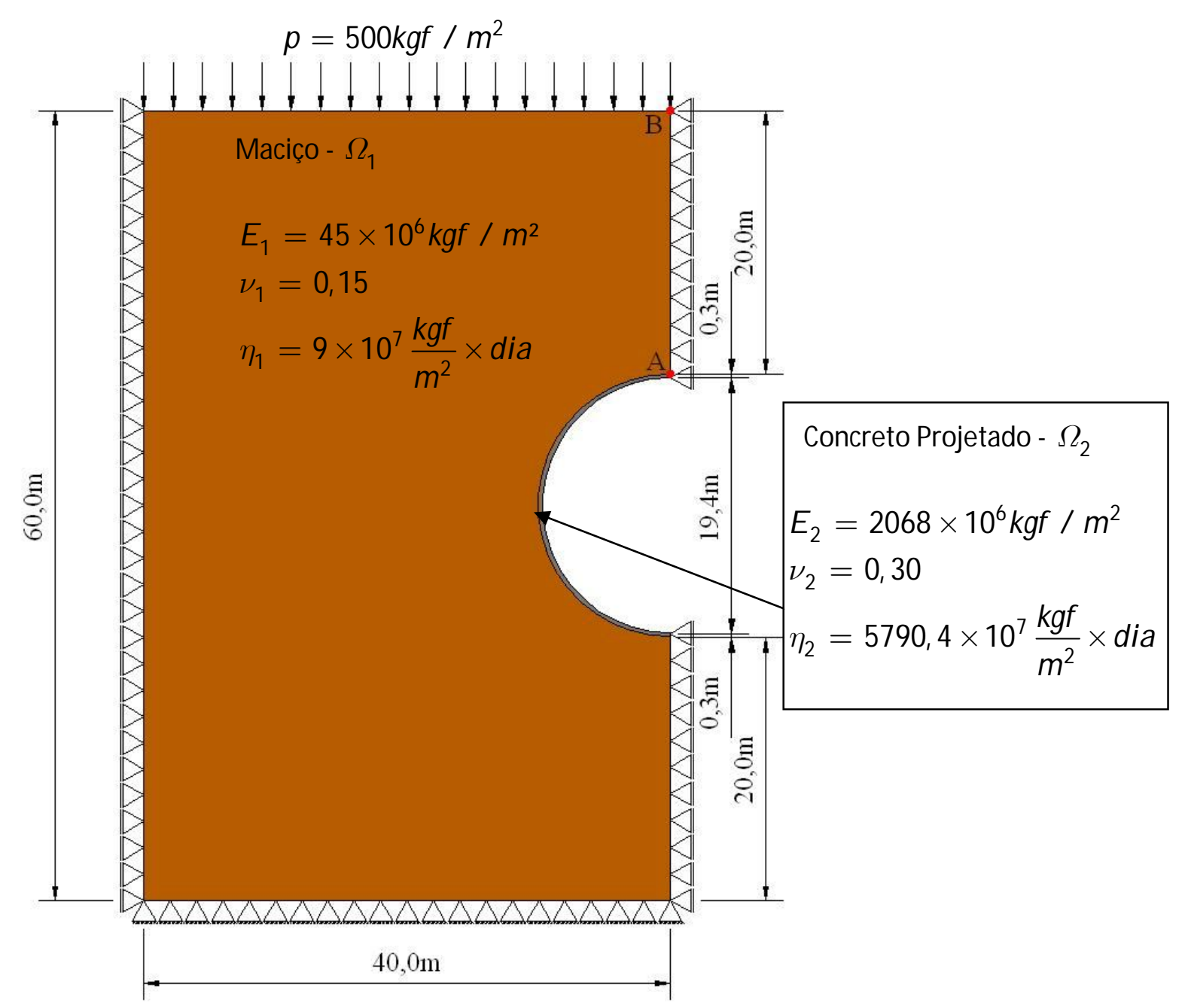

Figura 57 - Problema 1: seção transversal de um túnel e propriedades.

A malha de elementos finitos proposta com $40 \times 60$ divisões nos lados (Figura 58) foi baseada na utilizada por Oliveira (2009) no programa ADINA. 


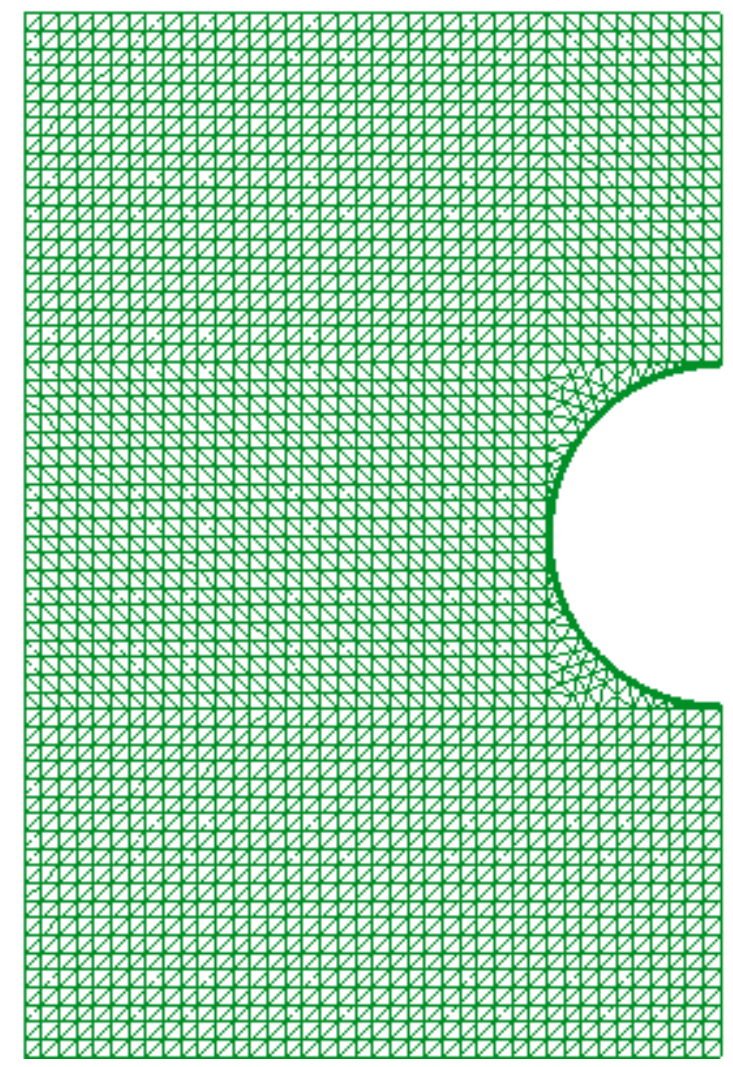

Figura 58 - Problema 1: malha $40 \times 60$ divisões.

Os resultados numéricos de referência são: deslocamento vertical do ponto $\mathrm{A}$ 0,000510m (MEC, Oliveira 2009) e 0,000506m (ADINA/MEF, Oliveira 2009) no instante $\mathrm{t}=100$ dias. O deslocamento obtido com as implementações no PEFSYS para o ponto A é de 0,000509408m em linearidade geométrica, para o mesmo instante. Já para o ponto B, o valor de referência é 0,0006795m (ADINA/MEF, Oliveira 2009) e o deslocamento obtido com o PEFSYS foi $0,0006800975 \mathrm{~m}$.

Para o ponto A, os valores em função do tempo foram organizados no Gráfico 8 juntamente com os obtidos por Oliveira (2009). Ao comparar os resultados obtidos, percebe-se que até aproximadamente 30 dias tem-se uma diferença expressiva no desenvolvimento do deslocamento ao longo do tempo. Esta diferença é basicamente decorrente do tipo de formulação empregada, onde Oliveira (2009) utiliza uma formulação viscoelástica linear com integração de tensões que gera uma deformação imediata, enquanto que a formulação implementada no PEFSYS, por ser do tipo Kelvin-Voigt, não possui deslocamentos imediatos. 


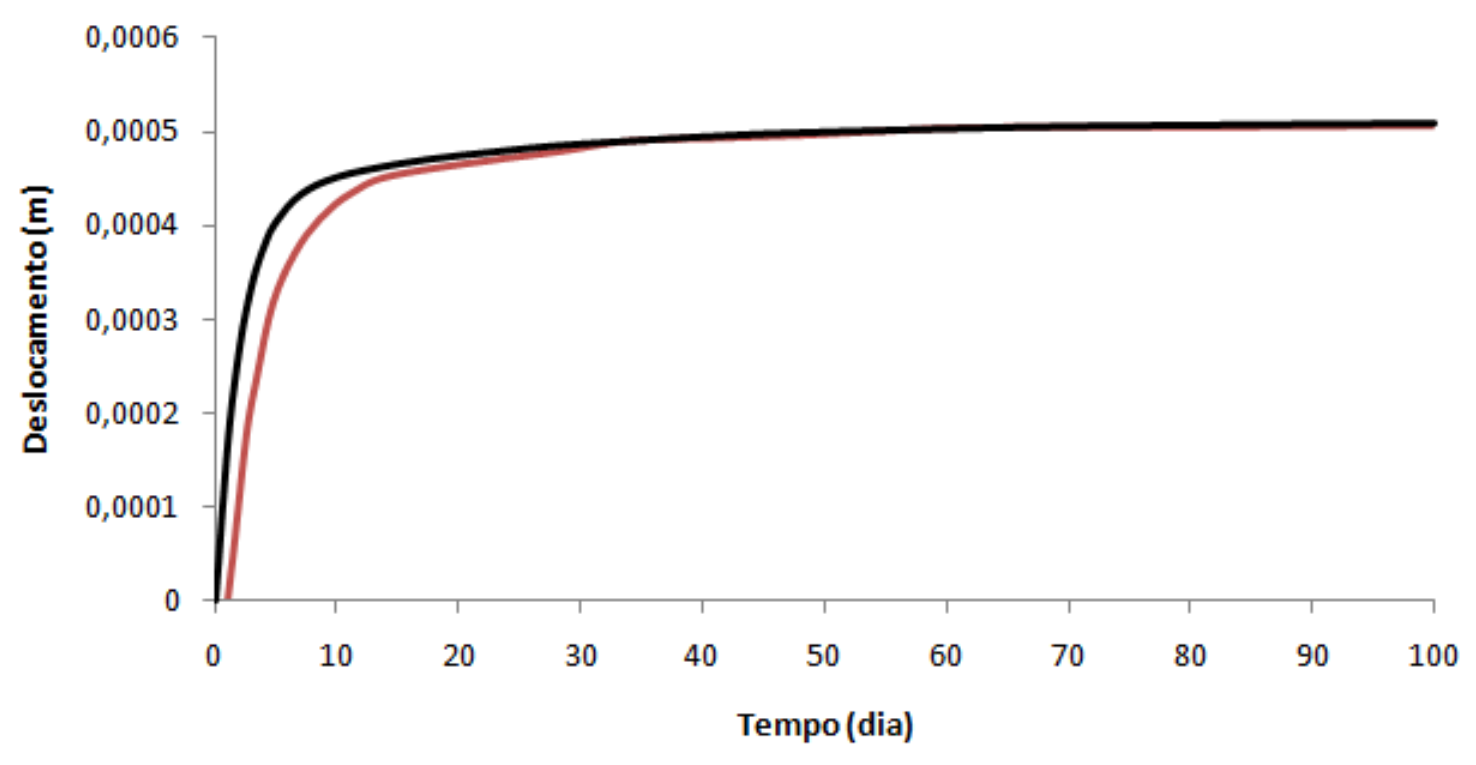

— Solução Numérica PEFSYS Solução Numérica (ADINA/MEF, Oliveira 2009)

Gráfico 8 - Problema 1: deslocamento vertical do ponto A em função do tempo (linearidade geométrica)

A configuração deformada está apresentada na Figura 59. Já o campo de deslocamentos (direção vertical) obtido está apresentado na Figura 60. Ambos foram obtidos para $\mathrm{o}$ instante $\mathrm{t}=100$ dias.

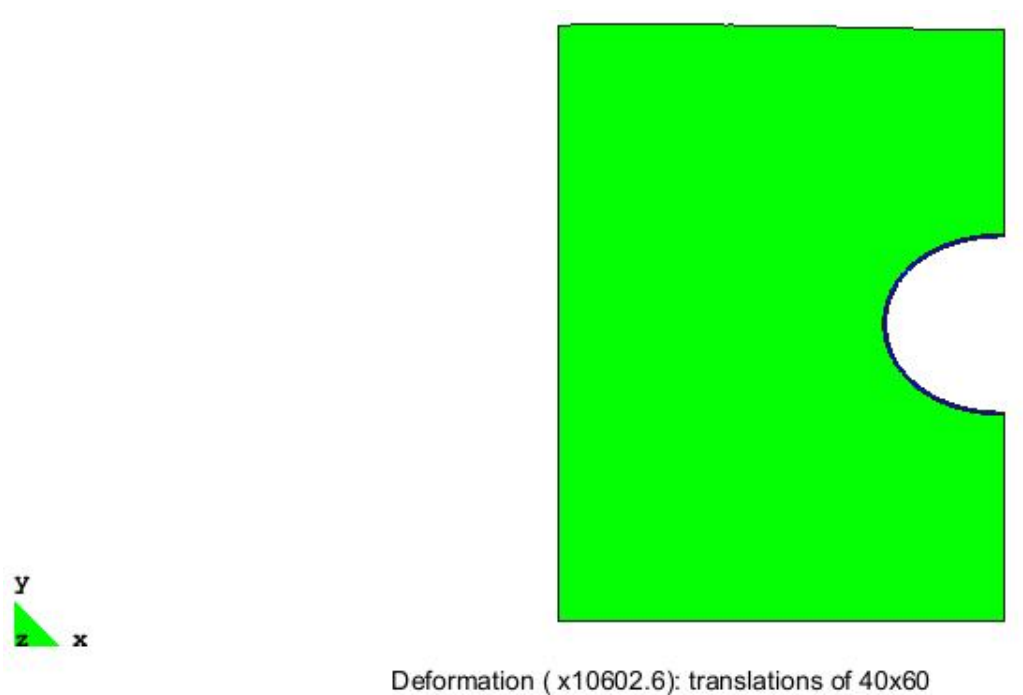

, step 1.

Figura 59 - Problema 1: configuração deformada para o instante $t=100$ dias (linearidade geométrica). 


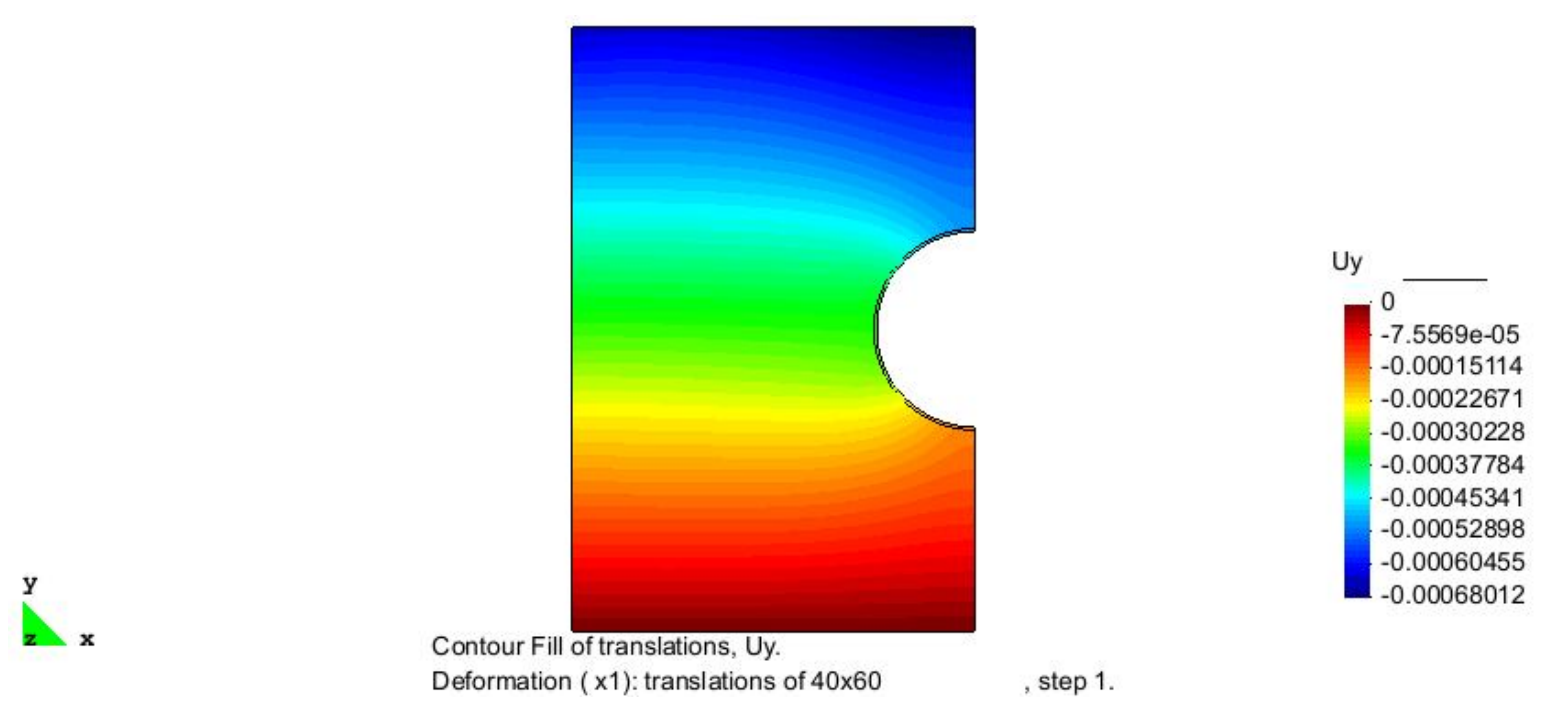

Figura 60 - Problema 1: campo de deslocamentos verticais para o instante $t=100$ dias (linearidade geométrica)

O campo de deslocamentos verticais obtido por Oliveira (2009) através do programa ADINA foi comparado ao campo de deslocamentos obtido com o PEFSYS para a análise linear e podem ser considerados semelhantes em todo o domínio do problema.

Ao analisar o problema sob o aspecto da não linearidade geométrica no PEFSYS, obteve-se o deslocamento vertical para o ponto A de $0,0005094206 \mathrm{~m}$ e para o ponto $\mathrm{B}$ de 0,0006801116m, ambos para o instante $\mathrm{t}=100$ dias. Observa-se que os valores obtidos são quase que idênticos aos da análise sob linearidade geométrica. Portanto, optou-se por não apresentar o deslocamento em função do tempo e o campo de deslocamento na direção vertical para a análise não linear.

Uma nova análise do problema 1 foi realizada, contudo, para uma pressão $p$ de $1,38 \times 10^{6} \mathrm{kgf} / \mathrm{m}^{2}$. O deslocamento obtido para o ponto A no instante $\mathrm{t}=300$ dias durante uma análise sob linearidade geométrica é $1,405735 \mathrm{~m}$, já para uma a análise sob não linearidade é de $1,516883 \mathrm{~m}$. Os deslocamentos na direção vertical para o ponto A está apresentado no Gráfico 9 e o campo de deslocamentos na Figura 61 para o instante $t=$ 300dias. 


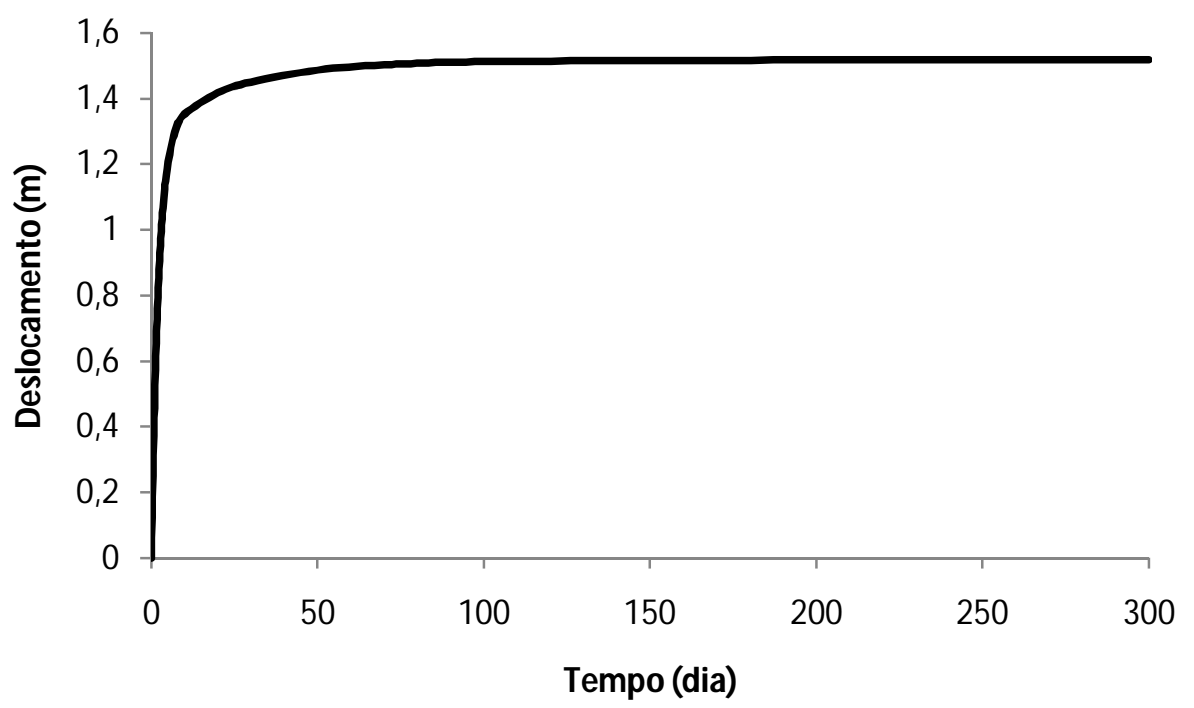

Gráfico 9 - Problema 1: Deslocamento na direção vertical em função do tempo para o ponto A (não linearidade geométrica).

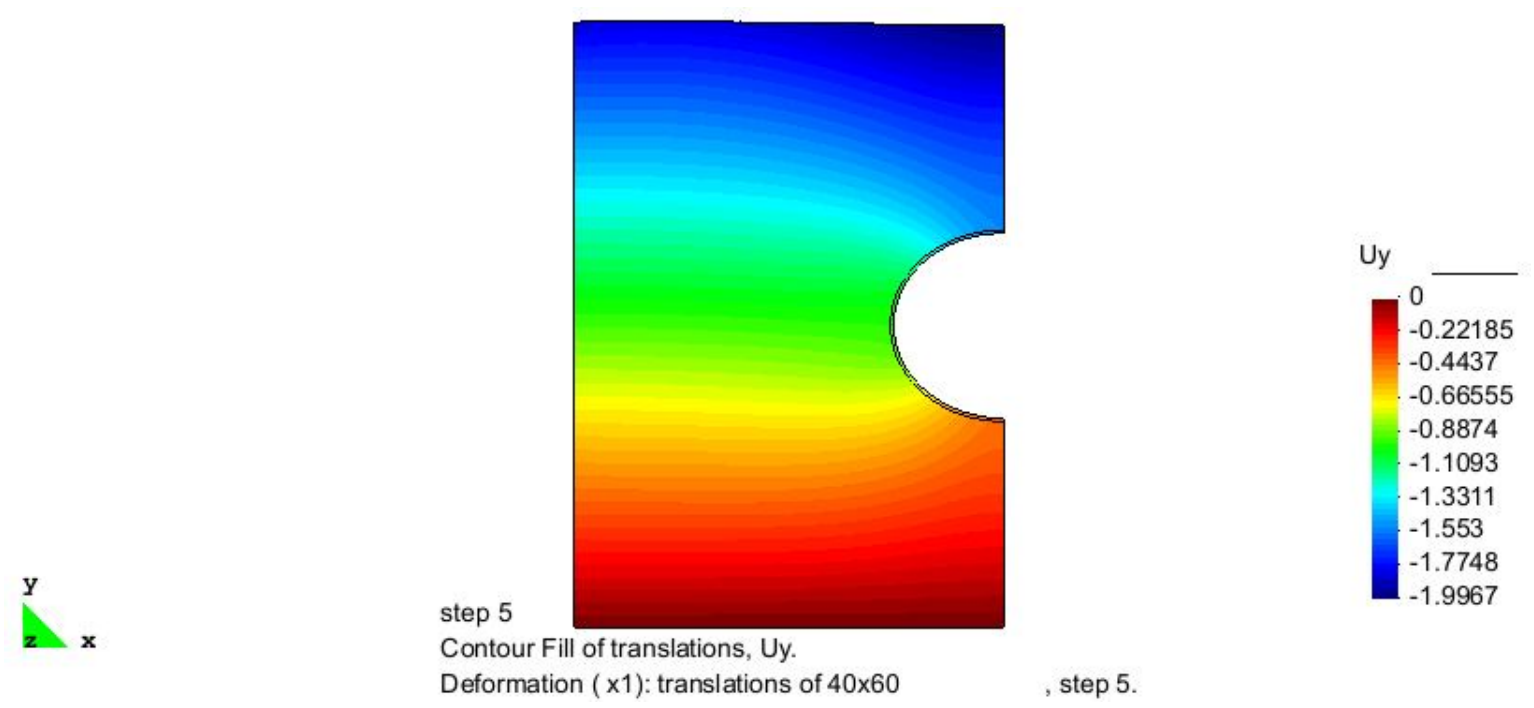

Figura 61 - Problema 1: campo de deslocamentos verticais para o instante $t=300$ dias (não linearidade geométrica).

O segundo problema proposto consiste em um maciço composto por três camadas com diferentes propriedades. Uma abertura em seu interior é revestida com um concreto projetado de espessura de $30 \mathrm{~cm}$. Uma edificação na superfície do maciço é simulada através da aplicação de uma pressão p (Figura 62). 


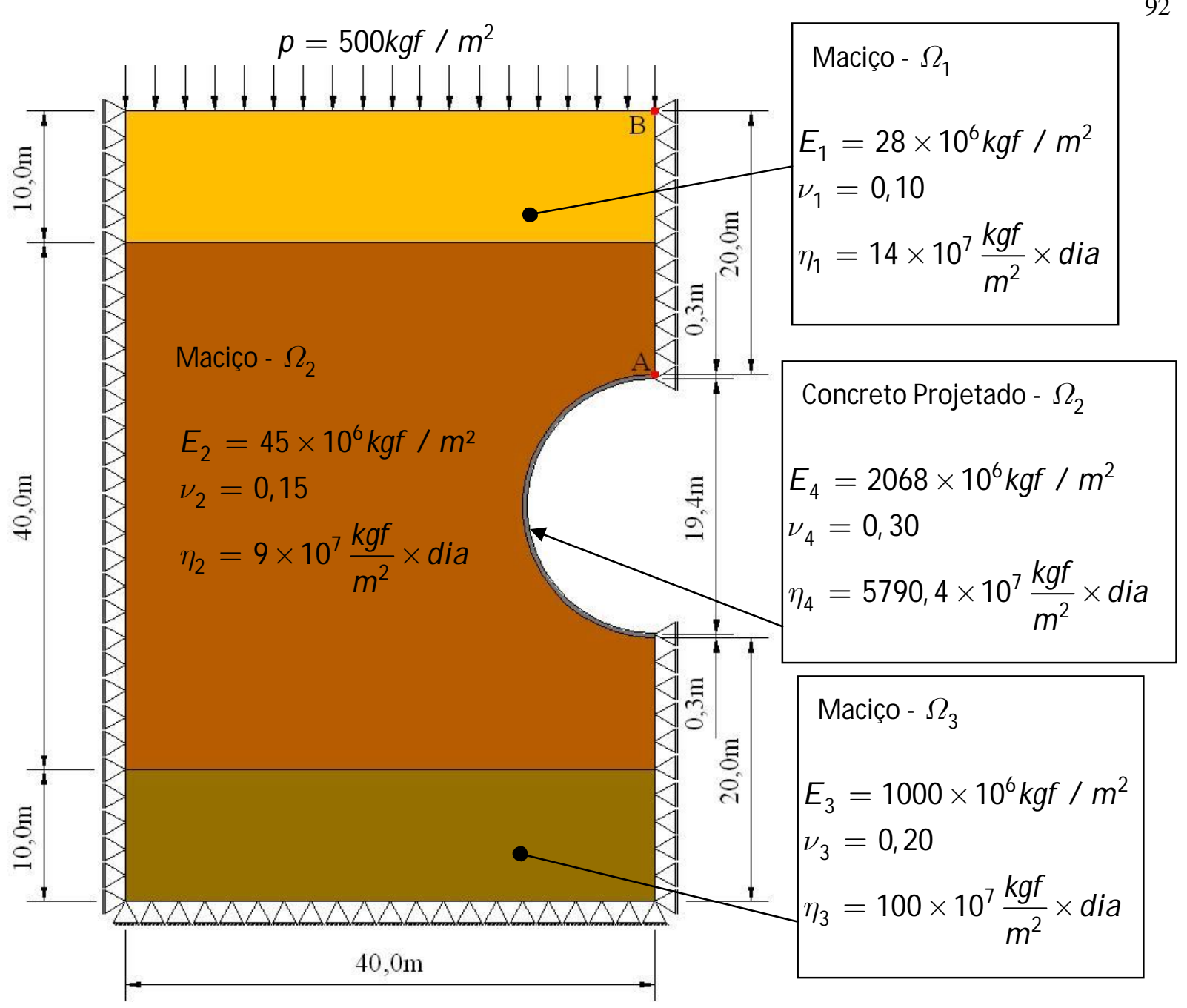

Figura 62 - Problema 2: seção transversal e propriedades.

Este problema foi analisado com a mesma malha de elementos finitos do problema anterior (40×60 divisões nos lados) e está apresentada na Figura 63 .

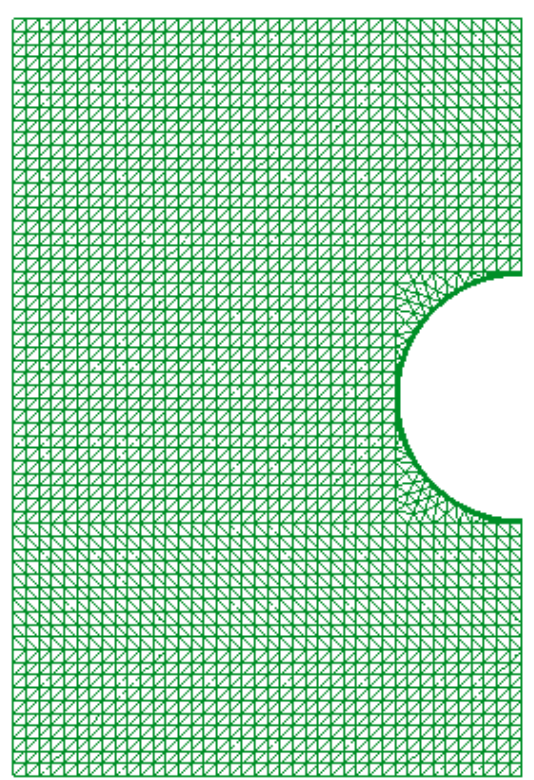

Figura 63 - Problema 2: malha $40 \times 60$ divisões. 
Os valores de referência para os deslocamentos verticais do ponto A são 0,000408m (MEC, Oliveira 2009) e 0,000413m (ADINA/MEF, Oliveira 2009) no instante $\mathrm{t}=$ 100dias. Utilizando o PEFSYS, o deslocamento obtido sob linearidade geométrica foi de 0,0004113583m. Já para o ponto B, o deslocamento obtido com PEFSYS foi de 0,0006519463m e o de referência (ADINA/MEF, Oliveira 2009) é 0,0006511m. Ressalta-se que os resultados numéricos são novamente satisfatórios.

Para o ponto A, os valores obtidos com o PEFSYS em função do tempo foram organizados no Gráfico 10 e comparados com os valores apresentados por Oliveira (2009). Neste gráfico, percebe-se novamente que a pequena diferença inicial entre as suas soluções que se deve ao fato de que o modelo implementado no PEFSYS não aceita deslocamentos imediatos.

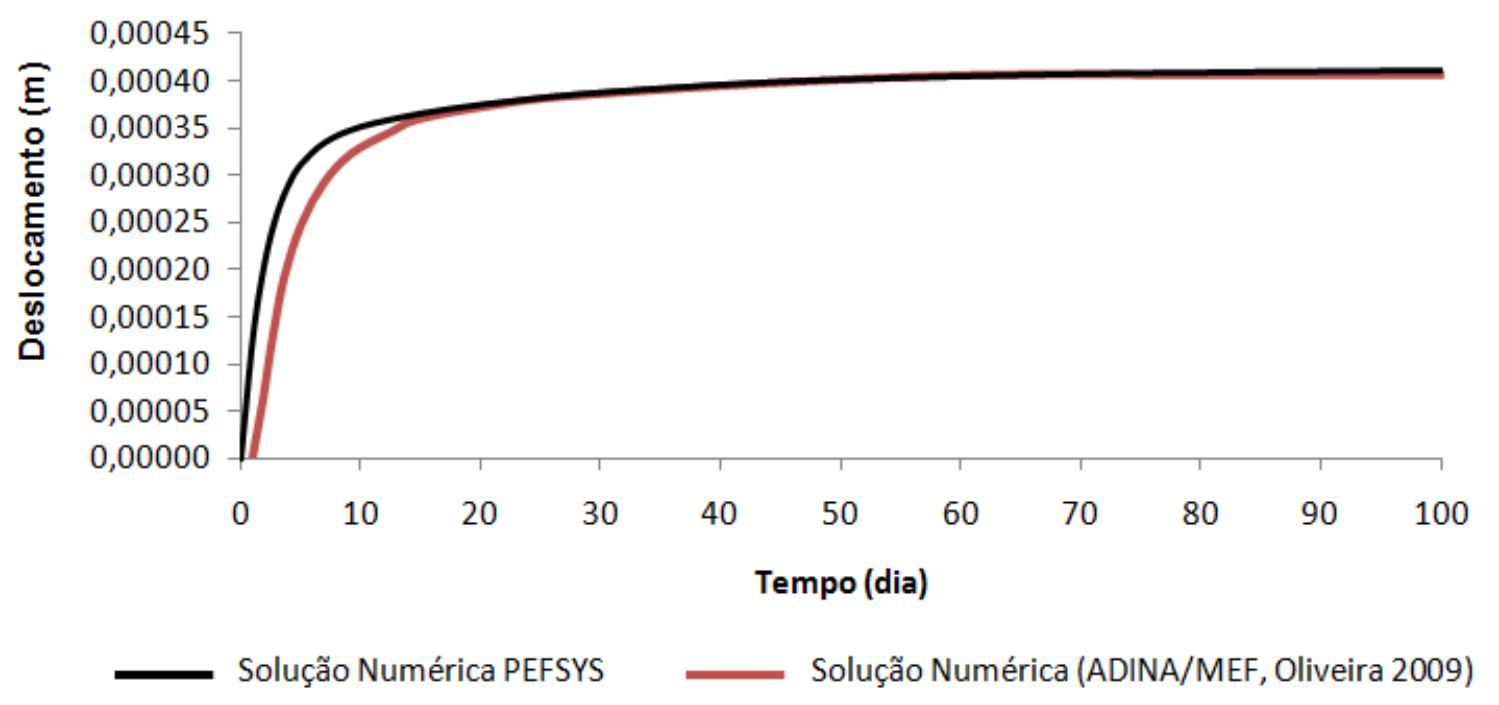

Gráfico 10 - Problema 2: deslocamentos verticais para o ponto A em função do tempo (linearidade geométrica).

A configuração deformada e o campo de deslocamentos (direção do eixo vertical) estão apresentados na Figura 64 e Figura 65, respectivamente. Novamente, comparou-se o campo de deslocamentos obtido por Oliveira (2009) com o obtido com o PEFSYS e podem ser considerados semelhantes. 


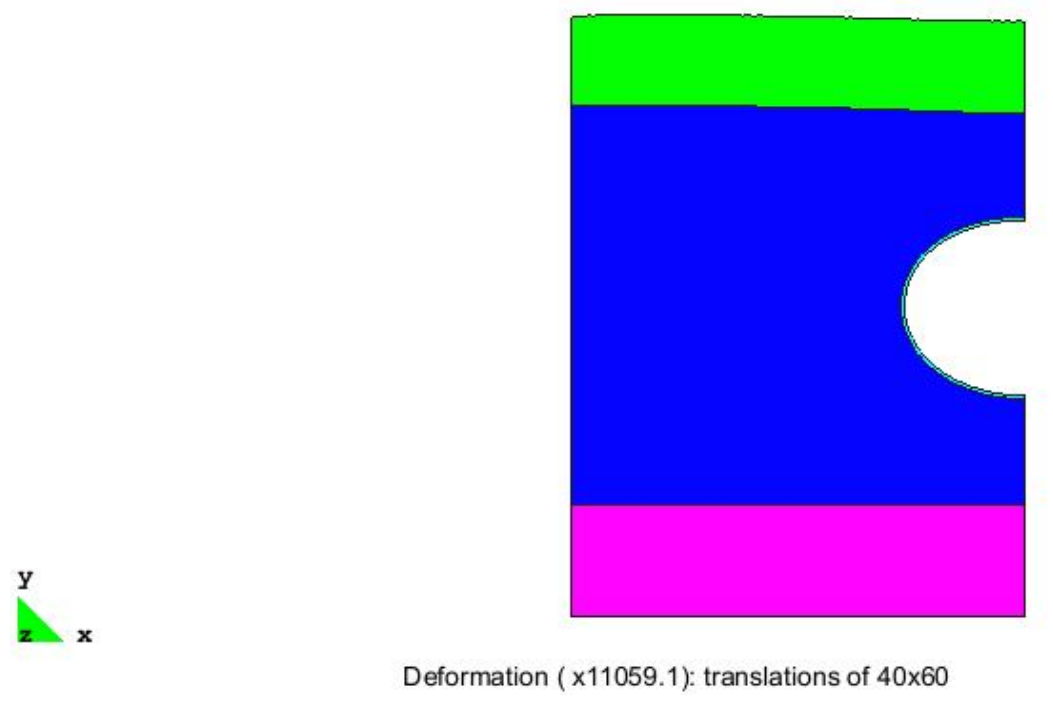

, step 1.

Figura 64 - Problema 2: configuração deformada para o instante $t=100$ dias (linearidade geométrica).
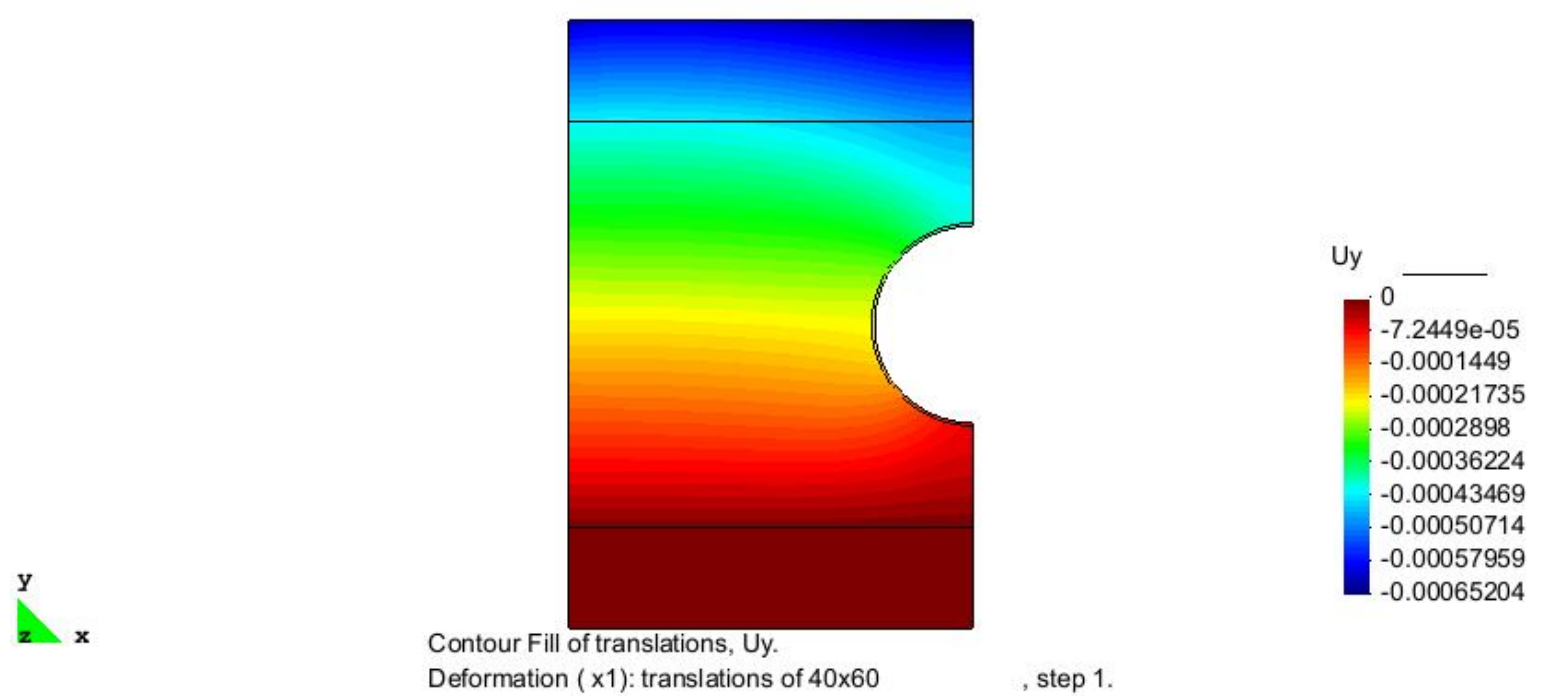

Figura 65 - Problema 2: campo de deslocamentos verticais para o instante $\mathrm{t}=$ 100dias (linearidade geométrica).

Ao analisar o problema sob o aspecto da não linearidade geométrica no PEFSYS, obteve-se o deslocamento vertical para o ponto A de $0,0004113696 \mathrm{~m}$ e para o ponto $\mathrm{B}$ de $0,0006519621 \mathrm{~m}$, ambos para o instante $\mathrm{t}=100 \mathrm{dias}$. Observa-se que os valores obtidos são quase que idênticos aos da análise sob linearidade geométrica. Portanto, optou-se novamente por não apresentar o deslocamento em função do tempo e o campo de deslocamento na direção vertical para a análise não linear.

Uma nova análise do problema 2 foi realizada, contudo, para uma pressão $p$ de $1,38 \times 10^{6} \mathrm{kgf} / \mathrm{m}^{2}$ (coincidente com a do problema 1 ). O deslocamento obtido para o 
ponto A no instante $\mathrm{t}=300$ dias durante uma análise sob linearidade geométrica é 1,136330m, já para uma a análise sob não linearidade é de 1,238204m. Os deslocamentos na direção vertical para o ponto A está apresentado no Gráfico 11 e o campo de deslocamentos na Figura 66 para o instante $\mathrm{t}=300$ dias.

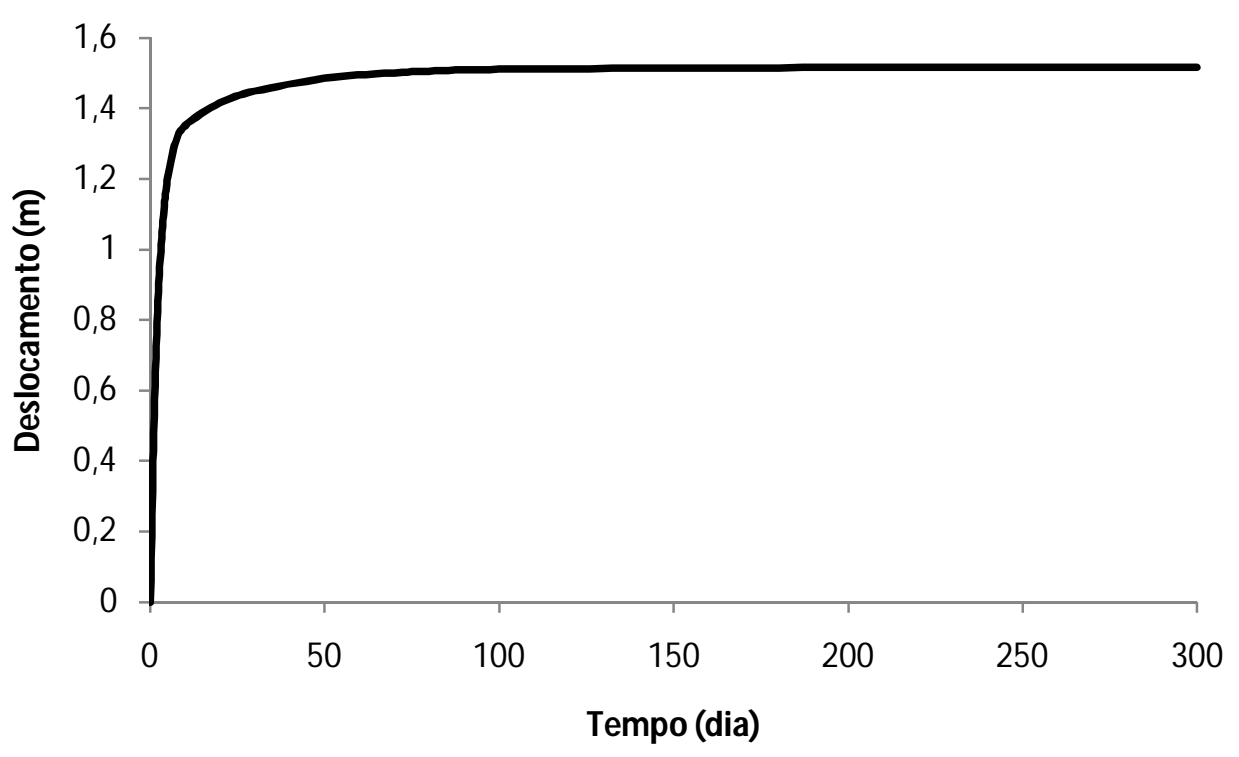

Gráfico 11 - Problema 2: Deslocamento na direção vertical em função do tempo para o ponto A (não linearidade geométrica).

$\mathrm{Y}$

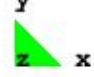

step 5

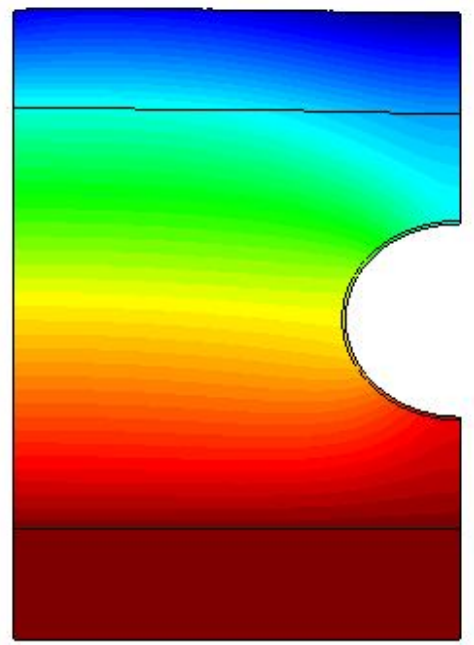

Contour Fill of translations, Uy.

Deformation ( $x 1$ ): translations of $40 \times 60$

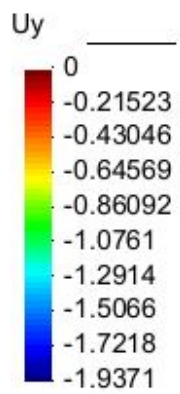

, step 5.

Figura 66 - Problema 2: campo de deslocamentos verticais para o instante $t=300$ dias (não linearidade geométrica). 
Observa-se que a análise não linear para estes dois problemas para uma pressão de $500 \mathrm{kgf} / \mathrm{m}^{2}$ não influenciaria na otimização de projeto e previsão de deslocamentos através do método, porém ao aumentar esta pressão a não linearidade do problema se manifesta. Ressalta-se que para realizar uma análise quanto à estabilidade é necessária uma formulação não linear. 


\section{CONCLUSÃO}

Este trabalho teve por objetivo aplicar uma formulação viscoelástica sob não linearidade geométrica à análise de problemas em estado plano de deformação. A formulação é baseada em grandezas energicamente conjugadas a partir do gradiente da transformação e do primeiro tensor das tensões de Piola-Kirchhoff.

A formulação proposta foi baseada na equação constitutiva do material de Kirchhoff- Saint Venant, com um módulo de elasticidade longitudinal dependente do tempo. Esta dependência foi expressa através da função de fluência do modelo viscoelástico de Kelvin-Voigt.

A implementação da equação constitutiva do material hiperelástico foi validada através de dois exemplos, onde os resultados obtidos foram comparados com soluções analíticas e resultados numéricos encontrados na literatura. Após esta etapa, validou-se a implementação viscoelástica realizada de forma simplificada. Lembra-se que houve dificuldade de encontrar exemplos de validação para estado plano de deformação.

Ressalta-se que boa parte dos trabalhos desenvolvidos anteriormente pela comunidade científica elaboram e/ou aplicaram uma formulação viscoelástica sob linearidade geométrica com integração de tensões, onde são utilizados o tensor das deformações de Green e o tensor das tensões de Cauchy.

Nos exemplos analisados, a não consideração da integração de tensões teve pouca influência nos resultados obtidos para os primeiros dias se comparados a outro trabalho que a empregou. Esta diferença se deve basicamente ao fato de não termos deslocamentos imediatos.

Apresentou-se o elemento finito triangular T6 utilizado nas análises numéricas. Ressalta-se que sua abordagem pura de deslocamentos garante as propriedades de convergência e estabilidade numéricas automaticamente. Observou-se através de todos os exemplos que não ocorreu o travamento do elemento. A escolha do elemento triangular se deve a vantagem apresentada por este ao compor malhas não estruturadas. Seções transversais de túneis podem apresentar geometrias complexas, onde se torna necessário o emprego deste tipo de malha.

A elaboração deste trabalho dá abertura a um rico leque de novas pesquisas e desenvolvimento de implementações em elementos finitos no programa PEFSYS com 
aplicações práticas na Engenharia. Futuros temas a serem propostos envolvem a implementação da equação constitutiva do material Neo-Hookiano (policonvexo) de CiarletSimo; formulações viscoelásticas com integração de tensões; implementação de modelos reológicos mais complexos para representação de um comportamento mais realístico do concreto projetado e do maciço, como por exemplo, modelo de três parâmetros e modelo de Burger; análise da interação maciço-estrutura através da aplicação de implementações viscoelásticas e possivelmente viscoplásticas. 


\section{REFERÊNCIAS}

ALY, V. L. C.; FARJZSRTAIN, H. Método de escavação e execução de túneis. São Paulo: Escola Politécnica, Universidade de São Paulo, 2010. (Notas de aula da disciplina de graduação PCC2506 - Tecnologia de produção de obras de construção pesada.)

BATTHI, M. A. Advanced topics in finite element analysis of structures: with Mathematica. New York: John Wiley \& Sons. 2006. 590 p.

BEER, G.; SWOBODA, G. On the efficient analysis of shallow tunnels. Computational and Geotechnics, v. 1, n. 1, p. 15-31, 1985.

BELYTSCHKO, T.; FISH, J. A first course in finite element. Chichester: John Wiley \& Sons. 2007. 319 p.

BONET, J.; WOOD, R. D. Nonlinear continuum mechanics for finite element analysis. Cambridge: Cambridge University Press. 1997. 248 p.

BRITO, L. Megatatuzão abre túnel e chega à futura Estação Paulista. 2008: fotografia. São Paulo: 2008. Disponível em:

<http://g1.globo.com/Noticias/SaoPaulo/0,,MUL476835-5605,00.html>. Acesso em: 20 out. 2008.

CARBONE, Nicholas. Desenvolvimento de um novo algoritmo para análise viscoplástica com o método dos elementos de contorno. 2007. 88 p. Dissertação (Mestrado) - Escola Politécnica, Universidade de São Paulo. São Paulo, 2007.

CAMPELlO, E. M. B.; PIMENTA, P. M.; WRIGGERS, P. A triangular finite shell element based on a fully nonlinear shell formulation. Computational Mechanics, v. 31, n. 6, p. 505518.

CAMPELLO, E. M. B. Modelos não-lineares de casca em elasticidade e elastoplasticidade com grandes deformações: teoria e implementação em elementos finitos. 2005.127 p. Tese 
(Doutorado) - Escola Politécnica, Universidade de São Paulo. São Paulo, 2005.

CAMPELlO, E. M. B.; PIMENTA, P. M. Método dos elementos finitos aplicado à mecânica dos sólidos não linear. São Paulo: Escola Politécnica, Universidade de São Paulo, 2009. (Notas de aula da disciplina de pós-graduação PEF5712 - Método dos elementos finitos aplicado à mecânica dos sólidos não linear.)

CELESTINO, T. B. Projeto de revestimento de túneis em concreto projetado. In: Encontro técnico do CBT, 1., 1992, São Paulo. Anais. São Paulo: ABMS/CBT, 1992. p.1-21.

CELESTINO, T. B. et al. Túneis do Brasil. Comitê Brasileiro de Túneis, São Paulo: Dórea Books and Art, 2006. 327 p.

COSTA, R. C. Formulações dos métodos dos elementos de contorno para análise de placas viscoelásticas. 2008. 238p. Dissertação (Mestrado) - Escola de Engenharia de São Carlos, Universidade de São Paulo. São Carlos, 2008. Disponível em:

<http://www.set.eesc.usp.br/download/2008ME_RodrigoCoutoCosta.pdf>. Acesso em: 01 dez. 2008.

COMPANHIA DO METROPOLITANO DE SÃO PAUlO. Construção: tecnologia - o metrô de subterrâneo (mecanizado TBM - tunnel boring machine). 2008. Disponível em: <http://www.metro.sp.gov.br/tecnologia/construcao/subterraneo/tesubterraneo02.shtml>. Acesso em: 11 jan. 2009.

FAHIMIFAR, A. et al. Analytical solution for the excavation of circular tunnels in a viscoelastic Burger's material under hydrostatic stress field. Tunnelling and Underground Space Technology, v. 25, n. 4, p. 297-304, July, 2010.

FLÜGGE, W. Viscoelasticity. Waltham, Mass.: Blaisdell Pub., 1967. 127 p.

FRANÇA, P. T. Estudo do comportamento de túneis: análise numérica tridimensional com modelos elasto-plásticos. 2006. 185 p. Dissertação (Mestrado) - Escola Politécnica, Universidade de São Paulo. São Paulo, 2006. Disponível em: 
<http://www.teses.usp.br/teses/disponiveis/3/3145/tde-08122006-151549/public o/DissertacaoPedro.pdf>. Acesso em: 22 out. 2008.

FREITAS, J. C. A. DE. Método dos elementos de contorno aplicado à análise de escavações em túneis utilizando modelos aproximados bidimensionais. 2008. 130 p. Dissertação (Mestrado) - Escola de Engenharia de São Carlos, Universidade de São Paulo. São Carlos, 2008. Disponível em:

<http://www.set.eesc.usp.br/download/2008ME_JoaoCesarAFreitas.pdf>. Acesso em: 01 dez. 2008.

GOLSER, HARALD. The Application of Finite Element and Boundary Element Methods in Tunnelling. 2001. 117 p. PhD Thesis - Technical University of Graz, Áustria, 2001.

GOMES, R. A. M. P. Análise tridimensional de túneis considerando o comportamento dependente do tempo na interação maciço-suporte. 2006. 306 p. Tese (Doutorado) Escola de Engenharia de São Carlos, Universidade de São Paulo. São Carlos, 2006. Disponível em:

<http://www.teses.usp.br/teses/disponiveis/18/18132/tde-28032007-090004/publico/ dissertacao.pdf'>. Acesso em: 01 dez. 2008.

GUENOT, A.; PANET, M.; SULEM, J. An analytical solution for time-dependent displacements in a circular tunnel. International Journal Rock Mechanics Mining Science \& Geomechanics, v. 24, n. 3, p. 155-164, June, 1987.

HUANG, ZENG-LIN; PAN, YII-WEN. A model of the time-dependent interaction between rock and shotcrete support in a tunnel. International Journal Rock Mechanics Mining Science \& Geomechanics, v. 31, n. 3, p. 213-219, June, 1994.

KING, I. P.; WATSON, M.; ZIENKIEWICZ, O. C. A numerical method of visco-elastic stress analysis. International Journal of Mechanical Sciences, v. 10, n. 10, p. 807-827, October, 1968.

KOCHEN, R.; RIBEIRO NETO, F. Segurança, ruptura e colapso de túneis urbanos em 
NATM. Engenharia, n. 540, p. 55-62, 2000.

MACCAFERRI INDUSTRIAL GROUP. Túneis e galerias - necessidades e soluções. 2008. Disponível em:

<http://www.maccaferri.com.br/download/cat_tuneis.pdf?PHPSESSID=6ea7dqoo0v65s39qa0 30r34fh7>. Acesso em: 19 jan. 2009.

MEDEIROS, H. Engenharia Subterrânea. Revista Téchne, n. 107, Fev. 2006.

MESQUITA, A. D. Novas metodologias e formulações para o tratamento de problemas inelásticos com aclopamento MEC/MEF progressivo. 2002. 291 p. Tese (Doutorado) Escola de Engenharia de São Carlos, Universidade de São Paulo. São Carlos, 2002.

OLIVEIRA, T. R. S. T. Modelagem do suporte de túneis com comportamento viscoelástico usando o método de elementos de contorno. 2009. 103 p. Dissertação (Mestrado) - Escola Politécnica, Universidade de São Paulo. São Paulo, 2009.

PIMENTA, P. M. Fundamentos da mecânica dos sólidos e das estruturas. São Paulo; Escola Politécnica, Universidade de São Paulo, 2008. (Notas de aula da disciplina de pósgraduação PEF5742 - Fundamentos da Mecãnica das Estruturas II.)

PÖTTLER, R. Time-dependent rock-shotcrete interaction a numerical shortcut. Computers and Geotechnics, v.9, n.3, 149-169, 1990.

POTTS, D. et al. Guidelines for the use of advanced numerical analysis. Londres: Thomas Telford, 2002. $185 \mathrm{p}$.

QUIM, Francisco. Análise de escavações de túneis com revestimento utilizando o método dos elementos de contorno. 2010. 139 p. Dissertação (Mestrado) - Escola de Engenharia de São Carlos, Universidade de São Paulo. São Carlos, 2010.

SANTOS, H. C. Análise de estrutura de concreto sob o efeito do tempo: uma abordagem consistente com consideração da viscoelasticidade, da plasticidade, da fissuração, da 
protensão e de etapas construtivas. 2006. 132 p. Tese (Doutorado) - Escola Politécnica, Universidade de São Paulo. São Paulo, 2006.

SILVA, P. F. A. Concreto projetado para túneis. São Paulo: Pini, 1997. 92 p.

SOLOTRAT ENGENHARIA GEOTÉCNICA. Manual técnico Solotrat. São Paulo: Solotrat Eng. Geotécnica, 2010.93 p.

TAYLOR, R. L.; ZIENKIEWICZ, O. C. The finite element method - the basis. 5ed. Oxford: Butterworth Heinemann, 2000. 689 p.

VENTURINI, W. S. Boundary Element Method in Geomechanics. New York: Springer, 1983. $246 \mathrm{p}$.

WASHINTON POST. A complicated dig. 2009: imagem. Washington: 2009. Disponível em: <http://www.washingtonpost.com/wp-dyn/content/graphic/2009/10/18/GR2009101801273. html?sid=ST2009101800318>. Acesso em: 25 set. 2010.

WRIGGERS, Peter. Nonlinear finite element method. Berlin: Springer, 2008. 559 p. 